\title{
Colonoscopic polypectomy : a detailed analysis of 1930 polypectomies performed during 3500 colonoscopies
}

Citation for published version (APA):

Tan, K. G. (1981). Colonoscopic polypectomy : a detailed analysis of 1930 polypectomies performed during 3500 colonoscopies. [Doctoral Thesis, Maastricht University]. Rijksuniversiteit Limburg. https://doi.org/10.26481/dis.19810327kt

Document status and date:

Published: 01/01/1981

DOI:

10.26481/dis. $19810327 \mathrm{kt}$

Document Version:

Publisher's PDF, also known as Version of record

Please check the document version of this publication:

- A submitted manuscript is the version of the article upon submission and before peer-review. There can be important differences between the submitted version and the official published version of record.

People interested in the research are advised to contact the author for the final version of the publication, or visit the DOI to the publisher's website.

- The final author version and the galley proof are versions of the publication after peer review.

- The final published version features the final layout of the paper including the volume, issue and page numbers.

Link to publication

\footnotetext{
General rights rights.

- You may freely distribute the URL identifying the publication in the public portal. please follow below link for the End User Agreement:

www.umlib.nl/taverne-license

Take down policy

If you believe that this document breaches copyright please contact us at:

repository@maastrichtuniversity.nl

providing details and we will investigate your claim.
}

Copyright and moral rights for the publications made accessible in the public portal are retained by the authors and/or other copyright owners and it is a condition of accessing publications that users recognise and abide by the legal requirements associated with these

- Users may download and print one copy of any publication from the public portal for the purpose of private study or research.

- You may not further distribute the material or use it for any profit-making activity or commercial gain

If the publication is distributed under the terms of Article $25 \mathrm{fa}$ of the Dutch Copyright Act, indicated by the "Taverne" license above, 


\section{Colonoscopic polypectomy}

A detailed analysis of 1930 polypectomies performed during 3500 colonoscopies. 



\title{
COLONOSCOPIC POLYPECTOMY
}

\author{
A detailed analysis of 1930 polypectomies performed \\ during 3500 colonoscopies.
}

\section{PROEFSCHRIFT}

TER VERKRIJGING VAN DE GRAAD VAN DOCTOR IN

DE GENEESKUNDE AAN DE RIJKSUNIVERSITEIT LIMBURG TE MAASTRICHT OP GEZAG VAN DE RECTOR MAGNIFICUS

PROF. DR. W.H.F.W. WIJNEN, HOOGLERAAR IN DE FACULTEIT DER GENEESKUNDE.

VOLGENS HET BESLUIT VAN HET COLLEGE VAN DEKANEN

IN HET OPENBAAR TE VERDEDIGEN IN DE AULA VAN DE UNIVERSITEIT

OP VRIJDAG 27 MAART 1981, DES NAMIDDAGS TE 16.00 UUR.

DOOR

KOEN GIE TAN

geboren te Malang.

1981

grafische verzorging:

davids decor alblasserdam 
PROMOTORS: PROF. DR. JM. GREEP surgeon

CHRISTOPHER B. WILLIIAMS. B.M. F.R.C.P. gastro-enterologist, London

REFERENTS: DR. A.P.R. BLOK, pathologist, The Hague

PROF. DR. J. JEEKEL, surgeon, Rotterdam

PROF. DR. G.N. TYTGAT. gastro-enterologist. Amsterdam

This study has been performed by the author during his work at St. Mark's Hospital, London. The stay was made possible by a grant of the St. Mark's Research Foundation and the British Council. 
to my parents

leneke

Ingrid and Wanda 



\section{Acknowledgements}

This thesis would not have been realized without the help of many people. On this occasion I would like to express my gratitude to all those people who supported me in completing this study. Prof. Greep, your readiness to become my promotor made me very grateful. also your support and advice has been most valuable. I would like to express my utmost gratitude to you. Christopher Williams, for almost everything concerning colonoscopies, polypectomies and this thesis. You learned me the basic principles of colonoscopy, advised me in starting a new endoscopy unit and above all provided me with the opportunity to work at your endoscopy unit and analysing your colonoscopies, resulting in this thesis. Your advice concerning the subject, and the English language in this thesis have been most valuable, without which this thesis would not have been completed. My gratitude to you also, Christina, for your comments on this thesis and most of all for the warm welcome and kind hospitality. Dr. Blok, Prof. Jeekel and Prol. Tytgat you have all read the manuscript critically and I apppreciate your comments. My gratitude also goes out to Dr. Regout and Dr. Leo for giving me the opportunity for training in surgery and performing colonoscopies. and especially to Dr. Koumans, who introduced me into the field of colonoscopy and provided me with foreign experience.

I am much indebted to the Drs. Hedberg. Donaldson and Welch for the opportunity of gaining experience at the Massachusetts General Hospital.

Prof. van Houten, I am grateful for the opportunity enabling me to finish my thesis during my work at your department.

Support on the technical aspects has been given by Ir. G.D. Khoe; the microscopic pictures being provided by Drs. F.J.W. ten Kate

Valuable assistance regarding this thesis has been given by Miss $F$. Patterson and Mrs. C. Fendick; secretarial assistance being provided by Miss L. Rankin, Miss T.T. Lie and the surgical secretariat at the 
Dijkzigt Hospital (under supervision of Mrs. E. Benckhuijsen), especially Miss S. Talboom, Miss J. Herwegh and Miss E. Nijssen. The lables, figures and graphical lay-out has been provided by the Audio Visuele Dienst Erasmus Universiteit Rotterdam, C. Voskamp and E.J.W. Davids.

Withoul the dedicated help of my wife, this publication would never have been completed. 


\section{Contents}

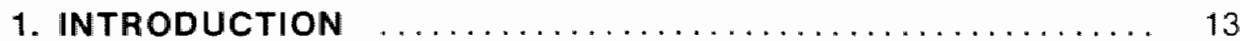

2. COLONIC POLYPS: A PROBLEM FOR MANAGEMENT $\ldots . . .$.

2.1. Management of colonic polyps: the past $\ldots \ldots \ldots \ldots \ldots \ldots$

2.1.1. Why polyps should be removed ................ 16

2.1.2. Polyps within the reach of the rigid sigmoidoscope ... 19

2.1.3. Polyps above the reach of the rigid sigmoidoscope ... 20

2.1.4. Summary .......................... 22

2.2. A historic review: from surgery to endoscopilc polypectomy . 22

2.2.7. Development of the light source ................ 23

2.2.2. Development of the endoscope ............... 25

2.2.3. Endoscopy of the lower gastro-intestinal tract ....... 26

2.3. Technical aspects of the fibre-optic endoscope $\ldots \ldots \ldots \ldots 28$

2.3.1. Introduction .......................... 28

2.3.2. Principles of light transmission in a fibre .......... 28

2.3.3. Light transmission in fibre bundles .............. 30

2.4. Colonic polyps and the adenoma-carcinoma sequence .... 32

2.4.1. Morphology ........................ 32

2.4.2. Incidence and distribution of polyps ........... 34

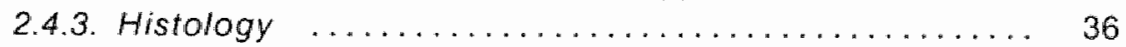

2.4.3.1. Neoplastic pollyps ................ 36

2.4.3.2. The adenoma-carcinoma sequence ....... 43

2.4.3.3. Non neoplastic polyps ............. 45

2.5. Management of colonic polyps:" the present ........... 50

3. COLONOSCOPIC POLYPECTOMY: MATERIAL AND METHOD . 53

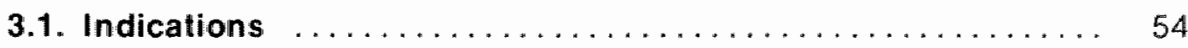

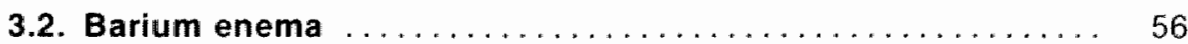

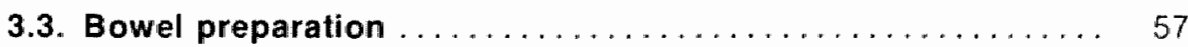

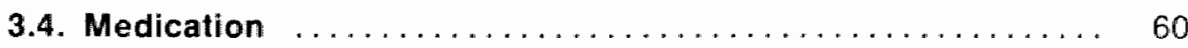




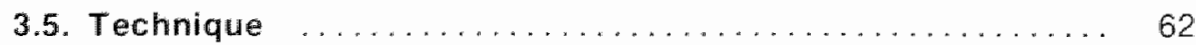

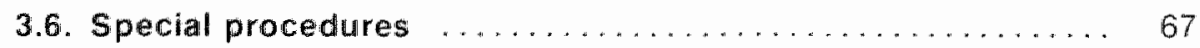

3.6.1. Retrieval of snared polyps ................. 67

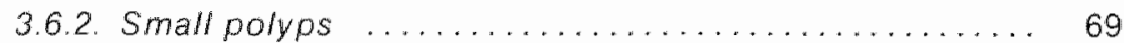

3.6.3. Multiple polyps .......................... 70

3.6.4. Sessile polyps .......................... 70

3.6.5. Large polyps .......................... 71

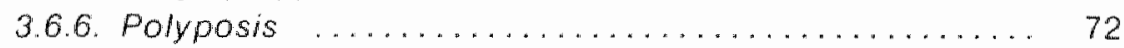

3.6.7. Peutz-Jeghers polyp syndrome ............... 72

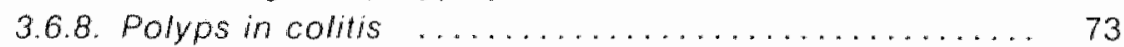

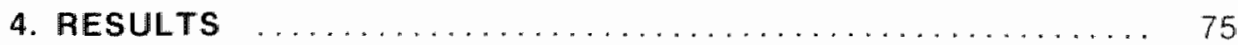

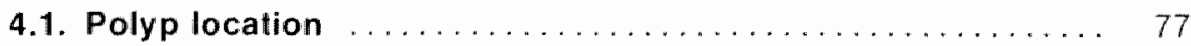

4.2. Polyp size and configuration $\ldots \ldots \ldots \ldots \ldots \ldots \ldots \ldots \ldots$

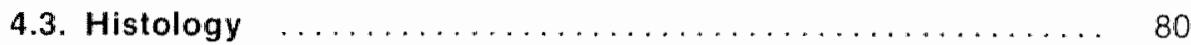

4.3.1. Neoplastic polyps ................... 86

4.3.2. Non neoplastic polyps ....................... 91

4.4. Malignant adenomas and polypoid carcinomas: removable polyps 98

4.5. Uniremovable polyps ....................... 107

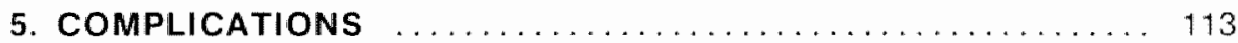

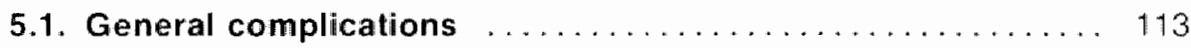

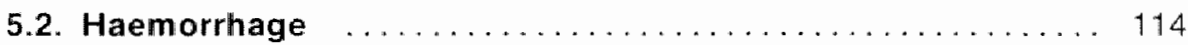

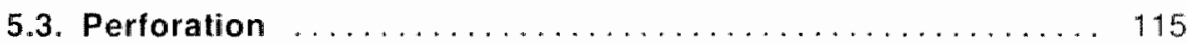

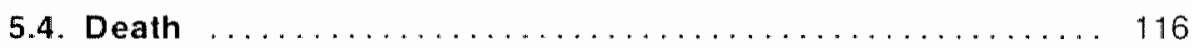

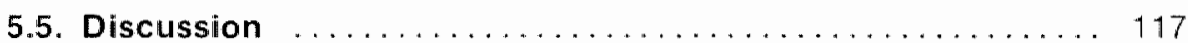

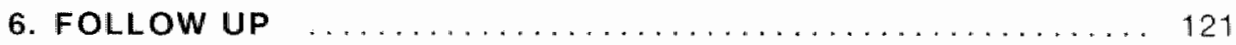

6.1. Benign adenomas $\ldots \ldots \ldots \ldots \ldots \ldots \ldots \ldots \ldots \ldots \ldots \ldots \ldots$

6.2. Malignant adenomas and polypoid carcinomas . . . . . . . . 124

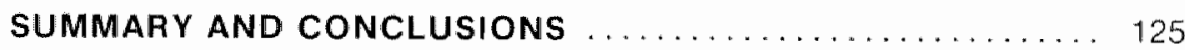

SAMENVATTING EN CONCLUSIES ................. 131

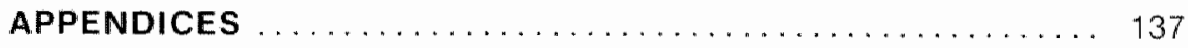

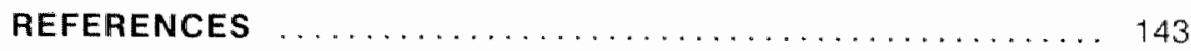

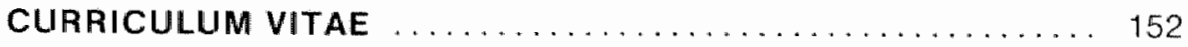


A colonic polyp is any circumscribed tumour or elevation that projects above the surface of the normal surrounding colonic mucosa.

A colonic adenoma is a precursor of a carcinoma (Muto. Bussey and Morson, 1975).

and therefore, every colonic adenoma should be removed. 



\section{Introduction}

Colonoscopy is now routinely performed as a diagnostic and therapeutic procedure. Its widespread use and still growing interest derives from improvements in the skills necessary to use the instruments and the technology for making them.

This study in its technical aspects and conclusions is based on personal experience in colonoscopy and polypectomy since 1975 at the Westeinde Hospital, The Hague; further experience being gained at the Massachusetts General Hospital, Boston and the St. Mark's Hospital, London. The total number of colonoscopies performed by the author is approximately 500 , of which 40 per cent at St. Mark's Hospital and being included in this study. Furthermore, the author is actively involved in coordinating and conducting a prospective follow-up study at St. Mark's Hospital. This comprises approximately 500 patients with colonic adenomas, removed by colonoscopic polypectomy in the previous years. This study is described in more detail in chapter 6 and is at present still going on.

The factual material used in this study derives from an analysis by the author of colonoscopic polypectomies performed at St. Mark's Hospital in the years 1971-1979.

The purpose of this study is to evaluate the impact of fibrecolonoscopic polypectomy on the management of colonic polyps. The study is separated into sections considering the historical, clinical and technical aspects of colonoscopic polypectomy and, wherever possible conclusions and recommendations have been introduced.

Finally, based on the opinions given and analysis of the results, speculations are presented on the future of colonoscopy and polypectomy. 



\section{Colonic polyps : A problem for management}

Colonic polyps have always been a management problem because of the possibility that they may be precancerous in nature (adenomatous polyps) or contain the early stages of invasive carcinoma of the colon. Throughout this study reference will be made to colonic polyps (as opposed to adenomas), since they are the problem facing the clinician; only the pathologist makes the discovery of which polyp is an adenoma, an adenoma with invasive cancer or a frank polypoid carcinoma.

Abdominal surgery was the only treatment for colonic polyps in the era before colonoscopy and polypectomy. Only polyps within the reach of the rigid sigmoidoscope could be removed trans-anally. In the last decade progress has been made on fibre-optic endoscopy and the management of colonic polyps is at present in a transitional period. Whereas in the past abdominal surgery prevailed, colonoscopy and polypectomy is nowadays the procedure of choice.

\subsection{Management of colonic polyps : the past}

In current literature it is unusual to find an article referring to abdominal surgery, i.e. laparotomy with colotomy and polypectomy or colonic resection as the management of colonic polyps.

This was the method of management for colonic polyps in the past. the era before colonoscopy, which started about 1970; it consisted of either surgery or trans-anal resection through the rigid sigmoidoscope. Nowadays this approach is used only in special cases such as carcinomas arising in adenomatous polyps or in polypoid carcinomas.

Because of the technical problems which previously existed for the removal of polyps beyond the reach of the rigid proctosigmoidoscope, it was necessary to apply dual standards in setting the criteria for 
polypectomy - a low threshold for those within reach endoscopically but a high threshold for those which would require abdominal operation.

This chapter will consider the strong evidence from the past as to why polyps should be removed and the two different approaches to how colonic polyps were treated in the pre-colonoscopy era, and is divided in three parts:

\subsection{1.: Why polyps should be removed: the evidence before colonoscopy.}

2.1.2.: Polyps within the reach of the rigid sigmoidoscope.

2.1.3.: Polyps above the reach of the rigid sigmoidoscope.

\subsubsection{Why polyps should be removed: the evidence before colonoscopy.}

There were several reasons for removing a colonic polyp. A certain number of polypoid lesions diagnosed on barium enema were not only adenomas but in fact cancerous lesions. Only histological verification of the whole lesion could distinguish between a benign adenoma or a malignant lesion and therefore the whole polyp should be removed.

If the polyp is not removed, certain adenomas would develop into cancer. If it was accepted that the malignant potential of an adenoma was 2 per cent (62) and that of a villous adenoma at least 30 per cent $(43,62,83)$, it could be estimated that $6-10$ per cent of the total might develop cancer (179).

Welch and Hedberg (1975) stated that since 70 per cent of the patients with polyps had symptoms, 20 per cent had cancer and 6-10 per cent might develop cancer, there were strong indications to remove the polypoid lesions. However, in every case the risks of operation had to be weighed against the risks mentioned above.

Although the operative mortality figures for colonic polyps were low, not every patient with a colonic polyp should be operated on.

In considering an operation, certain criteria were suggested:

- the age and the condition of the patient

- localization of the polyp

- size of the polyp

- configuration of the polyp

- the number of polyp(s)

- the presence or absence of symptoms. 
The age and condition of the patient influenced the operative risks. As for other surgical procedures, elderly patients or poor clinical condition carried high risks for any operation, especially colonic surgery. However, with modern facilities for anaesthesia and postoperative care, the mortality and morbidity were significantly reduced.

Even so mortality figures reported were between $1-3$ per cent $(36,62$. 179). while morbidity figures varied between $5-20$ per cent $(21,88)$. Needless to say the operative risk varied individually in every patient.

The localization of the polyp was important. If it was located within the reach of the rigid sigmoidoscope, a sigmoidoscopy was performed with polyp removal. If the polyp was located more proximally in the colon, surgery had to be considered.

This will be discussed further in chapter 2.1.2. and 2.1.3.

The size of the polyp was the most important feature. Operation was advised for all polypoid lesions over $1.5 \mathrm{~cm}$ in diameter, since the risk of such a lesion being cancerous outweighed the operative mortality. Several authors supported this figure $(62,77,97,179)$.

The chance of a polyp less than $1.5 \mathrm{~cm}$ in diameter being a cancerous lesion is estimated as $1.0-1.8$ per cent $(62,179)$. Polyps larger than 1.5 $\mathrm{cm}$ have an increased risk being cancer as shown in table 1. Listed here are the findings of the malignancy rates in polyps of different sizes as reported by various authors. Spratt and Ackerman (1960) even illustrated that in polyps with a diameter between 1.98 and 3.12 $\mathrm{cm}$ the incidence of cancer was 75 per cent: larger tumours were almost always cancerous.

Since the operative mortality of polyp removal from the colon was between 1-2 per cent $(36,62,179)$, the critical polyp size was up to 1.5 $\mathrm{cm}$. The operative mortality would be higher than the risk of cancer in these small lesions. Therefore, surgery was advised in patients with polyps larger than $1-1.5 \mathrm{~cm}$ in diameter $(77,97,179)$. In smaller polyps, expectant management was suggested, but careful follow-up had to be performed using barium enemas.

The reason for careful follow up was the direct evidence that adenomas can grow $(47,95,102,149,156)$, so that cancer risk rises. The rate of growth is estimated by Welin who found a 35 per cent chance of cancer if the tumour mass doubled on X-ray in less than 300 days (cited by Welch and Hedberg, 1975). Spratt and Ackerman (1960) stated that if a lesion was cancer, its size would double some time between 49 and 123 days. Their figures were based on observations of Collins et al (1956) on doubling time for metastatic rectal cancer. 
However small benign polyps could remain unchanged in size or disappear over the years $(42,60)$.

At that time, radiology was the only way to follow-up these polyps. Despite the risks of excessive radiation, the advised frequency of barium enema as a follow-up procedure differed between once in 6-12 months (77) to once in every 3 years (97).

Table 1: Felation between size of colonic adenomas and malignancy rate as reported by various authors $(43.62,77,114)$

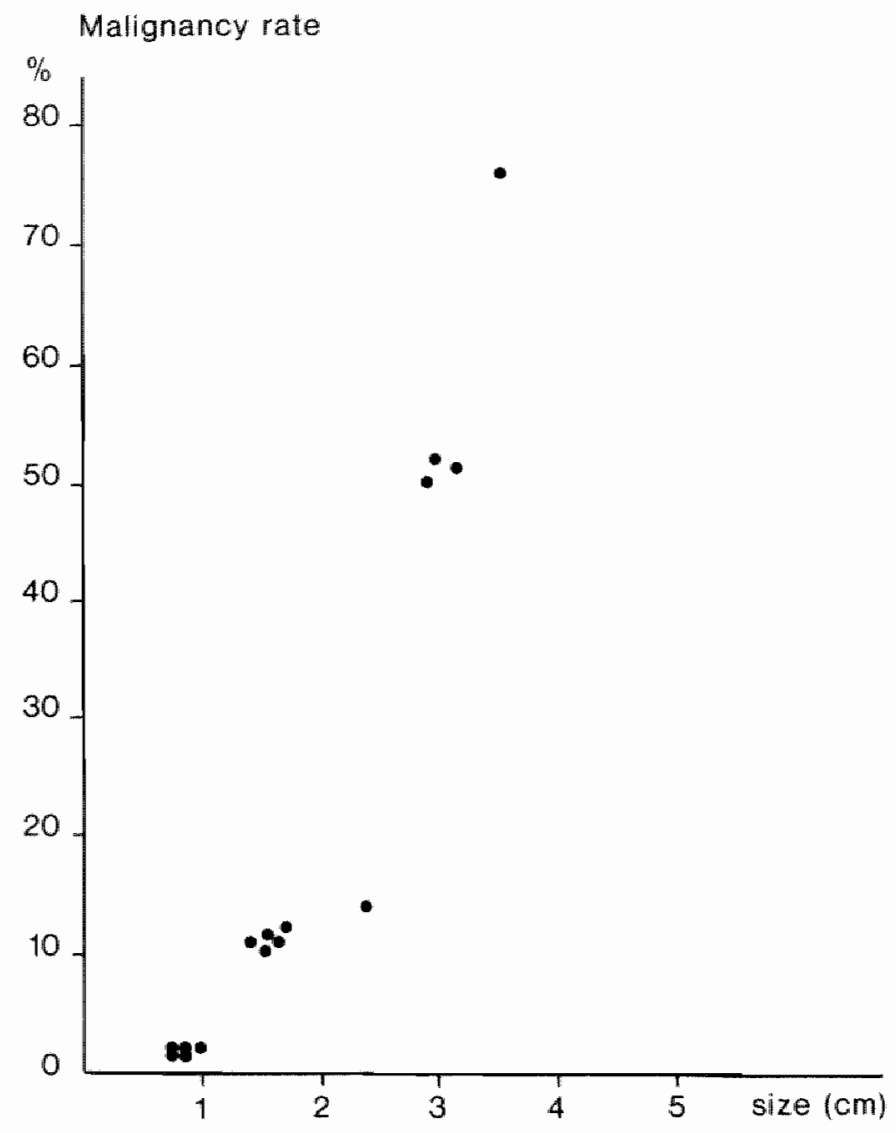

The configuration of a polyp on barium enema was considered to be a valuable feature. The presence of a long stalk indicated the tumour to be relatively benign. However, carcinomas on long stalks had been reported $(87,99,179)$ in several cases even with metastases $(87,99)$. 
Sessile configuration increased the chance of a polyp being malignant, particularly if the surface was lobulated or irregullar. It was stressed that in many instances it was difficult for the radiologist to determine the presence or absence of a stalk.

The number of polyps influenced the decision on surgery, since there was a strong relationship between the number of adenomas and the incidence of associated carcinomas 19). These figures varied from 51.7 per cent if two adenomas were present to 80.0 per cent when more then six adenomas were discovered.

In patients with multiple polyps, surgery was indicated because of the hïgh malignancy risk. Resection and anastomosis was prevailed above multiple colotomies and polypectomies.

The presence or absence of symptoms influenced the decision on management of the colonic polyp. Small polyps can rarely cause symptoms, and not infrequently other pathological conditions may nave been the cause of the symptoms. Welch and Hedberg (1975) considered that up to 70 per cent of the patients with adenomas have symptoms ascribable to the adenoma itself. This percentage seems rather high, but no detailed study has been presented. Grinnell and Lane (1958) found symptoms like bleeding in 52 per cent of their patients, but this may be due to accompanying conditions like hemorrhoids or fissures. Rider et al (1954) found pollyps as frequently in patients without symptoms as in those with them. Bleeding occurred in 61 per cent of the patients with polyps with secondary cancer. However, if a polyp was assumed to be causing symptoms, surgery was more frequently indicated (97).

\subsubsection{Polyps within the reach of the rigid sigmoidoscope (the past)}

Polyps in the rectum and most distal colon were frequently not recognized at barium enema. Rigid sigmoidoscopy was therefore a complementary diagnostic aid.

Any pollyp discovered, either by barium enema or at rigid sigmoidoscopy was excised to achieve histological diagnosis.

Depending upon its size, this procedure could be performed either as an in-patient or as an out-patient, with or without anaesthesia. If the polyp was small in size (less than $0.7 \mathrm{~cm}$ in diameter) a forceps biopsy was sufficient to remove the whole polyp, usually as an outpatient procedure without anaesthesia.

Polyps larger than $0.7 \mathrm{~cm}$ needed a different approach. In the past biopsies were taken from the pollyp to determine histological diagnosis and further management. But it is a good principle not to 
fragment the polyp by multiple biopsies but ro remove it totally and a larger sigmoidoscope was necessary. This instrument could only be inserted after dilation of the anal sphincter, hence anaesthesia was required. Electro-surgical removal was possible using a snare through the sigmoidoscope.

Other methods included the extraction of the polyp through the dilated anal sphincter with lacal excision and suture ligation of the pedicle or bowel wall, removal trans-anally through a posterior proctotomy, various methods of resection and anastomosis such as low anterior resection, anterior resection and posterior anastomosis (D'Allaines), various sphincter saving procedures or abdomina-perineal resection (Miles).

\section{1.3. Polyps above the reach of the rigid sigmoidoscope (the past)}

Polyps found on barium enema and located above the reach of the rigid sigmoidoscope could only be managed by abdominal surgery. when the decision to remove the polyp had been taken.

Proper preparation of the bowel was essential and perhaps even more important than it was for any other type of colonic disease.

Mechanical cleansing of the bowel using aperients combined with enemas produced a clean and empty bowel. This could be combined with oral antibiotics such as sulfathalidine or neomycin.

Parenteral antibiotics were used prophylactically during a short period pre-, per- and postoperatively.

After opening the abdomen, the surgeon's first problem was finding the lesions described on the barium enema and it was often extremely difficult to find them. Flat and soft lesions like villous adenomas were difficult to palpate and many soft adenomatous polyps, even on long stalks, might be difficult to feel. Especially in cases when the appendices epiploicae were fat, it was very hard to feel a lesion inside the colon. As a general rule, these lesions were demonstrated more clearly by barium enema than they could be by the surgeon on the operating table.

Since palpation of the bowel could not be relied upon completely, ather methods were introduced.

Transillumination of the bowel wall was occasionally helpful, but again large and fatty appendices epiploicae made this difficult. A light carried on a flexible cord could be introduced anally and propelled proximally by the surgeon's hand. 
The best method available was the use of a rigid sigmoidoscope at the time of operation.

If the polyp could not be palpated, a colotomy was performed and the rigid sigmodoscope (sterile) was introduced proximally and distally to find the lesion (166). Using several colotomies in different parts of the bowel, it was found possible to inspect the lumen of the whole colon. Deddish and Hertz (1959) reported 70 patients who had total peroperative inspection of the colon by this method. He found additional polyps in 35 patients $(50 \%)$. In 33 patients with an inspection of a part of the colon only, 13 patients had additional polyps.

As expected, this type of operation resulted in an increased risk of postoperative complications. In Deddish's series of 106 patients, there was one death and 18 cases of peritonitis even though the whole procedure was performed with the strictest attention to asepsis and a perfectly prepared colon.

Other methods were suggested by various surgeons to find the polyps. Gants et al (1956) advised three incisions, $6-10$ inches long at the antimesenteric border of the ascending, transverse and descending colon, in order to inspect most parts of the bowel Although they reported no difficulty in healing in experimental animals or patients, this method did not gain wide support.

In 1964 Kratzer sent questionnaires to the members of the American Proctological Society. Of the 140 reports received, 43.5 per cent used the rigid sigmoidoscope for the entire colon, 36.4 per cent only for the left colon, 13.7 per cent used it only in the area of a single lesion. while 6.4 per cent did not use it at all. Using the rigid sigmoidoscope for inspection of the colon, additional polypoid lesions not seen on $X$ ray were found in 23 per cent of the patients.

\section{Type of operation}

After finding the polyp, the next step was to decide what kind of operation had to be performed: colotomy and polypectomy or resection and anastomosis.

Colotomy and polypectomy was performed on single pedunculated adenomas, while if the lesion was hard or sessile, indicating a carcinoma or a villous adenoma, resection and anastomosis was indicated. It was stressed that frozen section diagnosis on polyps was notoriously difficult and might lead to an erroneous treatment.

Welch (1975) suggested that the standard operation for all collonic polyps should be resection and anastomosis rather than simple colotomy and polypectomy, but this policy never gained popularity. 
Welch and Hedberg (1975) described in detail the problems concerning polypectomy or resection. The mortality rate in their series following colotomy and polypectomy in the period $1954-1963$ for 153 single adenomas was two per cent, and after 107 resections and anastomoses 0.9 per cent. However, Grinnell and Lane (1958) found a 0.5 per cent mortality rate in the polypectomised patients, whereas for resections the rate was six per cent.

There was controversy but it was generally concluded that the surgeon should be prepared to perform a resection of the colon, but that this operation might be modified to a simple colotomy and polypectomy procedure if the lesion was soft, pedunculated, single and benign.

\subsubsection{Summary}

In the past colonic polyps seen on barium enema have been treated in an inconsequent way. The risk of a polyp being carcinomatous has been stressed. These malignancy rates varied from approximately $1-2$ per cent in case of small polyps up to $1.0 \mathrm{~cm}$ in diameter, to $50-75$ per cent if the polyp is $3 \mathrm{~cm}$ in diameter or larger.

Because of this malignancy chance, every polyp, even the small sized polyp, was removed if located within the reach of the rigid sigmoidoscope.

Above the reach of the rigid sigmoidoscope, however, abdominal surgery was needed. Polyps smaller than $1.5 \mathrm{~cm}$ in diameter were treated expectantly, because the chance of postoperative morbidity and mortality would outweigh the chance of the polyp being malignant. If on radiological follow-up the polyp became larger. surgery was indicated.

In case of a polyp larger than $1.5 \mathrm{~cm}$ in diameter, abdominal surgery was advised because of the higher risk of malignancy.

Colotomy and inspection using the sterile rigid sigmolidoscope was advised for searching the - often difficult to palpate - colonic polyps. Polypectomy and suture ligation of the stalk was the procedure of choice, but in case of suspected malignancy segment resection and anastomosis should be performed.

\subsection{A historic review : from surgery to endoscopic polypectomy}

The history of endoscopy started with the need to inspect the inside of the different organs through their orifices. As Keele (1963) 
pointed out, this challenge goes back to the days of Hippocrates. when the ancient Greeks performed examinations using a vaginal speculum equipped with dilator blades. Since then, the instruments and skills needed to examine bodily organs underwent slow development, but in recent years an acceleration took place resulting in the now widespread use of fibre-optic endoscopy.

As the history of collonoscopy and colonoscopes is closely related to the history of endoscopy in general, the development of light sources. endoscopes and endoscopy of the colon will be described seperately as follows:

2.2.1. Development of the light source.

2.2.2. Development of the endoscope.

2.2.3. Endoscopy of the lower gastro-intestinal tract.

\subsubsection{Development of the light source}

Ancient Greek endoscopists used daylight as their light source. As the use of daylight has obvious limitations candle-light was then used for inspection of bodily organs. Only superficial and localized areas could be inspected, the deeper and consequently darker body cavities remained inaccessible or only obscurely discernible.

Bozzini developed in 1806 his "Lichtleiter" to be used for cystoscopy or urethroscopy. He used a tube inserted into the urethra with the "Lichtleiter" at the other end (fig. 1). The light was provided by a

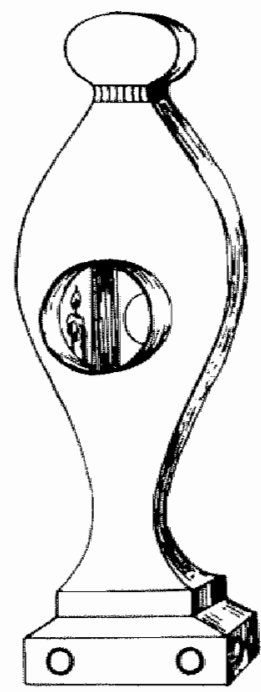

Fig. 1: A drawing af Bozzinis Lichtleiter 11806h. (From D. D. Gibbs in Modern Topics in Gastro-intestinal Endoscopy 1978\%. 
beeswax candle placed in a box and springloaded to keep the flame steady, with a silver mirror to reflect the light down the examining tube. The examiner looked past the mirror from behind the instrument. Although the system failed because of insufficient illumination, it provided a prototype for numerous improvements during the nineteenth century.

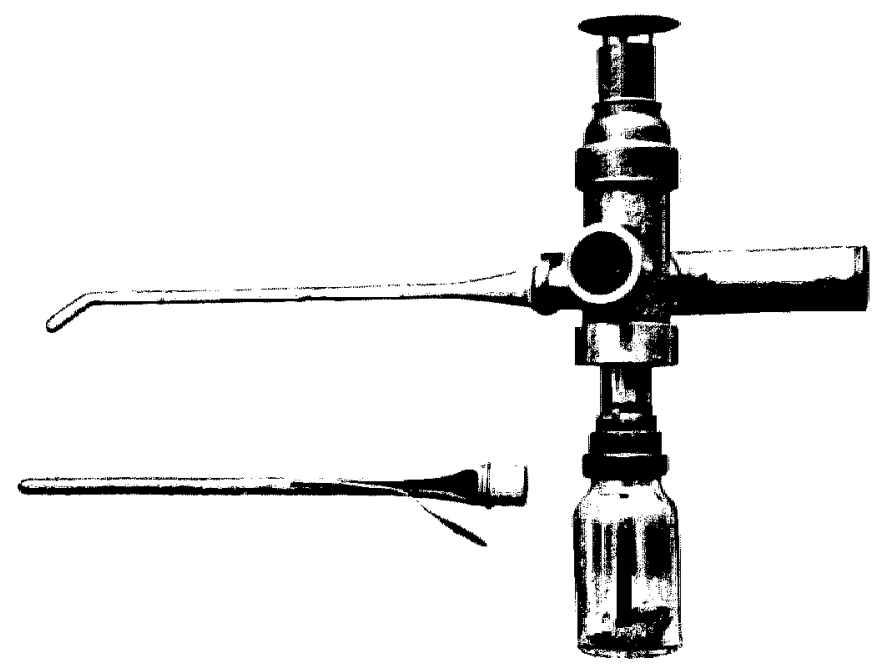

Fig. 2: The Desormeaux lamp burning gasogen with tubes designed for examining the urethra and rectum (From D.D. Gibbs in Modern Topics in Gastrointestinal Endoscopy 1978).

In 1865 the Desormeaux lamp was developed and at that time it was the most efficient light source available (fig. 2). The light was emitted by a burning mixture of alcohol and terpentine (gasogen) and the lamp was provided with a chimney which just cleared the examiner's head. A condenser lens and mirror was used to conduct the light. This type of light source was used by Kussmaul in 1868 performing inspection of the stomach using a rigid tube.

Although the Desormeaux lamp was at that time most effective, it had not gained wide acceptance because the light was too dim to illuminate. Bevan (1868) still used a reflected candle light for oesophagoscopy, although examination was confined to the proximal oesophagus.

At the end of the nineteenth century, certain important improvements had been made in the development of the light source. In 1880 Edison invented the carbon filament electric lamp, a leap forward in light 
development. More light intensity was achieved, but heat problems occurred and cooling devices were developed. These devices became the largest part of the whole instrument and managing it became difficult.

Initially the light source was placed proximally outside the body resulting in a poor illuminated body cavity. The need to place the light source distally at the end of the instrument was obvious and Mickulicz (1881) used his water cooled distally placed platinum loop lamp successfully for gastroscopies. The Nitze-Leiter cystoscope (1879) contained a tube with insulated wires, water cooling tubes and a telescopic tube, the bulk of the instrument consisting of the water cooling apparatus. However, soon after this the electric lamp came and gained more acceptance.

In $1928 \Downarrow$ Logie Baird noticed the phenomenon of the ability of a light conductor to convey light in a curve by a process of internal reflections. He used a glass tube for image carrying in his experiments. This idea was developed further in 1949 and 1950 by Hopkins and Kapany (74) using specially coated glass fibres for transmission of images. This resulted in the introduction of a new terminology in 1954: "fibre-optics".

After the invention of fibre-optics, the distally placed light source in the endascope was unnecessary, fibre-optics being used to conduct the light to the distal end of the endoscope.

The incandescent lamp light source was in the meantime superseeded by a much more efficient light unit using an external xenon arc lamp resulting in bright but 'cold' light externally and particularly internally after transmission down the fibre-bundle into the patient.

\subsubsection{Development of the endoscope}

The tubular instruments needed for inspection of body cavities dated back to Bozzini in 1806 who used a straight tube, attempting cystoscopy or urethroscopy. This method formed the base for numerous improvements in the nineteenth century when cystoscopy had become the most sophisticated branch of endoscopy, and the pace-setter for developments in endoscopy.

In 1850 Campbell had designs to inspect the stomach of a sword swallower using a rigid tube, but this was rejected by the man. A gastric tube for aspirating stomach contents was used by Kussmaul in 1865 and in 1868 after studying a sword swallower introducing his sword. Kussmaul performed a gastroscopy using a rigid straight and open tube with the aid of an obturator. His important achievement was the demonstration that the natural curves from parts of the 
gastro-intestinal tract could be adapted to accomodate a rigid straight metal tube.

As not all natural curves could be straightened out by metal tubes, experiments were made with angulation, guiding tubes and lobster tail devices. In 1863 Bodenhammer invented a long tubular speculum which was rendered flexible in part of its length by incorporating a series of mirrors to inspect the sigmoid colon, but this was overambitious and was soon forgotten.

It was not until 1916 that Lange reported that thick convex lenses would transmit a picture through a flexible tube and through variable curves. Some years later, Wolf and Schindler applied this idea to the rigid gastroscope, resulting in the semiflexible instruments (1932).

A fully flexible gastroscope was already developed by Wolf, but at that time a rigid instrument with a flexible distal end was found to be more practical.

In the following years such semiflexible endoscopes were used, but certain problems limited its widespread use. These limitations included blind areas, unacceptable risks in patients with cervical spondylosis or kyphosis and absence of facilities for taking biopsies under direct inspection. Certain specially designed instruments did incorporate a biopsy mechanism, but directed biopsy was not possible. The semi-flexible era ended, when fibre-optics were introduced and Hirschowitz (1958) developed a fully flexible fibreoptic gastroscope, with working channels for suction and taking biopsies under direct vision.

\subsubsection{Endoscopy of the lower gastro intestinal tract}

The previously mentioned "Lichtleiter" developed by Bozzini in 1806 could also be used to inspect the rectum using a rigid tube, but was too small to give good illumination, as was the Desormeaux apparatus

The attempts of Bodenhammer (1863) to inspect the sigmoid colon with a flexible mirrored speculum have been mentioned before. Sims (1845) performed vaginal examinations with air insufflation using a distended balloon. This was adapted to rectal examinations by Van Buren in 1881. Rigid sigmoidoscopy using a $35 \mathrm{~cm}$ straight tube with an obturator was further developed by Kelly in 1895. However, light was directed from a head mirror, until Pennington in 1899 closed the proximal end with a glass window and used an inflating bulb and a small electric lamp. This method of examination was further popularized by Lockhart Mummery (1906) and Bensaud (1919) and since then various improvements have taken place on instrument 
construction. size and length, proximal and distal lighting. suction and biopsy instruments and insufflating apparatus. With the introduction of high frequency electric current, the snare loop was developed for taking large biopsies and performing polypectomies. This has resulted in the widespread use of rigid sigmoidoscopy nowadays.

However, the need to inspect the other parts of the lower gastrointestimal tract above the recto-sigmoid area is obwious. When fibre-optics were introduced in the endoscopy, rapid developments took place in the collon as well as in examination of the upper gastrointestinal tract.

In 1959 Matsunaga et al (100, 101) in Japan devised the sigmoidocamera to take color photographs of the sigmoid colon mucosa up to the splenic flexure. The instrument was developed from the gastrocamera, $75 \mathrm{~cm}$ in length, later on extended to 1.5 and $2.0 \mathrm{~m}$. It was passed blindly using inflation of air and fluoroscopy-X-ray because no direct view examination was possible.

Niwa in 1960 reported his experiences in attempting to apply the fibre-optic gastroscope to direct view examinations of the rectum and colon. He developed this method further and described his experiences again $(121,122,123)$

Nagasako (115) reported three instances in which the instrument was inserted to the caecum. A different technique of inserting a fibre-optic bundle through the colon to the caecum by a trans intestinal intubation method was reported by Provenzale and Revignas (1969) and Fox (1969), but later abandoned as manoeuvrable colonoscopes gained popularity (130).

With improvements in the working channels in the endoscope, flexible biopsy instruments were used. The next step was the development of flexible snare loops and the colonoscopic polypectomy has started around 1970 .

In the United States. Turell (1963) had written a rather negative preliminary report on the flexible fibre-optic colonoscope and it was till 1968 when the first enthusiastic reports were published $(37,38$, 127. $128,130,151,191$ ) that fibre colonoscopy started to emerge as an important diagnostic method.

Since then, the use of the flexible fibre-optic colonoscope is increasing immensely and the technical developments are still going on. The walue of the colonoscopy has been reported by the Work Group $X$ of the American Gastroenterological Association in 1975 (146), stating that "collonoscopy may well prove to be the single most important recent advance in the management of colonic disease". Or, in other terms: "almost overnight the lights of collonoscopists shown from the rectum to the caecum in ever-increasing numbers" (132). 


\subsection{Technical aspects of the fibre-optic endoscope}

\subsubsection{Introduction}

Fibre-optic endoscopes used in colonic areas must satisfy the following requirements:

- provide Hlfumination to the relevant area

- transmit an image to the observer with large focussing range

- be flexible and manoeuvrable

- have additional functions such as biopsy, insufflation and aspiration accessories.

The first three aspects are closely related to the properties of optical fibres. The principles of light and image transmission through optical fibres are discussed in this section. Fabrication of fibre bundles is mentioned in view of the flexibility problems.

\subsubsection{Principles of light transmission in a fibre}

The basic principles of light refraction and reflection at a boundary plane between two different transparent materials are explained in fig. 3. Material 1 is an optically denser medium than material 2. The densities of optical materials are characterized by the value of the "refractive index" $n$ (which is unity for air). The value of n for glass can be between 1.4 and 2 but most industrial glasses have values between 1.5 and 1.7 . Light coming from material 1 having index $n_{1}$ will be refracted or reflected at the boundary with material 2 depending on the angle of incidence $i$, as shown in fig. 3 .

For large values of $i$ light rays will be refracted on the boundary and light rays with small values of $i$ will be reflected back into material 1. The critical value $i_{c}(81)$ determines the maximum angle which is still reflected at the boundary. The value of $i_{c}$ is determined by the values of $n_{1}$ and $n_{2}$. If the values of these refractive indices are very close to each other the value of $i_{c}$ will be very small. Large differences between $n_{1}$ and $n_{2}$ will result in large values of $i_{c}$. For $n_{1}=1.7$ and $n_{2}$ $=1.5, i_{c}$ is $28^{\circ}$. A combination of $n_{1}=1.6$ and $n_{2}=1.5$ will result in $a$ value of $20^{\circ}$ for $i_{C}$.

An optical fibre is basically a glass cylinder with high refractive index surrounded by another material, usually glass also, with lower refractive index. Propagation of light in the fibre is illustrated in fig. 4 (158).

Light is confined in the core region because the rays are reflected back and forth between the core-cladding boundaries. However, if the angle of a particular ray is larger than the critical angle it will not be 


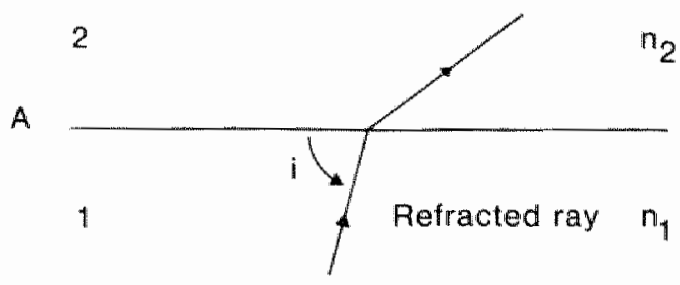

2

$n_{2}$

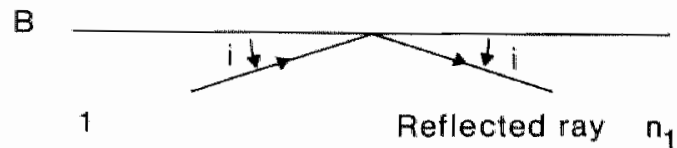

2

$n 2$

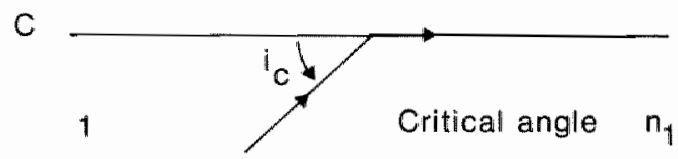

Fig. 3: Light ray crossing a boundary between materials with different refractive indices $n ; n 1>n 2$

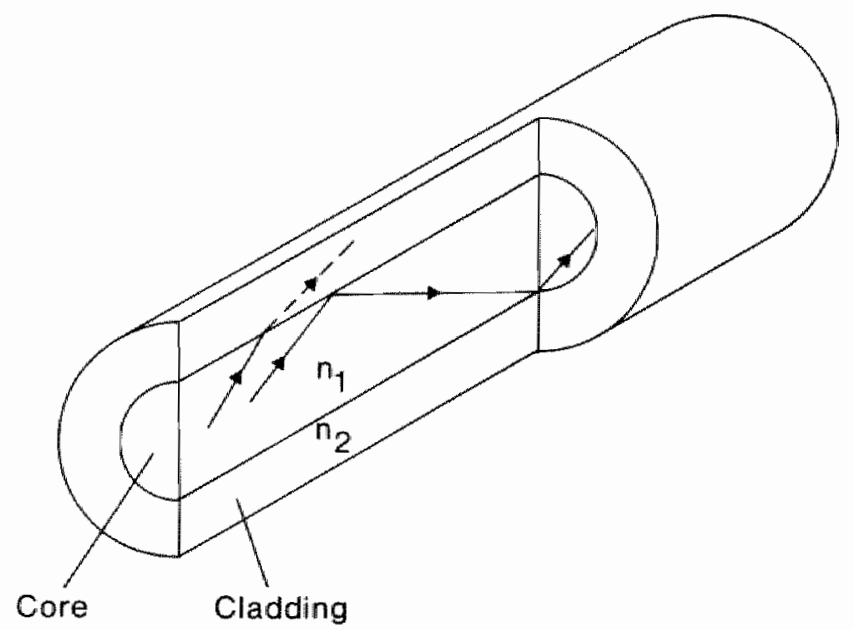

Fig. 4 : In an optical fibre, rays with angles smaller than $i_{c}$ are reflected back and forth between the boundaries. 
reflected back into the core anymore. Instead this ray will be refracted into the cladding layer. The cladding layer is usually fabricated of material with low transparency glass and rays leaking into this region will be attenuated very rapidly.

In cylindrical configuration of the fibre, the critical local angles at the core-cladding boundary creates a critical cone. Rays with (84) angles inside the cone is accepted by the core. A fibre with a large difference between the refractive indices of the core and cladding will have a large accepting cone and therefore will accept more light than those having small refractive index differences. More light can be accepted by the fibre if the size of the core is increased, but the size of the fibre can only be increased at the cost of flexibility. To avoid this problem. fibre bundles are used to increase the efficient size of the core, while maintaining sufficient flexibility.

Common industrial fibres are drawn from a preform consisting of a glass rod with high refractive index surrounded by a tube of glass with lower refractive index. The diameter of this preform is usually 1 $\mathrm{cm}$ with a length of $1 \mathrm{~m}$. The end of the preform is then heated to several hundreds degree centigrade and the molten end can be drawn to a small fibre. Due to the small size of the fibre, it will cool down very rapidly and the solid fibre can already be wound on a drum a few meters below the preform. Several hundred meters of fibre can be obtained from a single preform. More than one kilometer can be drawn in a single rum if larger preforms are used (2). Finally the fibre is cut in appropriate pieces to form a bundle.

\subsubsection{Light transmission in fibre bundles}

An important aspect of fibre bundles for light transmission is the "packing fraction". which is basically the ratio between cladding area to core area (173). Cladding layers are usually very thin, to allow a good packing fraction (fig. 5).

Each illuminating fibre usually has a core diameter of $0.05 \mathrm{~mm}$ surrounded by a cladding layer of $0.005 \mathrm{~mm}$. These fibres are then joined together lo form a bundle of a few $\mathrm{mm}$ diameter.

To transmit an image properly, the fibre bundle must satisfy some additional requirements. A deformation free image can be obtained only if a good coherence is present at both ends of the bundle, which means that the libres must be arranged exactly in the same way at both ends. These allignments are fixed at the ends of the bundle onlly and the rest of the fibres along the bundle remain loose to maintain the 


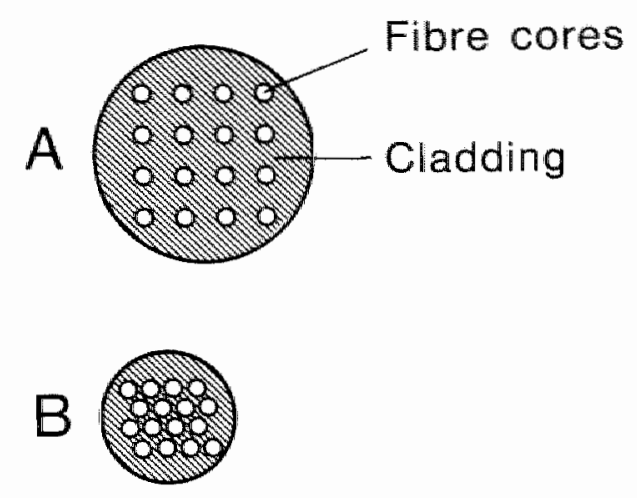

Fio. 5: A. Low packing fraction due to excessive cladding material and poor arrangement B. Higher packing fraction due to thin cladding and efficient packing.

required flexibility, Coherent bundles are fabricated using a special sequence of techniques (29).

Another important aspect is resolution and contrast. The fibre bundle cuts an image into separate points corresponding to each individual fibre-core. It is obvious that more points allow observation of the image in more detail. For this reason, imaging fibre bundles contain more fibres than illumination fibres. To avoid size and flexibility problems, the individual fibres are made much thinner. Present imaging fibres can have core sizes of about $0.005 \mathrm{~mm}$. Bundles consisting of 200,000 fibres have been made.

Decrease in image contrast is caused by rays leaking from one fibre to another one. As was discussed before, rays having angles larger than the critical value will be refracted into the cladding layers Although cladding layers are made from highly absorbing materials, part of the refracted rays may reach the adjacent core. In a flexible bundle, rays with large angles are continuously created along bends Therefore image contrast is always reduced due to curvatures in the bundle.

A fibre bundle alone is not suitable for transmitting images from inside the body because the end of the bundle must be placed in contact with the tissue. A lens system is therefore required to project the image on the surface of the bundle. Basically, the lens can be used to enlarge the image and to focus along a large depth of viewing field. For these purposes, very small llenses have been developed (45). Present lenses can have diameters less than one $\mathrm{mm}$, a field of view larger than $100^{\circ}$ and is able to focus on distances from a few millimeters to infinity. 
An important part of the endoscope is the light source used to illuminate the fibre bundle. Xenon arc lamps are very common. Present lamps are modified in such a way to avoid undesirable heating of the tissue to be illuminated. Heat energy flow from the lamp can be reduced by filtering out the infrared part of the spectrum of the lamp before coupling into the fibre bundle (cord-light) (124). The coupling efficiency between a lamp and a fibre is very low, usually only a few percent, for the following reasons. The arc is larger than the size of the fibre core and light is directed to all directions simultaneously. On the other hand, as was discussed before, only a small cone of light is accepted by the fibre.

In the endoscope, the illuminating system and imaging system is combined in a single instrument.

\subsection{Colonic polyps and the adenoma-carcinoma sequence}

The term polyp describes only the morphology of a lesion and is a clinical term. It does not imply any histological description.

The term polypoid lesion would be preferable but for practical clinical purposes every polypoid lesion is described as a "polyp" and although adenomatous polyps are those which are important in colon-cancer development, the radiologist or endoscopist sees only a "polyp" of undetermined nature.

\subsubsection{Morphology}

As a polyp is any circumscribed tumour or elevation that projects above the surface of the normal surrounding bowel mucosa, its shape and size varies widely. Fig. 6 demonstrates the different types of polyps often found in the large bowel.

Basically, from the endoscopic point of view there are two types of polyps, the sessile and pedunculated polyps. However, in between are different shapes of polyps and grades of pedicles depending upon the length of the stalk. A true pedicle is a tubular off-shoot of normal bowel mucosa on top of which the polyp head is located. If the polyp head is adherent to the bowel wall, it is called sessile.

However, often a pseudo pedicle can be made endoscopically and the polyp can be managed as a pedunculated lesion, if it is not too large. Illustration and explanation is shown in fig. 7 . 


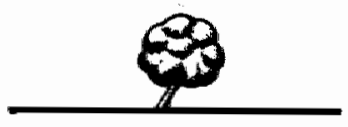

Peduncillated polyp

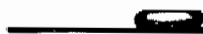

Small, flat elevation

Larger, flat elevation

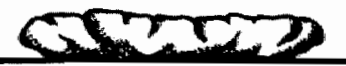

Very large, flat or sessile tumor substantially elevated above surrounding normal mucous membrame

Fig. 6: Various shapes of polyps found in the calon. (From B.C. Morson. The pathogenesis of colorectal cancer 1978).

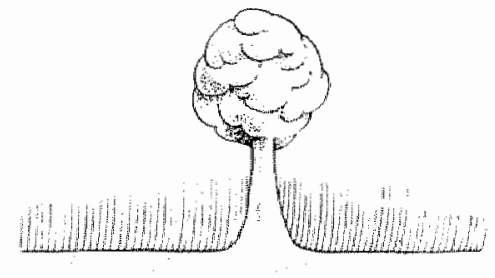

pedunculated polyp

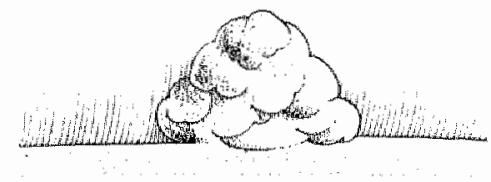

sessile polyp

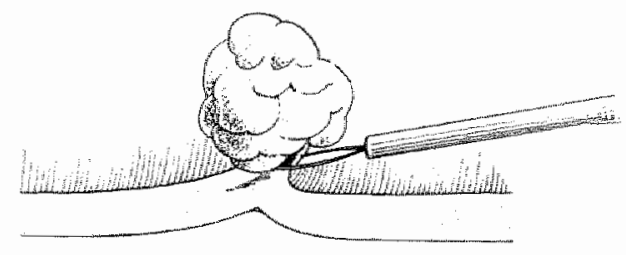

endoscopically "pseudo-pedunculated"

Fig. 7: Pedunculated. sessile and pseudo-pedunculated polyps 


\subsubsection{Incidence and distribution of polyps}

The various reports on the incidence of polyps of the colon are confusing because of the wide variations reported by different authors. More confusing is the fact that several authors described only the adenomas found, while others did not use any histological classification and refer to any polypoid lesions.

The histological verification could previously only be achieved on surgical specimens or at autopsy studies, while clinical studies such as sigmoidoscopy, surgery and barium enema could only describe the prevalence and distribution of polypoid lesions which is of limited value.

Sigmoidoscopic studies did provide a histological diagnosis, but were of very limited value since only the recto-sigmoid area was included. Polyps removed surgically from the colon did not reflect the true incidence of polyps in the colon, because only large polyps were treated by surgery, while small lesions were left untreated. Barium enema studies were frequently used to determine the incidence and distribution of colonic polyps, but this method is frequently diagnostically inadequate. It was (and still is) very difficult to differentiate radiologically between a polyp and fecal concretions, and in poorly prepared bowels it is hard to find polyps. Therefore, barium enema studies may not represent the true incidence and distribution of colonic polyps.

Obviously, the most accurate method in obtaining figures on incidence and distribution should be provided by autopsy reports, although some selection bias is inevitable present, and the rapid autolysis of the gastro-intestinal tract after death can interfere with accurate histological diagnosis.

The use of fibre-optic colonoscopy nowadays is a good method to study the incidence and distribution of the colonic polyps. It has the advantages of differentiating between polyps and fecal concretions and it can also remove or biopsy every polyp in the colon to obtain histological verification.

Because of the wide variations reported by the various investigators, some reports are discussed here, including autopsy studies as well as clinical investigations.

There is a wide discrepancy in the published figures from autopsy series on the incidence of polyps. The figures range from $7-51$ per cent $(6,11,14,24,68,165)$. Chapman (1963) pointed out that this 
wide discrepancy was caused by the fact that the autopsies were performed by a number of prosectors, and the results obtained retrospectively. If one person performs the autopsies in a prospective study, a more reliable figure can be obtained. It is also a laborious task to examine minutely the whole surface of the large intestine and to section every mucosal abnormality. so that some authors have restricted their study to polyps over a certain size. Other factors are the possible influence of time trends, diet and geographic variations on the prevalence of polyps (28).

The incidence of polyps found on sigmoidoscopy varied between 1.6 19.2 per cent $(1,22,42,65,125,137,165,175,190,196)$.

Barium enema studies revealed an incidence of polyps between 1.0 10.0 per cent $(5,54,117,180)$. In a combined sigmoidoscopic and radiological study on 9.669 patients Rider et al (1954) found an incidence of 5.5 per cent. The clinical studies on distribution of the colonic polyps were of limited value, because rigid rectosigmoidoscopy and barium enema were the only procedures for distribution studies. A great majority of polyps, $80-90$ per cent, were found in the rectosigmoid area $(42,62,179)$.

In sharp contrast were the autopsy studies $(11,14)$, in which $27-50$ per cent of polyps were found in the rectosigmoid area. Both methods are obviously of limited value as described previously in this chapter.

From all these studies some important features emerge. Adenomas are uncommon before the age of 30 , but thereafter they are present with increasing frequency as the population ages. On autopsy the distribution of adenomas throughout the colon has been said to be evenly spread much more than clinical studies has suggested.

However, since the fibre-optic colonoscope was introduced, more reliable figures are now obtained; one can be certain if the lesion seen is a polyp, its exact location, size and histological diagnosis. Even very small lesions can be detected by this method. It seems that fibreoptic colonoscopy is a good method to study the distribution and incidence of the polyps, even perhaps the whole development of colonic polyps. Therefore, the figures presented previously are very doubtful when compared to colonoscopic studies.

One of the first colonoscopic reports was from Wolff and Shinya (1971), in which they found 46 polyps in 125 cases, of which three were villous adenomas. Eight polyps were located in the rectum, sigmoid 23 , left colon 10 and the right and transverse colon 5 polyps. Furthermore, they found carcinomas in 24 cases. 
After this report many publications were made on polyps found at colonoscopy $(40,58,134,154,159,187,193)$. These authors found most of the polyps in the left colon distal to the splenic flexure. Their figures ranging from $35-87 \%$ in the sigmoid colon and $8-53 \%$ in the descending colon, while in the transverse colon $3-16 \%$ of the polyps were found and $3-8 \%$ in the ascending colon. More polyps were found in the proximal colon in large series compared to smaller ones. The findings in this present study will be discussed in chapter 4

\subsubsection{Histology}

In the large intestine several histological types of polyps are found. They all vary in their clinical significance and in their malignant potential. It is therefore essential that a colonic polyp should be removed and submitted for histological analysis. Without this, assessment of a polyps clinical significance and malignant potential is impossible.

A biopsy should not normally be taken from a polyp. The histological diagnosis made on such a biopsy is of very limited value and a definite histological assessment can only be given if the whole polyp is examined. Taking a biopsy makes subsequent histological examination of the whole specimen more difficult because of the partial removal and the trauma involved. The correct way of management of a colonic polyp is therefore by its removal in toto.

Table 2 shows the histological classification of colonic polyps most frequently seen in clinical practice (112). The histological diagnoses made in this study are based on this classification. As one group of polyps has malignant potential whereas others do not, it is very important to distinguish between these polyps. To date, only the adenomatous type of polyps has been shown to have malignant potential, while for hamartomas, inflammatory and other unclassified polyps, no evidence has so far been given of malignant potential.

The several types of polyps will be discussed further separatelly, while at the end of this chapter the polyp-cancer sequence will be included

\subsubsection{Neoplastic polyps}

Polyps in the neoplastic group are better called adenomas. This is the most frequently found polyp type in the colon and rectum, with the exception of the metaplastic polyps in the rectum. They are also the most important group because of their malignant potential. 


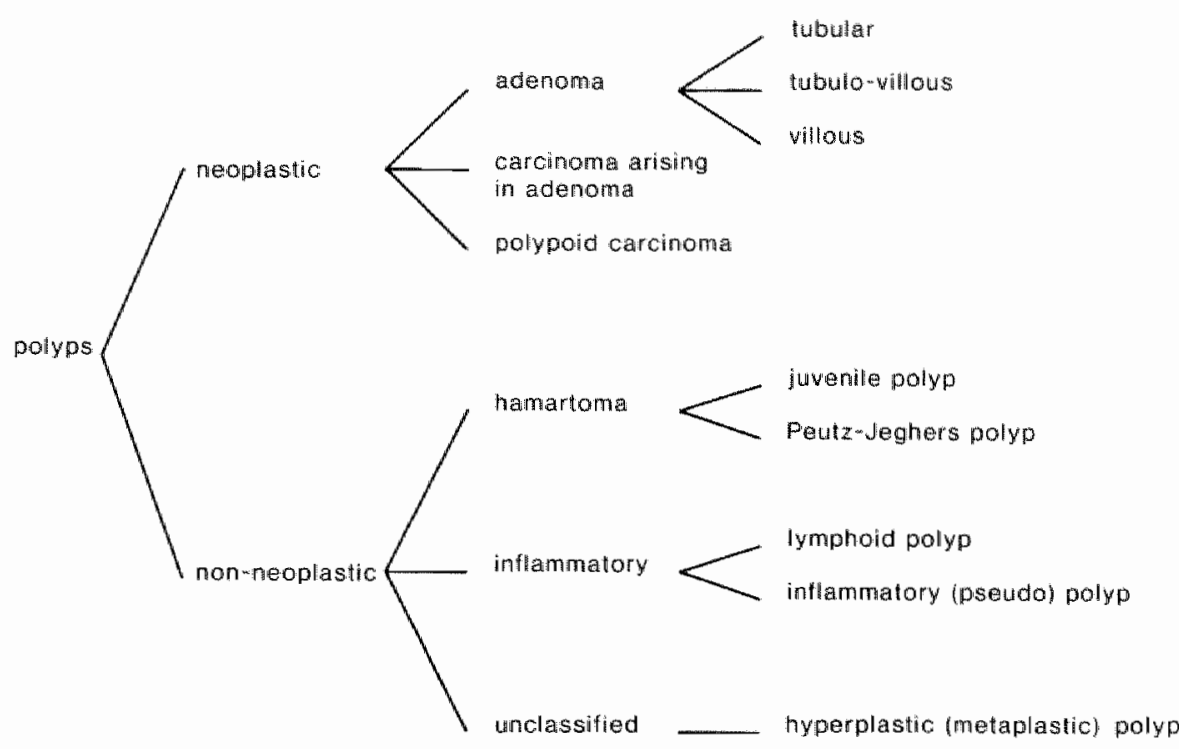

The incidence and distribution have been described previously. Although the general term polyp was used, usually adenomas are meant by the various authors.

Adenomas can present singlly or as multiple lesions, the extreme form of this is known as polyposis coli, a rare familial condition in which there are more than 100 adenomas in the large bowel, usually hundreds or even thousands of adenomas being present.

Between patients with a single adenoma and the familial polyposis coli. multiple isolated adenomas (2-10) are not infrequeritly seen Patients with between 10 and 50 adenomas are less frequent and those with 50-100 adenomas are rare (fig. 8).

There are three important members of the adenoma group: the tubular, tubulo-villous and villous adenomas. The malignant variant include cancer arising in adenomas as well as polypoid carcinomas All these entities will be described separately and the relationship between adenoma and carcinoma, the polyp cancer sequence, will be considered in more detail. 


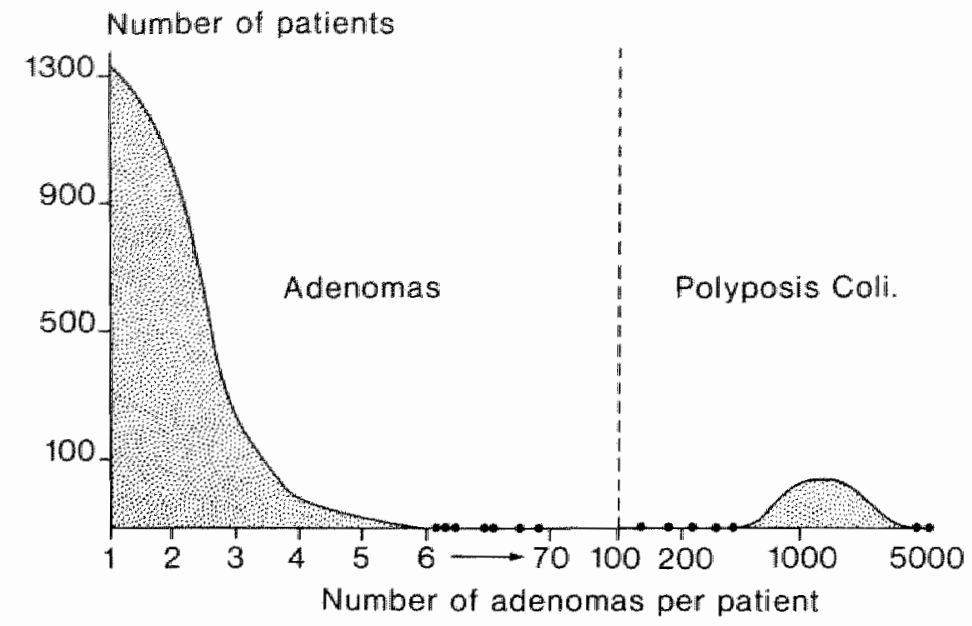

Fig. 8. The relation between number of patients and number of adenomas (From H.J.A Bussey (1975): Familia polyposis coli).

\section{Tubular adenomas}

Tubular adenomas are benign glandular growths of the colon that protrude into the lumen and do not infiltrate the bowell wall. In general they are pedunculated or sessile. They are soft tumours varying in size from very small to several centimeters in diameter. With time, they tend to develop progressively larger with longer pedicles.

These pedicles consist of a mass of stroma, blood vessels and lymphatics and are formed by the pull of peristalsis on mucosa and submucosa. In areas where the peristalsis is presumed to be the greatest, such as the descending and sigmoid colon, long pedicles usually occur. While the stalk, if present, is coated by normal bowel mucosa, the head is roughly spherical and may be smooth or lobulated (fig. 9), sometimes even multi-lobulated with several heads.

The microscopic structure of an adenoma (fig. 10) is made up of branching tubules embedded in lamina propria. Underneath the surface masses of underlying glands are found, that tend to enlarge. elongate and angulate. Size and number is increased resulting in queer shapes. Underlying cells become distorted and compressed.

Occasionally, a lobulated head is locally replaced by a flat and firm surface. Suspicion on carcinomatous change has to be considered. It is of interest that tubular adenomas tend to develop long pedicles, 

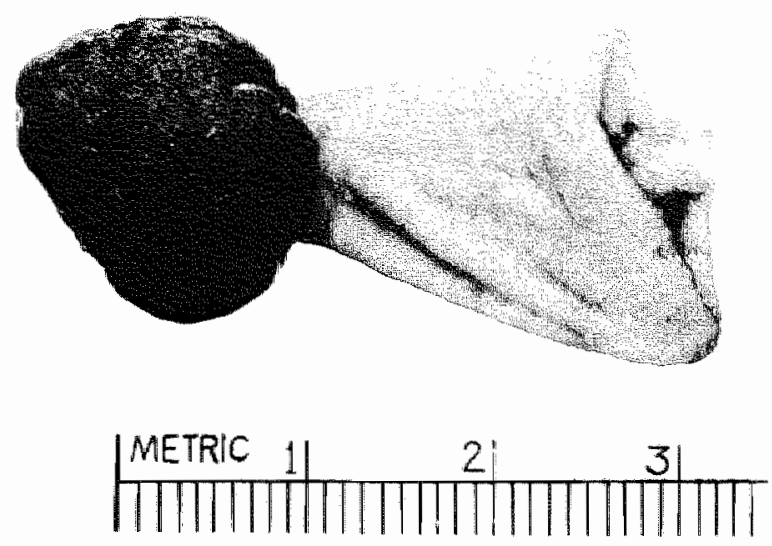

Fig. 9: A pedunculated adenoma of the colon. (From: C. E Welch(1975). Polypoidlesions of the gastrointestinal wach

while long pedicles are rare in the presence of invasive cancer. Castleman and Krickstein (1962) believe that invasive cancer fixes the mucosa to the underlying muscularis proper, so that stalk formation is impossible. Hence, the presence of a pedicle has been said to rule out invasive cancer, but many exceptional cases are described $(70,99$, $149,162)$ and many exceptions are now found during colonoscopic polypectomy.

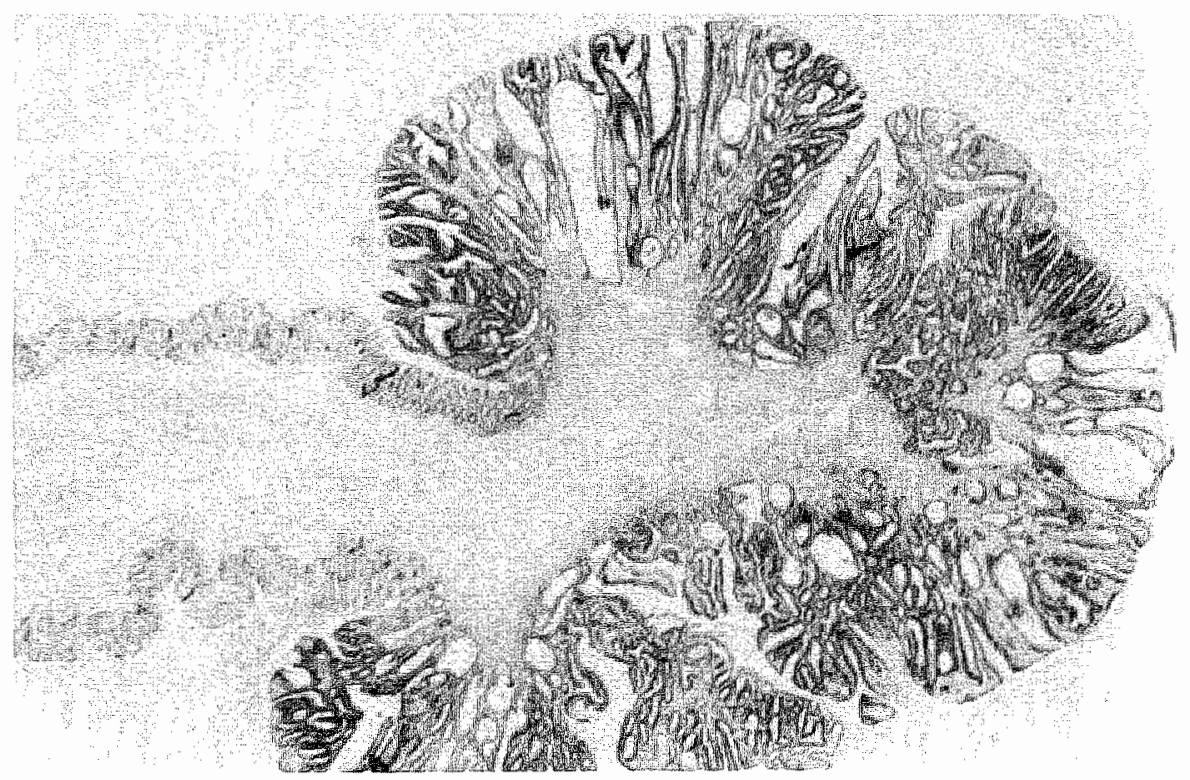

Fig. Mo: Microscopic structure of a tubular adenoma. 
The incidence of cancer arising in tubular adenomas is low. Spratt et al (1958) stated that it virtually never occurs, but Welch and Hedberg (1975) found five $(0.5 \%)$ out of 897 tubular adenomas contained cancer. Blatt (1961) and Castleman and Krickstein (1962) found four $(1 \%)$ of 465 tubular adenomas contained malignant epithelium with invasive characteristics. Muto et al (1975) found 90 cases of carcinoma $(5 \%)$ in 1880 tubular adenomas. Other authors quoted cancer rates of $2.9 \%(62)$ and $4 \%(83)$.

\section{Tubulo - villous adenomas}

It forms an intermediate between the tubular type at one end and the villous adenomas at the other (fig. 11).

Macroscopically, it is hard to differentiate between tubular and tubulo-villous adenomas. In general, the only differentiation can be made histologically.

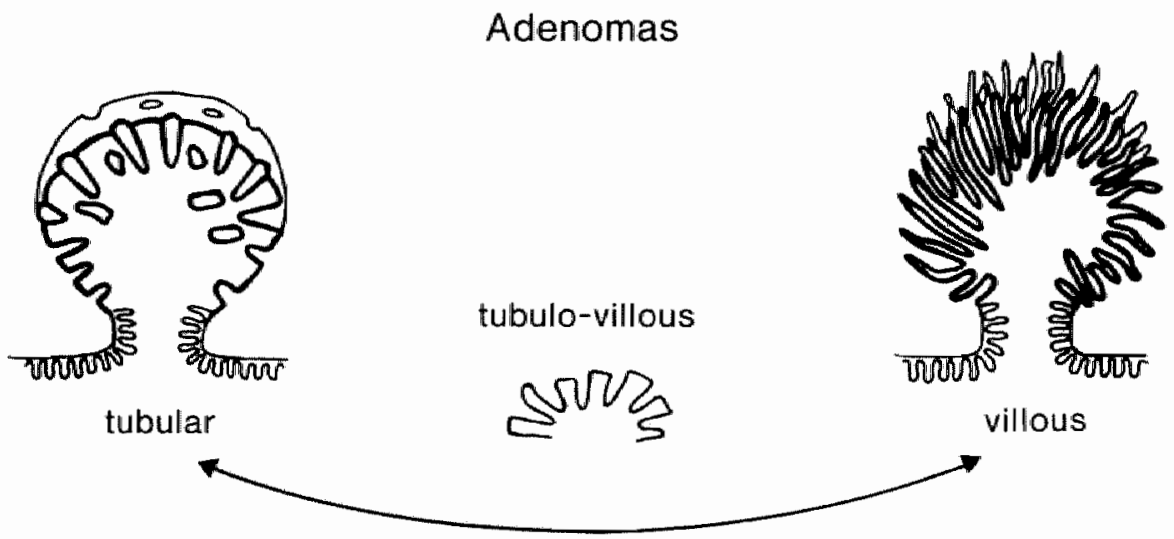

Fig. 11: The tubullo-villous adenoma shows a mixture of tubulous and willous patterns

Microscopic studies may show a mixture of tubular and villous patterns or they can have an umiform histology with broad and stunted villi with epithelial tubules similar to that in the tubular adenoma (fig 12). Although the three types of adenomas show differences in tissue architecture and are separable by subjective microscopic criteria, the more sections of a tumour are examined, the more frequently the mixed structure of a tubulo-villous adenoma is seen. 


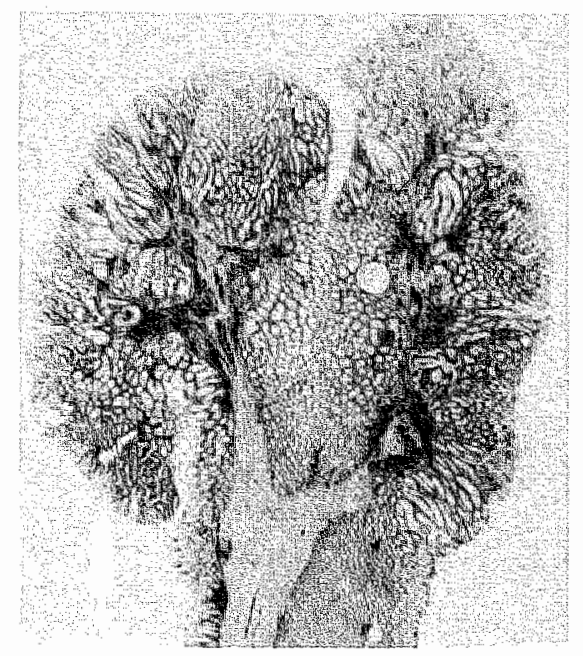

Fig. 12: Microscopic structure of a tubulo-villous adenoma

The incidence of cancer is between that of tubular and villous adenomas. Welch (1975) (179) found cancers in 3 per cent, while Hedberg (1975) (179) found an 8.1 per cent incidence. Muto et al (1975) found 86 carcinomas $(22.5 \%)$ in a total number of 388 tubulovillous adenomas.

\section{Villous adenomas}

The villous adenoma tends to be a sessile lesion, ranging from one to over $15 \mathrm{~cm}$ in diameter. They may involve more than half of the circumference of the bowell wall, and a certain number are anmular. particularly in the rectum. The exact margin of the lesion can be difficult to determine because of changes extending into the adjacent mucosa The lesion has almost the color of normal mucosa sometimes darker. but instead of a smooth surface. numerous fronds protrude from that surface. It is soft and velvety to palpation in the rectum and can be missed by the examining finger; if areas of firmness are found, a malignancy is suspected. Approximately ten percent of the villous adenomas are pedunculated, but this does not diminish their malignant potential. Histologically there are numerous pointed or blunt finger-like processes of lamina propria covered by epithelium which often reach down to the muscularis mucosa (fig. 13). This is contiguous with that of the underlying glands, so that there is no clear demarcation. The cells are elongated with compressed nuclei located in the centre or at the base of the cell. 


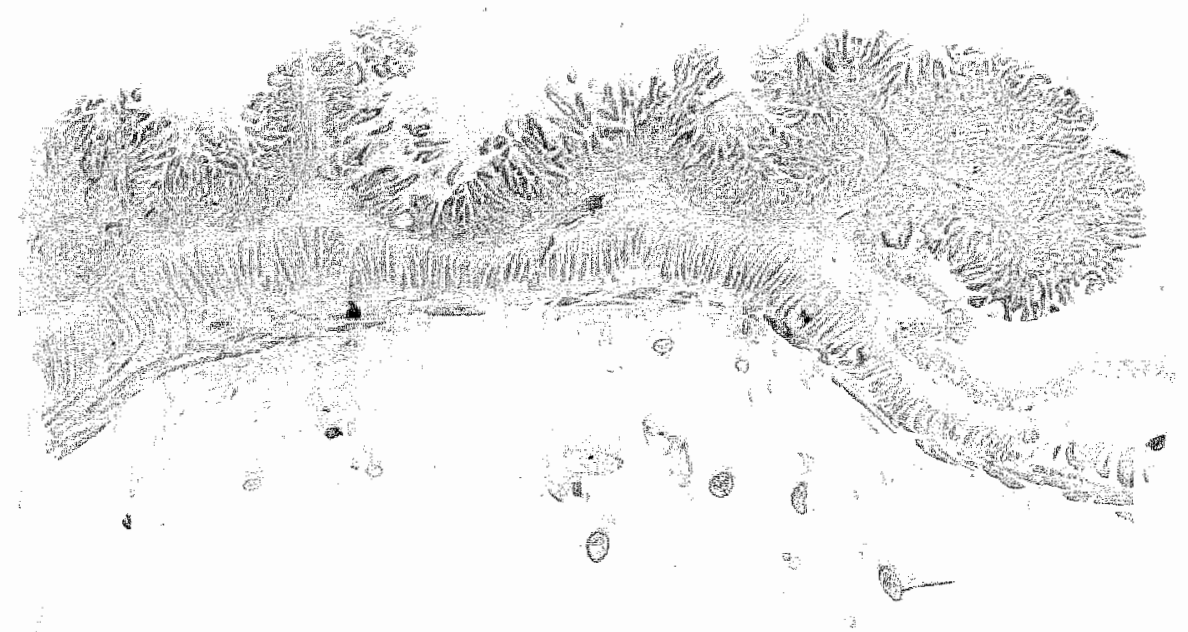

Fig. 13: Microscoph structure of a whous adenoma. showing fingerlike processes of lamina propra.

The villous adenomas are frequently found in the rectum and sigmoid colon, but occasionally in other parts of the colon, especially in the caecum and ascending colon.

They are found in elderly patients, at a later age than the tubular adenomas. Sunderland and Binkley (1948) found an average age of 62.9 years compared to 54.5 years with the tubular adenomas. Grinnell and Lane (1958) reported similar figures.

The incidence of cancer in villous adenomas is reported to be very high. Welch and Hedberg (1975) found an incidence of 28 per cent. whille Sunderland and Binkley (19.48) found 68.7 per cent of their villous adenomas showing areas of cytological carcinoma with a 39.2 per cent invasive carcinomas. The carcinoma may occur at any site of the adenoma, therefore complete removal of the adenoma is essential. These authors (163) pointed out that there was a much higher incidence of colloid carcinomas than adenocarcinomas. They found 42 per cent of cancers in villous adenomas were colloid carcinomas, compared to 7.7 per cent usual cancers. These observations were confirmed by Welch and Hedberg (1975). The invasive carcinomas 
that develop in villous adenomas are often highly malignant with a low cure rate, as would be expected with the colloid carcinomas.

Muto et al (1975) found a 40 per cent malignancy rate in these villous adenomas, while other author's $(43,62,83)$ found cancer rates varying from 20-55 per cent.

\section{Polypoid carcinomas}

Occasionally malignant tumours are found in the large bowel growing in a polypoid form. They are called polypoid carcinomas.

Most of them are flat sessile lesions and firm on palpation, but some are pedunculated. The head is usually flat, sometimes with ulcerations.

There is still some uncertainty about the origin of these malignant lesions. Some of these cancers may originate de novo, while many have their origin in benign adenomas, the adenomatous tissue being overgrown by the carcinoma.

\section{Summary}

The most important colonic polyps are the adenomas, because only these adenomas could develop malignancy. Next to these adenomas are the polypoid carcinomas, in which no adenomatous tissue can be identified.

The adenomas are divided into the tubular tubulo-villous and villous adenomas. The most frequent type found is the tubular adenoma the villows adenomas the least. The tubulo-villous adenoma is a mixture of the tubular and the villous adenomas.

The incidence of cancer arising in tubullar adenomas is between 0.5 5 per cent, while in tubulo-villous adenomas these rates are between 3 -22.5 per cent. The villous adenomas have the highest incidence of cancer, varying from $28-68.7$ per cent.

\subsubsection{The adenoma-carcinoma sequence}

Adenomas are clinically important and should be removed from the large intestine. Their importance lies in their malignant potential the so called adenoma-carcinoma sequence, resulting from the evidence that adenomas can develop into carcinomas $(44,62,82,109,111,113$. 114).

Morson and Dawson (1972) found that one in three surgical specimens removed for carcinoma of the colon or rectum contained 
one or more adenomas. Bussey etal (1967) found that in seven per cent of patients with adenomas in the specimen resected for carcinoma of the large bowel a second or metachronous tumour developed subsequently in the remaining colon. which is about twice the rate expected in patients in whom no adenomas are present. Heald and Bussey (1975) found in a series of 157 patients with synchronous carcinomas (i.e. two or more cancers found at the same time) 75 per cent had associated adenomas. Patients with familial polyposis coli and ulcerative colitis were excluded from the series. Further evidence for the adenoma-carcinoma sequence is the finding of continuous benign adenomatous tissue in a carcinoma. These malignant tumours may show all gradations from the adenoma with a microscopic focus of invasive adenocarcinoma to the frank cancer with a small area of residual benign tumour in it. Sometimes a polyp is exclusively formed of adenocarcinoma, the so-called polypoid carcinoma, in which case it is not possible to say whether it arose from the previous benign adenoma. Muto et al (1975) described the various types of adenomas from which adenocarcinoma may arise; they found a higher malignant potential in villous adenomas compared to the other forms. Morson (1966) suggested that as carcinomas enlarge progressively, more of the precursor adenoma is destroyed or transformed into malignant tissue. He considered that most cancer of the colon and rectum arises from previously benign adenomas.

There are three factors that determine the malignant potential of an adenoma: its size, its growth pattern and the degree of epithelial atypia. The malignant potential is increased in large adenomas (43, $62,111,153)$. Whereas the malignancy rate in polyps less than $1 \mathrm{~cm}$ in diameter is low (approximately $1 \%$ ), this rate increases rapidly in larger polyps. Between 1 and $2 \mathrm{~cm}$ in diameter the rate is about ten per cent malignancy and over two $\mathrm{cm}$ in diameter, it is nearly $50 \%$. If adenomas grow, and there is direct evidence that they can $(47,95$. $102,149,156)$, the cancer risk also rises. However, most adenomas do not grow appreciably and may never reach sufficient size to become a significant risk for malignant change (111).

In general, an adenoma with a villous pattern has a greater malignant potential than one with a tubular pattern. In the St. Mark's surgical material, the malignancy rate for tubular adenomas is five per cent, rising to $40 \%$ for villous adenomas (114). The $22 \%$ malignancy rate for the tubulo-villous adenomas suggests that they behave more like villous than tubular adenomas. Although histological grading is important it seems that size is more important in determining the malignant potential of an adenoma (43). One reason why villous adenomas have 
a greater malignant potential than tubular adenomas is that they are usually larger in size than the latter. However, even smaller villous adenomas have a ten times greater malignant potential than tubular adenomas of the same size which must be explained by the degree of epthelial atypia in these adenomas. The grading of epithelial atypia is divided into mild, moderate. and severe dysplasia. Severe dysplasia is more frequently found in larger polyps and malignant potential increases with the increased degree of atypia (114).

In summary, adenomas are precancerous lesions with a variable malignant potential, depending on histological type, size and epithelial atypia. The larger the polyp, the greater the malignant potential and similarly severe epithelial dysplasia gives a higher malignancy rate. It cannot yet be determined whether polypoid carcinomas always arise from adenomatous tissue or occasionally de novo from large bowel mucosa. All adenomas of the colon should therefore be removed both to eliminate this risk and for complete histological assessment. If the polyp is an adenoma, complete removal or fulguration of the base should be achieved to prevent residual adenomatous tissue growing. Completeness of excision in cases of adenocarcinoma arising in an adenoma or of a polypoid carcinoma can only be determined by histological verification which also determines the further management and prognosis.

\subsubsection{Non-neoplastic polyps}

The polyps in the non-neoplastic group consist of the hamartomas. the inflammatory and the unclassified polyps. They are called nonneoplastic because they do not have the potential to form neoplasms. So far, no evidence has been given that these polyps become malignant.

\section{Hamartomas}

The hamartoma is a malformation composed of an abnormal mixture of tissues normally found in the affected part of the body, often with an excess of one particular tissue type (113).

In the colon the hamartomas include the juvenile and the PeutzJeghers polyps.

Juvenile polyps

The juvenile polyps are usually found in childhood, although occasional cases have been described in old age (103). The term juvenile is therefore occasionally misleading (145). 
Helwig (1946) found in a series of 449 consecutive autopsies in patients under 21 years of age juvenile polyps in five $(1 \%)$ cases. If these polyps are left alone, nearly all will undergo spontaneous selfamputation at a later date.

Poth and Helwig (1963) found in his series a most unusual age distribution. Ninety-nine polyps were found in children and 59 in adults. with the mean average of age at the time of treatment for the children of 4.1 years and for the adults 25.5 years. The oldest was 61 years of age. These polyps were more common in males than in females, the ratio approximately $2: 1$.

Holgersen et al (1971) reported juvenile polyps in 55 patients, in which 60 per cent were males, and 76 per cent of the lesions occured in the first decade of life.

Mazier et al (1974) reported 174 juvenile polyps with detailed age differentation. Most of them were found in the age group between 6 10 years.

Many of these polyps are probably symptomless, but if there are symptoms, they are related to inflammation, ulceration, torsion. invagination or auto-amputation. The commonest symptom is painless bleeding after defaecation, sometimes with passage of the polyp in the stools. Prolapse out of the anus may occur in low located polyps. Multiple polyps are associated with iron deficiency anemia due to recurrent heamorrhage. Inflammation is common, but this is belleved to be secondary to episodes of torsion of the pedicle and surface ulceration rather than related to an inflammatory bowel disease.

Juvenile pollyps are usually pedunculated, though six per cent in the series of Roth and Helwig (1963) were sessile. These polyps are typically round in shape with a smooth surface, but a coarsely lobulated surface can occur, the result of secondary inflammation and ulceration. (fig. 14)

Endoscopically, they have a bright red surface with patches of white due to the presence of underlying cysts filled with mucin. They vary in size wp to $2 \mathrm{~cm}$ in diameter and are rarely larger. Mazier et al (1974) found that 93 per cent of the polyps in his series were $2 \mathrm{~cm}$ or less in diameter.

In a follow-up study Roth and Helwig (1963) reported incidental findings of a second polyp, but no cancer was reported. Other investigators found recurrences (76), but there is no evidence that juvenile polyps have any malignant potential $(56,145,179)$.

The juvenile polyp has a different macroscopic appearance to the adenoma. The surface of the first one is smooth, while the adenoma surface is crevassed. Furthermore, juvenile polyps must be 

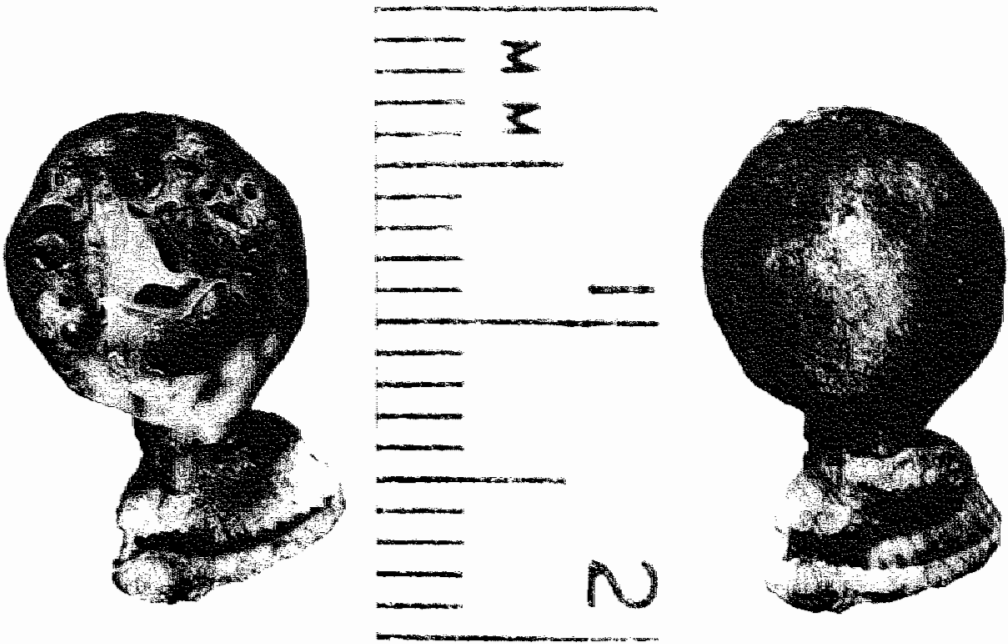

Fig. 14: Macroscopic appearance of a juvente polyp. showing smooth surtace. short stalk and cystic sifucture (From: B.C. Morson (1978): The palhogenesis of colorectal cancer).

differentiated from inflammatory polyps, which can be difficult sometimes, especially in multiple juvenile polyps. Both because of symptoms and doubt about the histolagical nature, removal of the polyp with histological assessment is the only way of management.

Peutz-Jeghers polyps

Peutz (1921) and Jeghers (1944) independently described patients with intestinal polyposis combined with skin pigmentation, mainly in and around the lips and in the buccal mucosa. The polyps, usually in dozens rather than in hundreds "are most common in the small intestine. Although occasionally they are found in the colon, rarely are they limited to the large intestine only.

Colicky abdominal pain due to intussusception is the commonest symptom, but rectal bleeding or anaemia can occur.

The polyps vary in size and cam become large, reaching $3.5 \mathrm{~cm}$ in diameter or even more. Large polyps are usually pedunculated and have a smooth, firm lobulated surface. It is sometimes hard to distinguish them from adenomatous polyps.

The histological appearances show the typical network of branching smooth muscle bands, as a treelike malformation of the muscularis mucosae (106).

As Peutz-Jeghers polyps are predominantly composed of epithelium and represent a large population of cells growing in a small area, the 
chances of developing malignancy are greater than in normal colonic mucosa. However, no proof has been given sofar that colonic malignancy can occur in Peutz-Jeghers polyps. Dodds et al (1972) and Yaegashi et al (1979) reported carcinomas found in PeutzJeghers patients, but colonic adenomas were also present in Dodd"s patient. Since there is good evidence that carcinomas can occur in adenomas, the most likely explanation is that the carcinoma arose from the adenoma rather than from the Peutz-Jeghers polyp.

Occasionally, Peutz-Jeghers polyps show foci of dysplasia without invasion of the muscularis mucosa, but this is excessively rare (56). Neoplastic transformation of a Peutz-Jeghers polyp has never been seen. At worst, the Peutz-Jeghers polyps can be regarded as having a very low malignant potential.

\section{Inflammatory polyps}

These polyps are usually associated with inflammatory bowel disease and two types are known: the inflammatory polyps (pseudopolyps) and the lymphoid polyps.

\section{Infliammatory (pseudo) polyps}

These polyps frequently occur in patients with an inflammatory bowell disease such as ulcerative colitis, Crohn's disease or dysenteric colitis. They may result from ulceration with undermining of adjacent mucus membrane and the formation of mucosal tags of varying size and shape, and are sometimes called "pseudo-polyps". The number of such polyps varies and occasionally they can be present in hundreds. They are usually small, although in a few cases they are larger. They are often shiny and sometimes worm-like, sometimes with a characteristic slough covering. Occasionally large granulation tissue polyps develop, which are red or bleeding and irregular in outline, therefore requiring histological assessment to ensure that they are not adenomas or malignant lesions.

These polyps are most commonly found in association with ulcerative colitis (108) and sometimes in areas involved by regional ileitis, ileocolitis or ameblasis. Sometimes the inflammatory polyps in the rectum may be more prominent than the underlying ulcerative colitis. Less frequently are these polyps seen in Crohn's disease (50). The occurrence of these polyps is related to at least one severe attack of colitis, especially with toxic dilatation (79). It is not related to the length of the clinical history.

Although Dawson and Pryse-Davies (1959) suggested the precancerous nature of these polyps, this is no longer accepted (79). 
The inflammatory polyps have no malignant potential, although they may mask a carcinoma on barium enema examination. Clearly they can be confused with multiple adenomas or famillal polyposis coli. Colonoscopy an polypectomy can solve this problem, especially by removing the polyp. However, recurrences frequently occur. Besides ulcerative colitis and Crohn's disease, inflammatory polyps may occur in other diseases such as amebiasis (12), schistosomiasis (118), at anastomotic sites and near stercoral ulcers etc. They are usually rounded mucosal nodules and seldom pedunculated. Treatment of the inflammatory disease will frequently result in regression of the polyps.

\section{Lymphoid polyps}

Lymphoid polyps are listed among the inflammatory polyps. These are small tumours consisting of enlarged lymplnoid follicles and arise as the result of response to inflammation or as an immunological reaction. No malignant potential is known in this type of polyp.

Usually they occur in the terminal ileum and rectum, solitary as well as multiple. Many are discovered incidentally, but bleeding, constipation and pain are common symptoms.

The size is between $0.5-1.0 \mathrm{~cm}$ in diameter, in exceptional cases they may reach $3.0 \mathrm{~cm}$. Grossly, they are sessile mucosal nodules, in 25 per cent they are stalked (135a).

They must be distinguished from malignant conditions like the malignant lymfoma and of course from the adenomas. Many will regress if left untreated, but in case of symptoms or in doubt about the nature, polypectomy is indicated.

\section{Unclassified polyps}

This group of polyps are called unclassified because of their obscure nature. The metaplastic polyps are categorized in this group.

\section{Metaplastic polyps}

These polyps are also known as hyperplastic polyps. They are found frequently near carcinomas, but there is agreement that these polyps have no maliginant potential (7). They are most found in the rectum but occasionally in other parts of the large intestine. Their size varies from 0.2 to $0.5 \mathrm{~cm}$ in diameter, they are usually sessile and of the same colour or paler than the surrounding normal mucosa. These polyps are found incidentally; if the patient presents with symptoms, these are due to an associlated bowel disorder, and not to the polyps. 
Metaplastic polyps are nearly always multiple and can present in such large numbers, that they can mimic polyposis coli.

They are very common, increase in frequency with advancing years and have been compared to senile hyperplasia of the skin. It has been estimated that they occur in about 40 per cent of adults of both sexes under 40 years of age, but in 75 per cent over the 40 years.

The histological features are clearly recognised with elongated and dilated crypts and a reduced number of normal goblet cells

The pathogenesis of these polyps has been studied by Kaye et al (1973) and Hayashi et al (1974) using the electron microscope and cell kinetic methods. The polyp can be defined as a separate entity representing an alteration in maturation of normal mucosal epithellum with accentuated cell maturation characteristics at the apex of the crypts. It is often easy to distinguish these polyps from other types but if not readily recognized, they should be removed for histalogical assessment.

\subsection{Management of colonic polyps: the present}

Colonoscopy and polypectomy have nowadays broadened the indication for removal of colonic polyps. It is a very useful procedure both for therapeutic management of polyps and relatively small malignant lesions and also in prevention of colonic carcinoma by removal of its adenomatous precursor.

Virtually every patient with a radiologically demonstrated colonic polyp should undergo a colonoscopic polypectomy, whatever the size of the polyp may be because most polyps in the large bowel are adenomas and it is essential to obtain histological proof. Because of the very few contraindications such as peritonitis or acule colitis, almost every patient with polyps can be subjected to colonoscopic polypectomy. A schematic reproduction in the treatment of colonic polyps is shown in fig. 21.

Colonoscopic polypectomy now provides the correct means for the management of colonic polyps. At one extreme it gives the histological diagnosis in dealing with small polyps which are too trivial for surgery, preventing the need for repeat barium enemas, which would mean unnecessary radiation and discomfort. At the other extreme it can even make surgical management unnecessary for some relatively small malignant lesions, avoiding the possibility of postoperative complications.

The good results and low complication rate of colonoscopic polypectomy have been stressed elsewhere (see chapter 5). The onlly 
difficulty in colonoscopic polypectomy is in acquiring the skills for this special procedure. It takes some time to learn the skill and thereafter regular practice is necessary to maintain it. For this purpose several endoscopic centres exist with special arrangements for teaching and a number of colonoscopy courses are organized to disseminate the skills of colonoscopy and polypectomy.

Since colonoscopic polypectomy, almost no place exists for primary surgery in cases of colonic polyps. Only for very large sessile lesions and in those cases where malignancy is shown not completely removed, is surgery indicated. Also in cases with polyposis syndromes (familial adenomatosis) colonoscopic polypectomy is insufficient and surgery is advised. Apart from these cases all patients with colonic polyps should be subjected primarily to colonoscopic polypectomy. Even in cases where no colonoscopic polypectomy facillities are available, surgery should be deferred and patient referred to institutes with those facillities. 



\section{3 colonoscopic polypectomy : Material and method}

This study is primarily concerned with colonoscopic polypectomy, all polypectomies in 3,500 colonoscopies being reviewed. These 3,500 colonoscopies were performed mainly at St. Mark's Hospital, during the period 1971 to 1979 . The majority of cases $(80 \%)$ being performed by one experienced endoscopist and the remainder, by several other endoscopists, including the author. Approximately half of the patients were referred from other hospitals in and outside London.

Of 3,500 colonoscopic examinations, a total number of $972(28 \%)$ procedures were analysed in detail and included in this study because of the polypectomies performed. This review will discuss the various features of those 972 procedures including the indications, bowel preparation and technical aspects of the colonoscopies and polypectomies with a chapter on special procedures in colonoscopic polypectomy.

Diagnostic colonoscopy is usually regarded as a second line procedure, whereas a barium enema is a first line diagnostic aid. The barium enema is easier to perform and is less time consuming and more economical. Colonoscopy is a complementary diagnostic procedure to the barium enema but also a therapeutic one in patients with polyps. It is therefore common practice to perform primarily a barium enema on suspicion of colonic abnormality. Based on the radiological findings a colonoscopy can be performed if indicated. However, with the increasing experience in colonoscopy, this procedure could be more easier to perform, less time consuming and more accurate in its yield compared to the barium enema. Therefore, in some endoscopy centres, the colonoscopy is at present regarded as a primary diagnostic procedure and the barium enema is not always needed.

A colonoscopy should ideally always be a total colonoscopy, which means that the caecum must be reached and identified. Only then can 
one inspect the whole bowel accurately. There are of course exceptions, like patients in whom the caecum is not or can not be reached because of various technical reasons. In these cases, the colonoscopy is of limited value unless the remaining collon has been perfectly demonstrated on $X$-ray.

In this study all colonoscopic polypectomies reviewed were performed during attempted total colonoscopy, an accurate inspection of the whole colon being made. It was sometimes necessary to perform a second procedure if the first colonoscopy was incomplete.

Most calonoscopies were performed on an out-patient basis except when large polyps were being removed. At the end of the procedure and reversal of any medication if necessary (see chapter 3.4.), the patient is observed in the recovery room. When completely awake, in about 30 minutes, a cup of tea is given and the patient can leave the hospital. Certain patients need an overnight stay. They are patients with large polyps, in whom after polypectomy observation is necessary because of the possible complications

\subsection{Indications}

Although there are many reasons for performing colonoscopy $(38,49$ 183), polypectomy is now probably indicated whenever a polyp is seen, either on barium enema or at colonoscopy. However, in this study, collonoscopy resulting in polypectomy was performed for several types of initial indications.

More than $50 \%$ of the cases were referred from other hospitals. These patients were referred for various reasons, including the lack of facilities for colonoscopy or polypectomy or a failed previous colonoscopy. Some hospitals perform only diagnostic colonoscopy, patients for operative colonoscopy being referred elsewhere.

All the patients studied were divided into three groups according to indication: the first group with polyps seen on barium enema, the second with a barium enema but no polyps seen and the third group of patients without barium enema (table 3 ). In the first group all the patients had had a barium enema and the polyp seen was the indication for colonoscopy and polypectomy (72\%). If the polyp was a large one with a large stalk the patient was admitted for overnight stay and blood taken for cross matching. Although the stalk size is often not clearly visualised on a barium enema, large polyps usually have large stalks. If, because of the large size of a polyp, there was any doubt about the possibility of malignancy or technical problems 
Table 3. Indications for colonoscopic polypectomy.

\begin{tabular}{|c|c|c|c|}
\hline Barium enema: & polyp seen. & & $705(72 \%)$ \\
\hline \multirow[t]{4}{*}{ Barium enema: } & no polyp seen. & & $105(11 \%)$ \\
\hline & rectal bleeding & $79(8 \%)$ & \\
\hline & follow-up colonoscopy & 11 & \\
\hline & athers & 15 & \\
\hline \multirow[t]{5}{*}{ No barium enema: } & & & $162(17 \%)$ \\
\hline & rectal bleeding & $46(5 \%)$ & \\
\hline & follow-up colonoscopy & & \\
\hline & others & 31 & \\
\hline & & Total & $972(100 \%)$ \\
\hline
\end{tabular}

during removal, a limited colonoscopy was sometimes performed on an out-patient basis to assess the situation. If a frank carcinoma was found and complete removal judged impossible, a snare-loop biopsy was taken to confirm this diagnosis and the patient referred for surgery. If the polyp appeared to be endoscopically removable, the size of the polyp and its stalk were judged and the patient booked for for operative colonoscopy with overnight stay and blood crossmatched.

Even when the radiologist was in doubt about the polyp demonstraled on barium enema, this was often taken as an indication to perform colonoscopy and if a polyp was found, polypectomy then undertaken. The various original reasons for performing the barium enema are not relevant to this group of patients since the polyp seen on barium enema was the indication for colonoscopy and polypectomy. Another group of patients was referred for colonoscopy for different clinical reasons, no polyps were seen on barium enema (11\%). Among these reasons were rectal bleeding (8\%), change in bowel habit, abdominal pain, diarrhoea etc. The polyp found at colonoscopy might have been the cause of the symptoms but frequently was judged to have been an unrelated incidental finding, The last group of patients did mot have a recent barium enema because the colonoscopy was being performed for follow-up purposes. 


\subsection{Barium enema}

Before the colonoscopy era, the only method to examine the colon was the barium enema. This started as a single contrast enema, but Welin (1958) introduced the modern double contrast barium enema using the Malmó technique, which proved to be far more superior than the single contrast enema $(180,197)$, especially locating colonic polyps.

Since colonoscopy was introduced, with direct wiew examination of the colon, a comparison is possible with the single and double contrast barilum enemas regarding the polyp findings.

Williams et al in 1974 found that $96 \%$ of the polyps over $5 \mathrm{~mm}$ in diameter could be shown on the double contrast enema, while only $73 \%$ were seen on the single contrast enema. Teague et al (1973) found pathologicallesions in $26.5 \%$ of patients undiagnosed by barium enema. Although the results vary widely the double contrast enema represents a valuable gain in accuracy. This study was compared to the colonoscopy findings. Many other authors have described such comparison studies $(4,10,31,35,90,93,98,172,194)$. In general, the colonoscopy has the advantage of direct view examination, is more useful in finding small lesions and allows taking biopsies and polypectomies. However, the colonoscopy is a technically difficult procedure and more skill and time is needed compared to the barium enema. As a screening procedure double contrast enema is more likely to be used than colonoscopy.

The succes of a double contrast enema depends largely on the bowell preparation. To achieve a succesful result, perfect bowel preparation is necessary to remove all fecal residue, a minimum amount of barium is needed to obtain a fine coating of the mucosa, maximum use of air to obtain full distension and careful choice of position including laterall decubitus and oblique views.

However, reporting errors are common and it is advisable that the endoscopist should review the $X$-rays with the radiologist before starting a colonoscopy, especially when there are questionable findings on the barium enemas. Basic knowledge of the radiology is also necessary for the endoscopist to understand certain radiological problems. The sigmoid, for instance, is a difficult area to exclude the presence of polyps, especially in diverticular disease.

In case a polyp is seen on barium enema, the magnification effect should be considered. This magnification factor is usually between $10-20 \%$, which means that the true size of the polyp lies between $80-$ $90 \%$ of the polyp size on the barium enema. 
Table 3 shows also the tolal number of barium enemas performed in this study. Eighty-three percent ( 810 patients) of the polypectomized patients had recently before the colonoscopy and polypectomy a barium enema. while $17 \%$ had no recent barium enema. Of the 810 patients with a barium enema, only 705 patients $(87 \%)$ had polyps shown radiologically, while the other 105 patients (13\%) showed no polyps on barium enema, but endoscopically a polyp was found and excised.

However, no more precise analysis has been attempted comparing polyps seen radiologically and endoscopically in this overall series. The majority of the patients were referred from elsewhere and their barium enemas were also performed in their own hospitals and were of widely differing quality.

\subsection{Bowel preparation}

It is essential to perform colonoscopy in a well-prepared bowel. A badly prepared colon makes collonoscopy slow, difficult and dangerous Colonoscopic polypectomy is especially hazardous in a poorly prepared colon because of the explosion hazard $(15,16,138)$. It is therefore wise from both the patient's and the endoscopist's point of view to abandon the procedure if the bowel proves to be poorly prepared.

It is therefore of the utmost importance to motivate the patient to achieve succesful bowel preparation. A well-prepared bowel examination is easy for the endoscopist and safer and more accurate for the patient. Nothing is more disappointing for the patient than to require further bowel preparation and endoscopy because the previous colonoscopy is impossible due to poor cleansing.

Usually bowel preparation is left to the nursing staff but the choice of preparation is usually made by the colonoscopist depending on the requirements of the particular patient and examination. Each patient therefore requires specific choice of bowel preparation.

There are two types of bowel preparation, either full or limited preparation.

Full bowel preparation is intended to clean the whole colon as is essential for a total colonoscopy. This type of preparation is used for the majority of patients. There are several available regimes and all require to give the patient fluid diarrhoea followed by evacuation of the bowel, usually by an enema given one to two hours prior to the examination.

The use of five to seven days clear liquid diet alone is sometimes 
used in order to avoid purgation (170). Iron medication should not be taken for lour days before examination but other medications can be continued normally (see Appendices).

Most of the problems of good bowel preparation occur in patients with diverticular disease or stricturing. Drastic purgation achieves the best results but this can be unbearable for the patient and an acceptable compromise is necessary (183). The administration of hyoscine-n-butyl bromide (Buscopan (40) (4. i.v.) or glucagon 10.5 mgs i.v.) during preparation of patients with diverticular disease sometimes helps, particularly in the administration of enemas. Several types of aperients are available and the most commonly used is castor oil 30-60 mls $(23,64,182,183,192)$. Other frequently used aperients are sennosides (Senokot DX $X$ prep (34), magnesium citrate (170), magnesium sulphate (116). liquid paraffin (23) or bisacodyl (Dullcolax (ึ) (130).

In combination with these aperients, one or more enemas are given prior to the colonoscopy. The most frequently used enemas are tapwater $(23,170)$, saline (130) or hypertonic solutions (116).

Purgatives are also used including oxyphenisatin (Veripaque (183) or bisacodyl (Dulcolax (130). Oxyphenisatin enemas do not cause jaundice, as has been reported after oral administration of oxyphenisatin (183).

More recently, bowel preparation has been reported using mannitol solution or saline orally. These solutions are administered by a nasogastric tube or by drinking. Careful observation is necessary in these patients, especially if elderly, because of the possible problems of dehydration and electrolyte imbalance.

However, the reports are encouraging (57) and the whole preparation can be achieved starting early on the day of the examination. Using mannitol for bowel preparation may however be hazardous; an explosion has been reported during colonoscopic polypectomy following mannitol preparation (13) and the possible relationship between mannitol preparation and the explosion has been discussed (1105).

Recently whole gut irrigation has been advocated as a perfect method for bowel preparation $(32,71,94,155)$. However, since no experience has been gained using this method, no further description can be given.

The most important assessment of bowel preparation is by the nurse. who should check that clear fluids are being returned before the colonoscopy starts. This is the only guarantee that no solid stools are left in the colon. Occasionally, especially with patients with 
diverticular disease or stricturing, the enemas may not reach above the effective obstruction and clear returns may not indicate a properly clean colon.

Limited preparation is sufficient in a few cases. Since such preparation cleans only the left collon, colonoscopy must be restricted to the left side. Check examinations of the sigmoid colon, for instance, can be performed after limited preparation, assuming that the proximal colon had been adequately examined in a prior examination. In some cases where the right colon has been perfectly visualised by the radiologist and the only demonstrated abnormality is in the left colon, limited preparation for colonoscopy may be judged sufficient. In a few patients limited preparation can clean the whole colon. allowing total colonoscopy but this is not always predictable. In children, limited preparation will sometimes allow examination of the right colon. In colitis patients, in whom the bowel contents are already liquid, limited preparation with saline enemas can clean the whole colon. Other enemas used in non-colitis patients include disposable, hypertonic phosphate preparations or purgative contact laxatives such as oxyphenisatin (Veripaque ${ }^{\text {बi }}$ ) or bisacodyl (Dulcolaxin).

For this study the most commonly used full bowel preparation regimes were either castor oil or sennosides followed by oxyphenisatin enemas (see Appendices). Occasionally magnesium citrate, magnesium sulphate, mannitol or saline solutions were used and in a few difficult cases one or other combinations of castor oil, sennosides, mannitol or saline with additional enemas were used. This combination regime was used, for instance, in patients with a barium enema showing a poorly prepared bowel despite full bowel preparation prior to radiology.

For limited bowel preparation phosphate enemas were most frequently used and only a few patients prepared using oxyphenisatin or bisacodyl. Fuller details of the bowel preparation regimes used are listed in the Appendices.

Table 4 lists the results of all the different types of preparation during the colonoscopic polypectomies in this study. The preparation was judged to be "perfect". "acceptable" or "poor" by the endoscopist, the assessment being entirely subjective. Either "perfect" or "acceptable" bowel preparation is considered adequate for colonoscopy. so the successful preparation rate for the three commonest bowel preparations was 90\%. "Poor" bowel preparation did not necessarily result in falled colonoscopy because colonoscopic polypectomy could sometimes be performed even in a poorly prepared bowel, but 
Table 4: Results of the different ypes of bowel preparation in 743 patients for polypectomy.

\begin{tabular}{|c|c|c|c|}
\hline & Perfect & Acceptable & Poor \\
\hline \multicolumn{4}{|l|}{ Full preparation } \\
\hline Castor oil/enemas & 176 & -167 & 41 \\
\hline Sennosides/enemas & 94 & 69 & 10 \\
\hline Mannito ol & $41-$ & 22 & 9 \\
\hline Others & 16 & 10 & 11 \\
\hline total & 327 & 268 & 71 \\
\hline \multicolumn{4}{|l|}{ Limited preparation } \\
\hline Phosphote & & 13 & 9 \\
\hline Veripaque/dulcalax & 12 & 2 & 2 \\
\hline total & 51 & 15 & 11 \\
\hline
\end{tabular}

inspection of the rest af a poorly prepared bowel is insufficient. Failed colonoscopies due to poor bowel preparation were not reviewed in this study.

Occasionally the aperients used made the patient feel unwell, nauseated and vomiting. This ill-effect could occur with any form of bowel preparation and, should it occur, a different form of bowel preparation should be used for any follow-up colonoscopy or surgical procedure.

In conclusion, a regime of castor oil or sennosides with enemas gives good results for bowel preparation before colonoscopy. Extra attention must be paid to patients with diverticular disease or strictures. Mannitol preparation also gives reasonable results but is probably hazardous. Based on literature reports, whole gut irrigation seems to be a perfect method for bowel preparation.

\subsection{Medication}

Since colonoscopy is a potentially traumatic procedure, especially in less experienced hands, sedation is usually necessary. However, before starting the colonoscopy, explanation about the entire procedure to the patient is necessary. This might decrease the anxiety even before the procedure starts. 
In a few cases colonoscopy can be performed without any need for sedation; this is especially true of patients with a previous sigmoid colectomy which has removed the most difficull part of the bowel for the endoscopist. To help with anxiety and pain it is best to use a combination of a sedative and an analgesic drug. The combinations most frequently used are diazepam (Valium 5-20 mgs (170, 183) im or iv with an analgesic such as morphine or pethidine (Dolantin (ia), Demerol e) $25-50 \mathrm{mgs}$ iv $(116,183)$ or inhaled nitrous oxide (9). The amount given depends on the patients age, size and clinical condition. Since the most painful part of colonoscopy is negotiation of the sigmoid colon, medication should be given before the procedure starts. Once in the cecum withdrawal of the colonoscope is usually fast and painless. At this stage reversal of the opiate using naloxone (Narcan $0.4 \mathrm{mgs}$ im is possible, being especially useful in outpatients.

During insertion of the instrument, if the patient feels pain, the colonoscopist must be alerted and should try to alter the position of the instrument so as to stop the pain. There is no benefit in withholding medication simply in order to gauge the patient's reaction more accurately since the patient may then become very restless (as may the colonoscopist) and the procedure takes much longer resulting in a traumatised patient and possibly an abandoned procedure. After such an examination the idea of a repeat will certainly be rejected by the patient unless sedation is used. Even after sedation the most marked pain reactions of the patient are quite sufficient to help the colonoscopist.

If the medication is "titrated" against the patient's pain reaction, a good level of sedation and analgesia can be safely maintained. Too deep sedation can over-depress both the pain reaction and also the patient's respiratory system. It is clearly dangerous if there is difficulty achieving successful colonoscopy simply to increase the amount of sedation used.

Another medication often used is hyoscine-n-butyl bromide (Buscopan ${ }^{\circ}$ ). This anti-spasmodic makes the bowel relaxed and atonic and should not be given during insertion (see exception bellow), since an atonic bowel is likely to make intubation to the cecum more difficult. Buscopan given during withdrawal however; provides a good tubular view and permits more careful inspection, especially in the areas between the haustral folds, which are largely flattened out. When a polyp is about to be snared, anti spasmodics may be helpful to stop peristalsis moving the polyp about.

The one occasion in which hyoscine-n-butyl bromine is used during insertion is in patients with diverticular disease of the sigmoid colon. 
particularly those with severe spasms. The combination of luminal narrowing due to the muscle hypertrophy and the super-added spasms make passage of the instrument very difficult. Even temporary relaxation is very valuable.

The use of hyoscine-n-butyl bromide during bowel preparation in patients with severe diverticular disease has already been discussed in chapter 3.3 .

In some patients hyoscine-n-butyl bromide appears to have no effect at all on the bowel activities; the use of the alternative drug glucagon 0.5 mgs iv is then uselul.

Colonoscopy under general anaesthesia is usually unnecessary and inadvisable since there is a greater risk of bowel perforations under generai anaesthesia (183). Ocasionally there is a case for performing colonoscopy under general anaesthesia, possibly in some children and in those patients with a markedly low pain threshold. Peroperative colonoscopy is sometimes indicated and easily done. allowing the surgeon to guide the instrument by hand around the more acute flexures.

In this study almost all patients received diazepam and pethidine. Only occasionally patients received no medication. The usual dosage was diazepam $10 \mathrm{mgs}$ iv and pethidine $50 \mathrm{mgs}$ iv, the dose being varied according to age and body weight. Twenty-two per cent of patients given diazepam received less than $10 \mathrm{mgs}$ while only five per cent needed more than $10 \mathrm{mgs}$. Twelve per cent of patients receiving pethidine had less than $50 \mathrm{mgs}$, while $5 \%$ had more than this dose. The acceptance rate, which is entirely subjective, seems satisfactory since of all patients receiving diazepam and pethidine. $36 \%$ had no pain, $56 \%$ acceptable levels of pain and only eight percent complained of excessive pain. These data were obtained from the endoscopy reports (see Appendices).

In conclusion, the medication used for colonoscopy is extremely valuable from both an endoscopic and psychological point of view. The use of either no sedation at all or of general anaesthesia is only indicated in a few patients. Anti-cholinergic drugs prove to be useful in colonoscopic polypectomy and also against bowel spasm to ensure a careful examination.

\subsection{Technique}

The technique of insertion of the colonoscope will be discussed only briefly, since many authors have described it thorougly $(38,40,51$, 


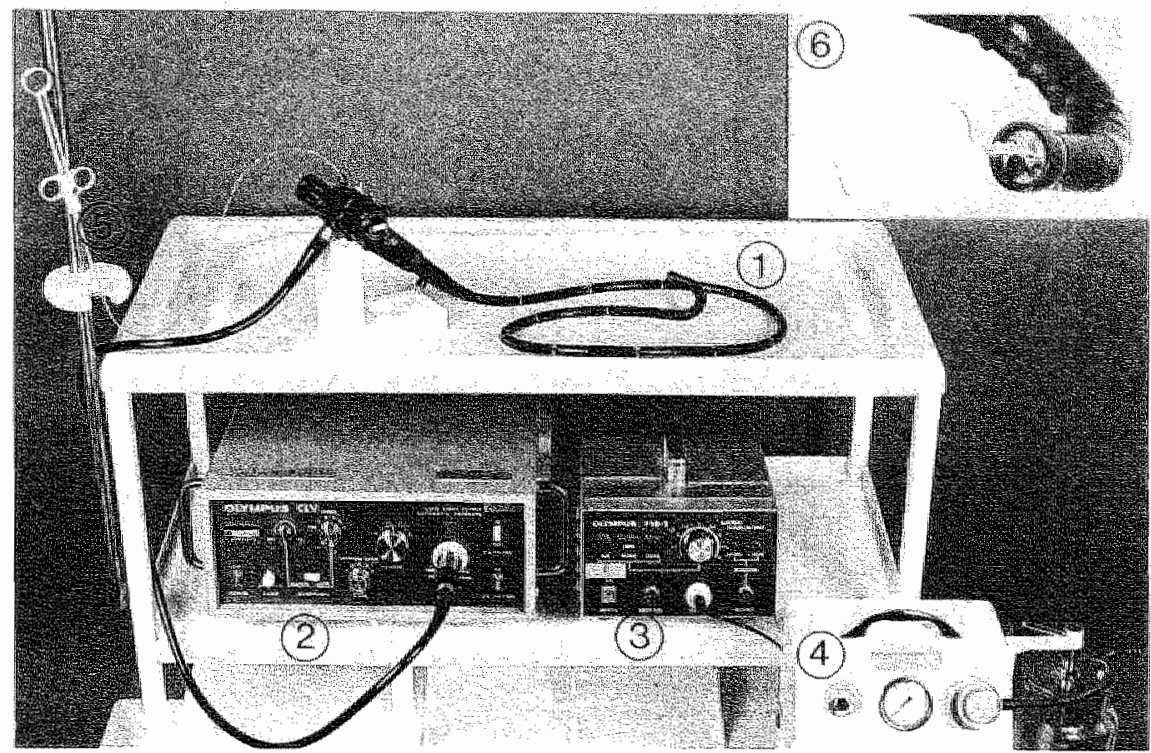

Fig. 15: Instruments for colonoscopy and polypectomy
1. fiberoptic colonoscope
2. light source
3. electro surgical unit
4. Suction apparatus:
5. polypectomy snare
6. detal: tip of the colonoscope with the snate

$129,130,147,178,179,182,183,187,188,191,192,193,194)$.

Before starting the procedure the instrument and light source should be checked to assure proper functioning (fig. 15).

The patient is placed in the left lateral position, although some endoscopists prefer the right lateral or dorsal position. The table used can be an endoscopy table, a trolley or an X-ray table.

After sedating the patient, rectal examination is performed and then the generously lubricated colonoscope inserted. Handling of the instrument can be in two ways: either the controls can be worked with both hands with an assistant inserting. withdrawing and rotating the shaft of the instrument on command, or the endoscopist uses his left hand to control the buttons and angling knobs and wilh his right hand manipulating the shaft. The further possibility is to use the shoulder brace, managing the controls with buttons with one hand and manipulating the shaft with the other (179). 
The single-handed method without an assistant is much preferable but more difficult to learn. It provides better control of the instrument tip and better and quicker co-ordination between instrument tip and the controls.

Whichever method is used, the tip should always be directed at the centre of the bowel lumen at all times with air insufflation kept as minimal as possible. Sometimes it is difficult to keep the tip in the centre of the lumen, especially in the flexures. "Blind" insertion is necessary but one should be aware of the possible hazards. It is safe provided that the colonoscope is immediately withdrawn when the mucosa stops moving by and whitens, or when the patient complains of pain. When this rule is ignored, there is a risk of bowel perforation. In cases of diverticular disease, this manoeuvre should not be attempted.

With the availability of modern instruments having improved flexibility, colonoscopy has become less traumatic to the patient and insertion seems easier and more succesful than with the stiffer, older instruments. The abillty in modern instruments to bend the tip more acutely is also a big improvement; whereas in the past passage of a difficult sigmoid loop might require contortions such as the "alphamanoeuvre", nowadays such procedures are hardly ever necessary. Using the modern flexible colonoscopes, combined with abdominal wall pressure, the passage of the instrument to the caecum is easier and more often succesful.

While some colonoscopists have stated that the use of fluoroscopy is unnecessary $(34,37,38,115)$, or those that consider that it is helpful (27, 132, 183, 188), fluoroscopy can make the examination quicker and more accurate with less trauma to the patient and the instrument. During insertion of an overtube (39), used in some patients with a redundant sigmoid, or transverse colon, fluoroscopy is also desirable to assure that the sigmoid colon is completely straight.

When in doubt that the caecum has been reached or not, there are several methods available to check the position of the instrument tip (115). The tip must be in the caecum if the appendix orifice is identified, the ileo-caecal valve is seen or the caecal pool recognized. These features are, however, not always readily distinghuished and the location of the light from the instrument tip transilluminating the abdominal wall can be useful. If the light is seen near the right inguinal ligament it can usually be assumed that the caecum has been reached. However, a tortuous and long sigmoid "transverse colon or hepatic flexure can also position the light in the right lower quadrant. Another method is to press the abdominall wall in the caecal region with one finger; if the impression can also be seen in the endoscopic 
view, the tip is probably in the caecum. The final method is obviously fluoroscopy to check if the tip is in the light lower quadrant, the caecal outline being shown by the air distension.

Of all these methods, the most reliable is to identify the endoscopic features of the ileo-caecal valve and appendix.

\section{Polypectomy}

Removal of polyps of almost any size from any site in the colon is possible using the colonoscope and the diathermy snare $140,126,183$, $184,193,194)$. The management of small polyps up to $7 \mathrm{~mm}$ in diameter is discussed later. For polyps larger than this diameter, the use of the diathermy snare has been well proven $(26,37,40,50,96$, $119,126,134,151,152,154,164,179,184,187,188,193$ i.

Pedunculated polyps are the most suitable for removal by the snare technique whereas large sessile polyps can be managed by multiple piece-meal resections.

If a polyp is seen, assessment must be made of its size, pedicle dimension and location. Any fluid or bowel contents covering the base or surrounding area should be sucked out first to ensure a good view and electrical efficiency. If on assessment of the polyp size and pedicle, it is judged suitable for colonoscopic removal, the best possible position of the colonoscopic tip must be achieved in relation to the polyp. This is done by manipulating the colonoscope and its tip or by re-positioning of the patient. Hyoscine-n-butyl bromide may be helpful in relaxing the bowel or stop movements of the polyp. The snare is then introduced and using a combination of instrument tip and snare manipulation the polyp head is lassoed and the stalk snared (fig. 16). It is important to manoeuvre the snare over the head

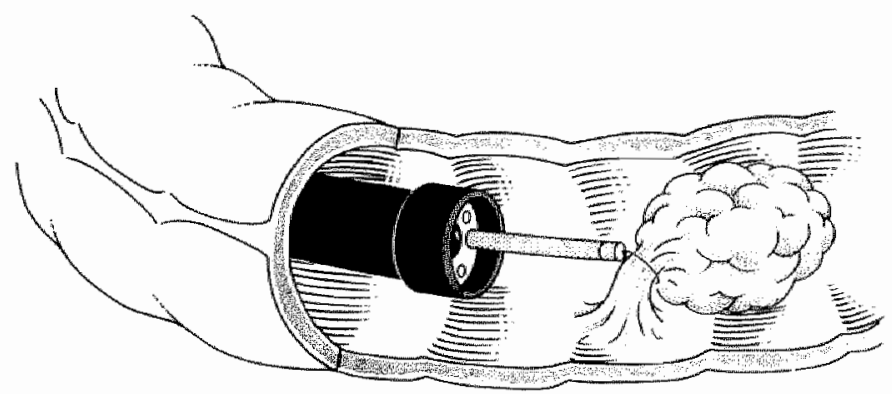

Fig. 16. The polyp is smared al ils stalk 
of the polyp and around the upper part of the stalk. This position may be very helpful in case of haemorhage (see chapter 5). The snare should not be closed too tight so as to assure optimal coagulation before severance. The snare wire should not touch the bowel wall, since this could cause burns. The polyp head is ideally kept in the centre of the lumen and not touching the bowel wall; if the polyp is large, this may not be possible and contact with the wall becomes unavoidable. Whereas the small contact area may result in burns, so long as the contact area is large there is no such danger. If there is seen to be poor bowel preparation. carbon dioxide is insufflated to prevent any risk of explosion due to the presence of inflammable gases. Some authors administer the $\mathrm{CO}_{2}$ only immediately prior to the actual polypectomy (143) whereas others (179) use $\mathrm{CO}_{2}$ instead of air insufflation during the whole procedure of colonoscopy and polypectomy.

After all the connections, the patient plate and the electrosurgical unit settings have been checked, polypectomy is achieved by applying electric current in short bursts. It is preferable to use either a blended or a coagulating current, starting with a low setting. When there are visible changes to demonstrate coagulation of the stalk, the use of a cutting current or tightening of the snare loop will result in separation of the polyp head. If no visible changes occur after applying current, the dial setting is increased. If subsequently there is still no visible change, the electrosurgical connections should be checked. After separation of the polyp head, the stalk is immediately inspected to check for bleeding or residual polyp tissue. If bleeding occurs, the stalk can be strangullated again with the snare loop, which is left closed in position for a period. If polyp tissue has been left, the stalk can be remsnared again. It is sometimes difficult to assess from the fulgurated stalk whether abnormal tissue remains and in this case forceps biopsies can be taken for histological verification.

Finally, the severed polyp head is re-snared and retrieved for the pathologist to examine.

The technique of removal of large sessile polyps is discussed in chapter 3.6. The use of $\mathrm{CO}_{2}$ has distinct advantages over air. $\mathrm{CO}_{2}$ is more quickly absorbed from the colon than air, causing the patient less discomfort after the colonoscopy. In electrosurgical procedures the use of $\mathrm{CO}_{2}$ rather than air ensures that the highly inflammable gases hydrogen and methane cannot be ignited $(15,16,143)$ especially in patients where bowel preparation has been lless than pertect. 


\section{Limitations}

Since colonoscopy is sometimes a difficult procedure it may not always be possible to reach the caecum or to snare a polyp readily. especially in the early experience of an endoscopist. With greater experience however, succesful colonoscopy is more often possible. There are, however, a number of technical limitations of the colonoscopy and colonoscopic polypectomy.

As described above, successful and accurate colonoscopy depends largely on bowel preparation. If the preparation is seen to be poor with residual solid and fluid bowel contents, it is both difficult and dangerous to proceed with the colonoscopy. When using a colonoscope with a large or double "operating" channel(s), it is possible to suck out fluids, but if there is solid residue it is aften both tedious and difficult to clean the bowel in this manner. It may be preferable to abandon the procedure as "failed colonoscopy" for safety's sake and then to repeat the examination using more rigorous bowel preparation.

There are certain blind spots in the colon; pathology can be missed in these areas (fig. 17). The more flexible modern colonoscopes with acute tip-angling capability make the blind areas less and smaller. Management of colonic polyps around acutely angled loops is also easier so that the limitations of colonoscopy and colonoscopic polypectomy in these blind areas are much reduced.

Patients with a fixed bowel loop due to previous abdominal surgery or diverticular disease, still form the most difficult group to colonoscope. The use of modern flexible instruments and also the small sized endoscopes can be helpful passing the difficult parts of the colon, especially the sigmoid. In spite of this, there remains a number of patients in whom it is impossible to reach the caecum, usually because of a fixed loop with resulting pain and mechanical difficulty. Such patients should not be colonoscoped again, since the yield is likely to be small compared to the possible complications of perforation or instrument trauma. If follow-up is necessary. a barium enema would be the procedure of choice.

\subsection{Special procedures}

\subsubsection{The retrieval of snared polyps}

When a polyp is snared, the head frequently falls from the snare into the bowel lumen but it is important to retrieve it for histological assessment. A convenient practice is to re-snare the polyp head and 


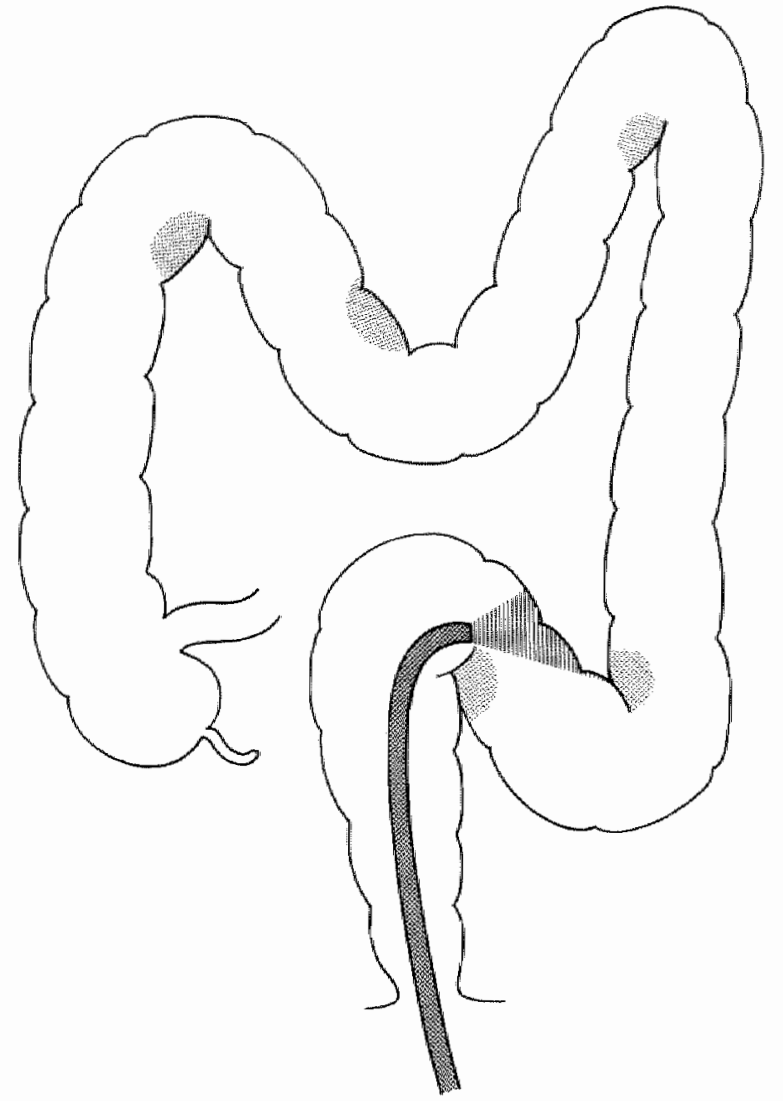

Fig. 17: Blind spots in the colon.

to withdraw it with the colonoscope at a sufficient distance to allow viewing of the rest of the bowel during withdrawal. Smaller polyps may be difficult to re-snare again and can be sucked onto the instrument tip. the colonoscope being withdrawn and the polyp recovered. The obvious disadvantage of this method is the difficulty or impossibility of inspecting the rest of the bowel on withdrawal which neccesitates re-insertion of the instrument to check what has been missed.

Very small polyps can sometimes be retrieved by aspiration through the suction channel, the separate small suction trap being placed between the instrument and the main suction bottle to aid recovery. If grasping forceps are employed to retrieve a snared polyp, they should be used with care since they may easily damage the polyp and confuse histological examination. The additional time taken in singlechannel instruments to remove the snare and to replace it with the 
grasping forceps or the Dormia-type basket is also a disadvantage. If a polyp cannot be found after polypectomy or cannot be retrieved after several attempts, a small saline or phosphate enema can be given after the colonoscopy. The returns are carefully searched to find the lost polyp. Theoretically such washouts might remove the coagulum from the polyp stalk, but no bleeding has occurred in this series after washouts for recovery of a lost polyp.

\subsubsection{Small polyps}

Small polyps around $0.5 \mathrm{~cm}$ in diameter are seem in a large number of patients. These are often multiple and the temptation is either to ignore them because of their small size and benign appearance or to destroy them using electro-coagulation (193). Either approach is unsatisfactory because the histological type of the polyp cannot be determined by colonoscopic inspection alone and the lesion may be potentially pre-cancerous. If any polyp is left the patient should be followed-up by either X-ray or colonoscopy. A simple but efficient way to manage the small polyps is the "hot-biopsy" procedure introduced by Williams in 1973 which combines fulguration of the base of the polyp with the taking of the tissue specimen from the head of the polyp for histological assessment (fig. 18). Even so many of these tiny biopsy specimens may be lost for technical reasons or during processing because of their small size (58).

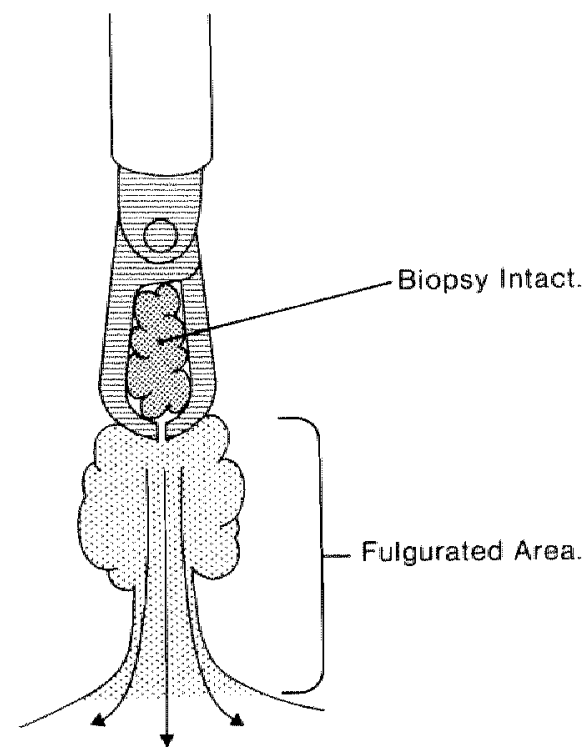

Fig. 18: The "hol biopsy" procedure 


\subsubsection{Multiple polyps}

Not infrequently patients present with multiple colonic polyps not amounting to polyposis coli or other forms of multiple polyposis such as the Peutz-Jeghers syndrome. In such patients, especially if elderly. it may be judged preferable to perform multiple colonoscopic polypectomies rather than colonic resection. Such polypectomies can be performed in several sessions, in each session removing a number of polyps. Because of the need for frequent re-insertion of the colonoscope the use of an over-tube may be helpful especially in patients where the sigmoid colon is difficult to negotiate. The overtube is kept in place to form a tunnel through which the colonoscope can be passed frequently and quickly to the proximal colon.

The total number of polypectomies in each session depends on the colonoscopist and the patient. The maximum number of polypectomies carried out in this series in a single session was 23 . If the colonoscopic insertion was technically very difficult, multiple polypectomies may have to be performed without the ability to withdraw and to re-insert the colonoscope repeatedly. The snared polyps are therefore left in situ and recovered using washouts. An obvious disadvantage of this method is the inability to provide an exact anatomical location for the polyps, which might be of great importance if one proved to have invasive malignant change. Every effort should therefore be made to retrieve any polyp with appearances suspicious of malignancy. such as irregular contour, surface ulceration or apparently hard consistency. Smaller or "benign" looking polyps are snared off for retrieval by washout.

\subsubsection{Sessile polyps}

Sessille polyps are technically the most difficult for polypectomy. If they are less than $1.5 \mathrm{~cm}$ im diameter, conventional snare polypectomy technique can be used. If they are larger, piecemeal polypectomy is the method of choice, the snare being closed round parts of the polyp, different parts being snared off piece by piece untill the whole polyp is removed. The raw area left is relatively large and oozing haemorrhage is sometimes seen. Such piecemeal removal is also a problem to the pathologist since the resection line cannot be identified. There is a possible danger of "tenting" the polyp when closing the snare, thus removing or heat-coagulating the part of the bowel wall, resulting in perforation. It is therefore wise to leave the removal of large sessile polyps to an experienced endoscopist. Even so there is a limit to the size of sessile polyps which can be snared 
and polyps larger than $3-4 \mathrm{~cm}$ should probably be regarded as endoscopically unremovable and surgical resection advised

\subsubsection{Large polyps}

Large polyps present a technical problem because of their bleeding potential. The critical factor is not the polyp head but the stalk: although large polyps usually also have large stalks, occasionally a large head may be on top of a small stalk, making normal polypectomy easy and safe.

For big stalks the use of the two-snare technique (89) is an example of a new procedure to prewent haemorrhage after polypectomy (fig. 19). The technique is used if colonoscopy reveals a polyp stalk over $1.5 \mathrm{~cm}$ in diameter and $2 \mathrm{~cm}$ or more in length. The home-made handle-less snare is passed to the operating channel and the stalk lassoed near its base. The colonoscope is removed, the handle-less snare being left in situ and its grip around the base of the stalk maintained by applying a forceps to the snare wire. This forceps is subsequently used as an electrical connector, being connected to the patient-plate outllet of the electro-surgical unit. The colonoscope is re-inserted to the polyp and the normal diathermy snare used to snare the polyp near its head in the usual way but avoiding contact between the two snare-loops. When electric current is applied it will follow the handle-less snare as a return path to the electrosurgical unit, since no patient-plate is employed. More efficient current flow results compared to the conventional use of the patientplate, probably resulting in a better coagulation to the stalk and its blood vessels. If bleeding does occur, the handle-less snare at the polyp base can be tightened and will act as tourniquet for a period of 15-20 minutes, which will usually stop the haemorrhage. The polyp stallk can alternatively be re-coagulated using the conventional snare once again.

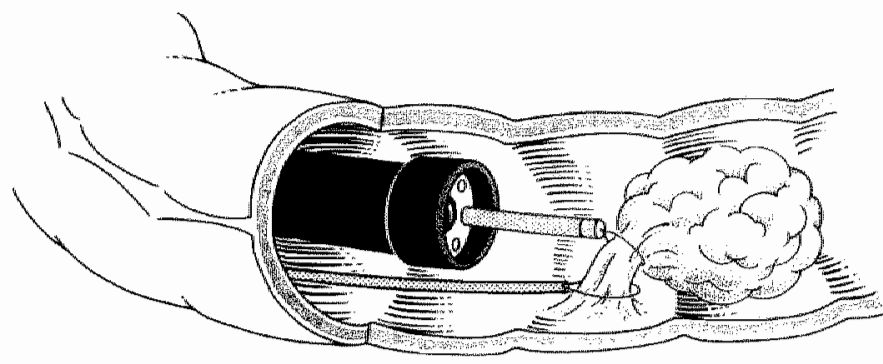

Fig. 19: The two-snare technique. 


\subsubsection{Polyoosis}

Patients with lamilial polyposis coli were not included in this series because of the large number of polyps involved and the irrelevance of colonoscopic polypectomy when surgery was indicated. There are however. several points which merit discussion. It is very important to establish the diagnosis of polyposis coll at an early phase in family members "at risk": colonoscopy is a useful procedure in those members of a polyposis family where the barium enema is doubtfull or negalive and diagnosis cannot be made on rigid proctosigmoidoscopy. If only one or two polyps are seen at colonoscopy in such patients. this does not constitute polyposis but may mean a warning of the colon's potential for future development of polyps. The use of dye-spray is an effective techmique to inspect the colonic mucosa for fine detail (168). If there are tiny polyps $1-2$ $\mathrm{mm}$ in diameter. which may indicate the early phase of polyposis coli bul invisible to the naked eye or the radiologist, the blue dye used will spread out and cover the normal flat mucosa, any excrescences standing out as obvious white areas for biopsy. If these tiny lesions prove to be adenomas, the diagnosis of polyposis coli is established probably some years before it would otherwise be made. The dye used is indigo-carmine $0.2 \%$ although washable blue fountain pen ink is equally effective.

In a few patients known to have adenomatous polyposis coli, where surgery must be deferred or avoided for other reasons, colonoscopy and polypectomy must be justified to remove the larger lesions or to determine the presence of carcinomatous change. One such patient in this series had refused surgery because another family member had died post-operatively due to a complicating desmoid tumour. Another bad a known small-intestinal desmoid tumour and the risk of proliferation of the desmoid tumour after surgery was judged to be greater than the risk of the multiple small colonic polyps. Both the patients appeared to justify the risk of follow-up by colonoscopy in order to decide. When, if ever, the indications for surgery become absolute. Though patients with subtotal colectomy and ileo-rectal anastomosis for polyposis colli are normally followed by proctosigmoidoscopy, limited colonoscopy may be indicated in the few patients where the anastomosis cannot be reached with the rigid instruments.

\subsubsection{Peutz-Jeghers polyp syndrome}

Patients with Peutz-Jeghers polyposis are also excluded from the numerical section of this study. The risk of carcinomatous. 
degeneralion in Peutz-Jeghers polyps is debatable and, if present. this rate is very low (56). Peutz-Jeghers polyps however. may cause bleeding or anaemia. Intussusception for colonic polyps has not occurred in this series. Up to 23 polyps have been removed in a single session, the procedure being expedited since retrieval is nomally unnecessary.

\subsubsection{Polyps in colitis}

Multiple polyps may be seen on the barium enema of palients with colitis. especially long-standing ulcerative colitis. At colonoscopy these polyps are usually seen to be smalli, shiny and sometimes worm-like, sometimes with a characteristic white slough covering. Occasional larger granulation tissue polyps develop which are red or bleeding and irregular in outline. therefore requiring histological assessment to ensure that they are not adenomas or potentially malignant lesions. Such polyps form the only indication for forcepsbiopsy, which will give representative histology. The smaller intlammatory polyps can be ignored.

Occasionally an adenoma may be present between the inflammatory polyps and require snaring. Although the smaller inflammalory polyps have no malignant potential, careful diagnostic colonoscopy is justified to ensure that no adenomatous polyp is overlooked. 


\section{Results}

The results of the 1930 colonoscopic polypectomies performed during 972 colonoscopies will be described here.

Fig. 20 shows the total number of colonoscopies performed since 1971. The excessive increase in 1978 is due to better facilities in a new endoscopy unit.

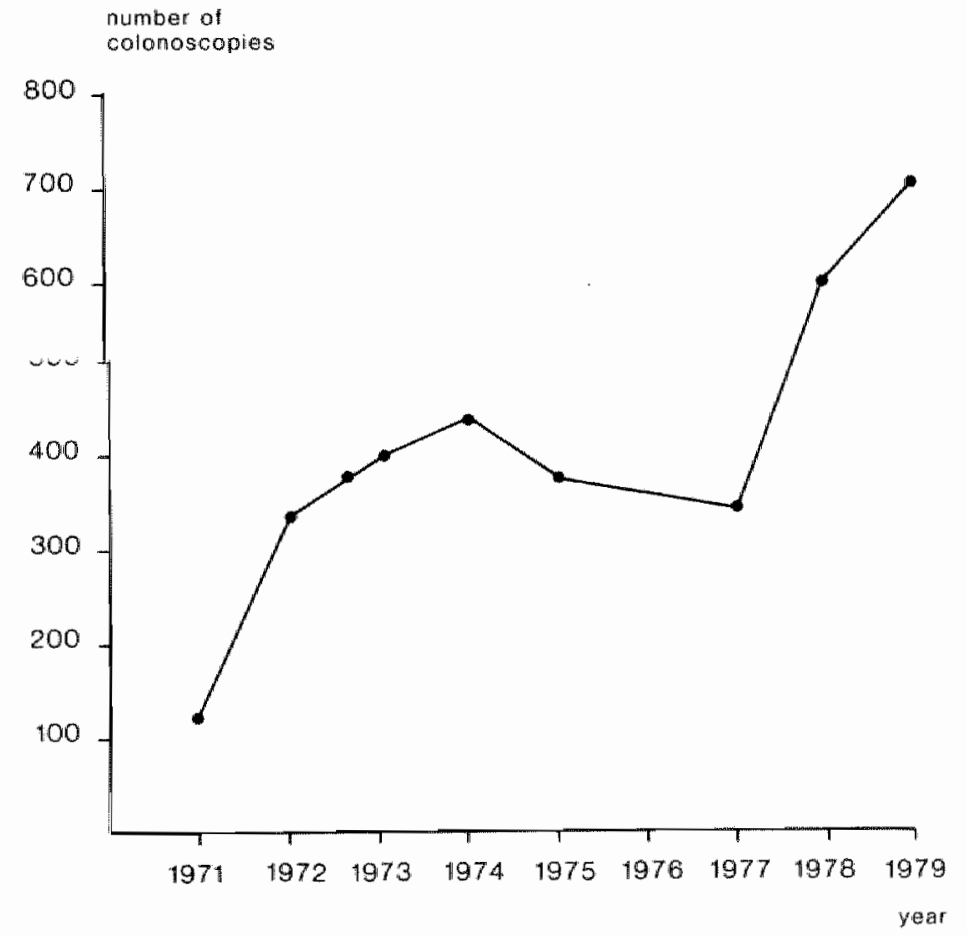

Fig. 20: Total number of colonoscopies pertormed at Si. Mark's Hospital London during the years $1971-1979$. 
The procedure on treatment of colonic polyps is shown in fig. 21 The majority of patients (over $50 \%$ ) have been examined physically and radiologically at their local hospital. After the indication for performing a colonoscopy has been established, they were referred to St. Mark's Hospital. From the 3500 colonoscopies performed. 1033 procedures involved colonic polyps and 1995 colonoscopic polypectomies were performed. Complete endoscopic removal was achieved on 1930 polyps, whereas 65 polyps were unremovable. Further subdivision in the malignant and benign types are as shown in fig. 21.

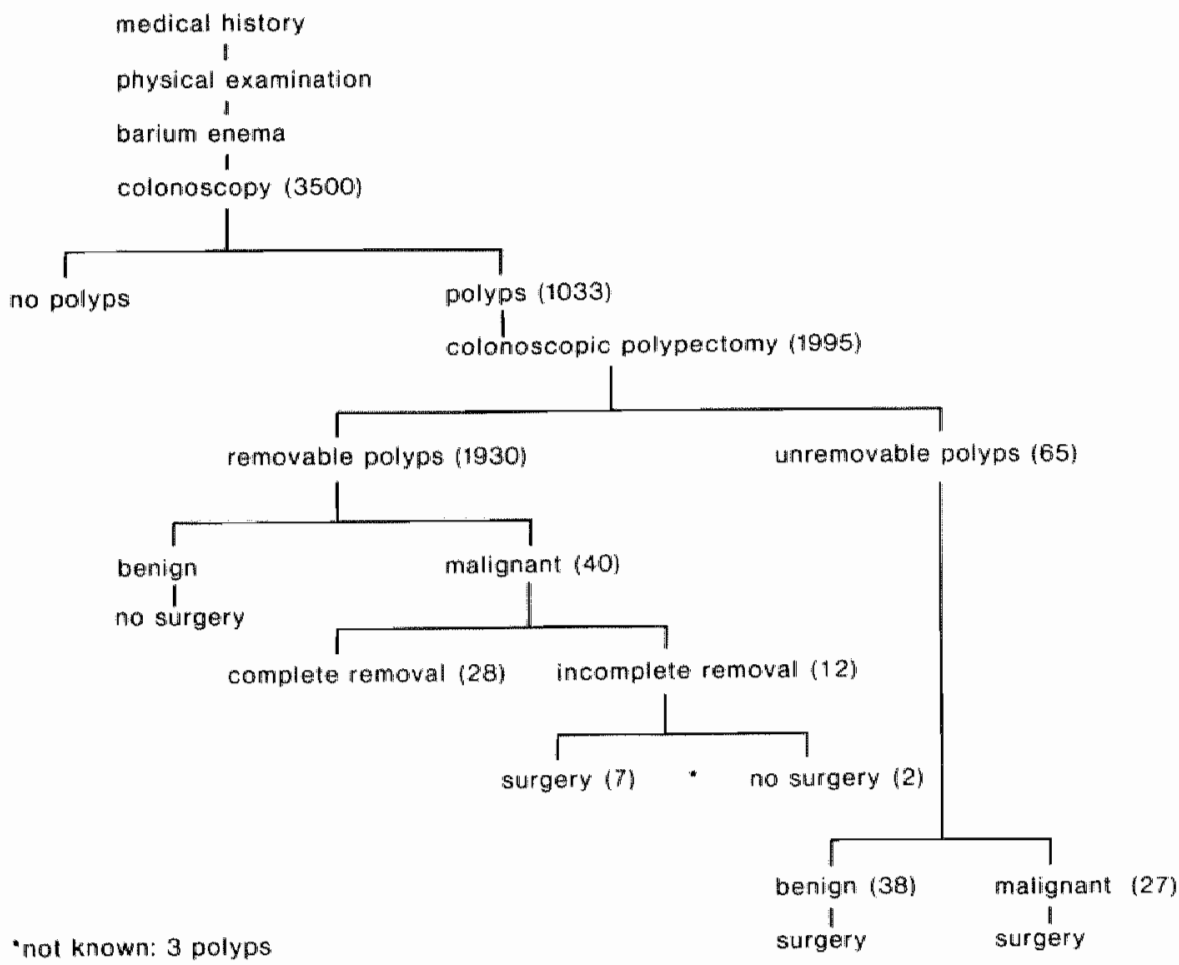

Fig. 21 Schematic diagram on treatment of colonic polyps. 
The data reviewed were retrieved from the endoscopy reports which include the patient's personal details, and clinical, histological and technical data (see Appendices). Wherever necessary, the patient's medical record was reviewed or separate histology reports studied. Only those snare polypectomies were included in the series where the procedure was undertaken for the therapeutic management of a colonic polyp. Small polyps of approximately $0.5 \mathrm{~cm}$ in diameter managed with the hot-biopsy procedure were included as well as all the snare polypectomies. Procedures involving only a biopsy of a polyp or a polypoid tumour using either smare or biopsy forceps were excluded from this study as not being therapeutic procedures. Also excluded were all the patients having colonoscopy for the different types of polyposis, such as familial adenomatous polyposis coli or the Peutz-Jeghers syndrome. In these patients the number of polyps present is irrelevant, but a discussion about these types of polyps is included in chapter 3.6.

Using the abovementioned criteria there were 972 procedures in which one or more colonoscopic polypectomies were performed During these procedures there were a total of 1930 polypectomies, 631 with the hot-biopsy forceps and 1299 with the diathermy snare In the following paragraphs the results and polyp characteristics are analysed with a closing discussion. In separate parts in this chapter the malignant types of the polyps are discussed, as well as the technically unremovable polyps; the complications following colonoscopy and polypectomy are discussed in the next chapter.

As no regular follow up colonoscopies have been performed on patients with removed adenomas, no follow up studies could be conducted. However, due to improved facilities, recently a prospective follow up study has started (see chapter 6). So far, not enough data have been obtained to present conclusive reports. Patients with malignant adenomas and polypoid carcinomas removed, were regularly checked by follow-up colonoscopy. These results are given and discussed in chapter 4.4 .

\subsection{Polyp location}

The data on the location of removed polyps are derived from the endoscopy reports. These locations were normally based on the endoscopist's estimation of the anatomical site, occasionally confirmed bij X-ray fluoroscopy. Fluoroscopy was always used where there appeared to be discrepancy between the endoscopist's 
assessment of polyp localiom and that shown on barium enema.

The location of all the polyps removed by colonoscopic means is shown in fig. 22. while the numbers of these polyps are shown in table 5 . No location data could be oblained in 63 polyps.

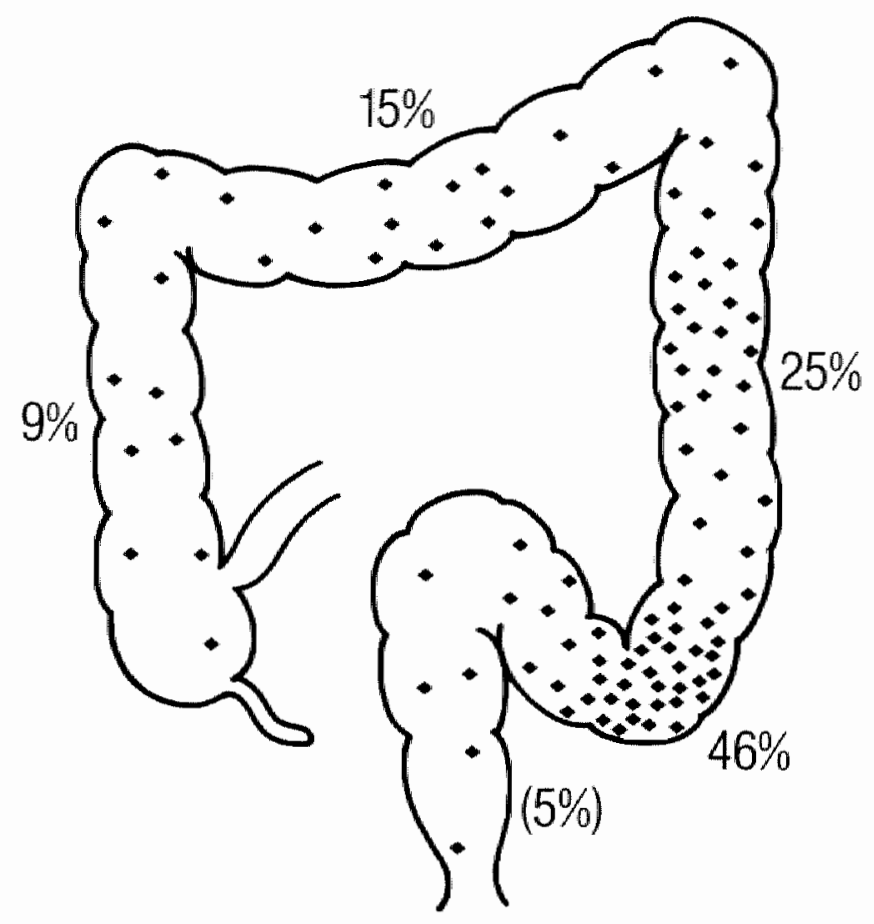

Fig 22: Distribution of all polyps

Table 5: Distribution of all polyps.

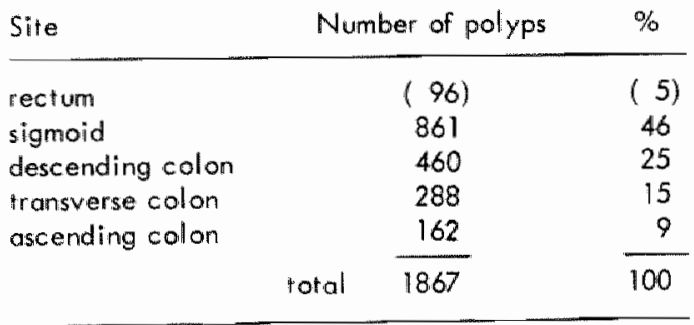

(site not revealed : 63 ) 
The total number of 96 polyps $(5 \%)$ located in the rectum is not representative. The reason is that many patients had had their rectal polyps removed by other methods. such as rigid sigmoidoscopy or even trans-anal surgery. Because a large number of these patients were referred from other hospitals, no correct information on these rectal polyps could be obtained.

Polyps found in the cecum were added together to those found in the ascending colon and shown in the tables as located in the ascending colon. Polyps in the hepatic flexure were added to the transverse colon, in the splenic flexure to the descending colon, in the sigmoiddescending colon junction to the sigmoid and in the recto-sigmoid junction to the rectum. The reason for this type of subdivision is to avoid small numbers of polyps located in small parts of the colon to be shown in tables or figures. Besides this, ome can endoscopically see the more proximally located junction as a part of the colon segment where one is situated at that time. For instance, if the colonoscope tip is in the descending colon, the splenic flexure can be seen in front of the colonoscope, so that the descending colon and splenic flexure can be regarded as one large bowel segment.

\subsection{Polyp size and configuration}

The polyp size was determined by the endoscopist"s assessment at the time of removal or by direct measurement of the retrieved polyp after polypectomy. Occasionally, when these two data were not available, the size mentioned in the histology reports was used. Based on these reports, a relation between the size of all polyps and its location could be determined, which is shown in table 6 .

Table 6: Relation between size and location of all polyps. Between brackets: the most signilicant percentages.

\begin{tabular}{|c|c|c|c|c|c|c|c|c|c|c|c|}
\hline \multirow{2}{*}{ Size $(\mathrm{cm})$} & \multicolumn{2}{|c|}{ rectum } & \multicolumn{2}{|c|}{ sigmaid } & \multicolumn{2}{|c|}{ descending } & \multicolumn{2}{|c|}{ transverse } & \multicolumn{2}{|c|}{ ascending } & \multirow[t]{2}{*}{ rotal } \\
\hline & No & $\%$ & No. & $\%$ & No. & $\%$ & No. & $\%$ & No. & $\%$ & \\
\hline$<0.5$ & 69 & (3) & 246 & (13) & 197 & $(10)$ & 157 & (8) & 75 & (4) & 744 \\
\hline $0.6-1.0$ & 24 & & 332 & (17) & 147 & $(8)$ & 81 & (4) & 68 & (3) & 652 \\
\hline $1.1-2.0$ & 2 & & 224 & (12) & 82 & (4) & 32 & & 17 & & 357 \\
\hline $2.1-3.0$ & 1 & & 49 & (2) & 30 & & 10 & & 2 & & 92 \\
\hline $3.1-4.0$ & - & & 8 & & 4 & & 8 & & - & & 20 \\
\hline$>4.1$ & - & & 2 & & - & & - & & - & & 2 \\
\hline total & 96 & & 861 & & 460 & & 288 & & 162 & & 1867 \\
\hline
\end{tabular}

(no data obtained in 63 polyps) 
From the endoscopic point of wiew the most important aspect of polyp configuration is the presence or absence of its stalk. If no stakk is present, a polyp is called sessile and the abnormal tissue being immediately on the inner surface of the bowel wall. When there is a length of normal bowel mucosa between the polyp head and the bowel wall, the polyp is called pedunculated or stalked (see chapter However, it is sometimes hard to distinguish between a sessile polyp and one with a short stalk.

Table 7 shows the relation between the size and configuration of all polyps in this study, except for 63 polyps in which no data on size and/or configuration could be obtained.

Table 7: Size and configuration of all polyps. Between brackets: puercentage af all polyps

\begin{tabular}{|c|c|c|c|c|}
\hline \multirow[t]{2}{*}{ Size $(\mathrm{cm})$} & Pedunculated & Sessilie & \multicolumn{2}{|l|}{ Toral } \\
\hline & No. $\%$ & No. $\%$ & No. & $\%$ \\
\hline$<0.5$ & \multicolumn{2}{|c|}{$744(40.0)$} & 7.44 & $(40.0)$ \\
\hline $0.6-1.0$ & $6.16(32.7)$ & $36(2.0)$ & 652 & $(34.7)$ \\
\hline $1.1-2.0$ & $325(17.3)$ & $32(1.8)$ & 357 & $(19.1)$ \\
\hline $2.1-3.0$ & $73(3.9)$ & $21(1.2)$ & 94 & $(5.1)$ \\
\hline $3.1-4.0$ & $17(0.9)$ & - & 17 & $(0.9)$ \\
\hline$>4.1$ & $3(0.2)$ & - & 3 & $(0.2)$ \\
\hline total & $1034(55.0)$ & $89 \quad(5.0)$ & 1867 & $(100,0)$ \\
\hline
\end{tabular}

(no data obtained in 63 polyps)

\subsection{Histology}

Because of its malignant potential, basically every adenomatous polyp should be removed and this was the guideline for all the colonoscopic polypectomies performed in this series. Every polypoid lesion is removed for therapeutic or prophylactic means, because it is endoscopically difficult to differentiate whether a polyp is adenomatous or not. Exceptions are patients with familial polyposis coli, in whom colonoscopic polypectomy would be insufficient and surgical removal of the colon prevails. Another exception is formed by patients with Peutz-Jeghers polyps, in whom cnly large and symptomatic polyps were removed, and patients with longstanding 
ulcerative colitis in whom mutiple small (pseudo) inflammatory polyps were also left unremoved. If there was any doubt about the neoplastic or non-neoplastic nature of a polyp, removal was always performed Based on this, all polyps regardless of size were removed from the patients in this study and submitted for histological verification. No polyps were left unremoved except in the abovementioned cases. or if the polyp was technically unremovable. (see chapter 4.5). All polyps were removed either by snare polypectomy or by the hot biopsy lechnique and submitted for histological assessment.

This study showed 324 polyps $(16.8 \%)$ removed but not histologocally assessed for several reasons. Some polyps were lost during retrieval. not being found in spite of meticulous search in the large bowel or using enemas for recovery; others were lost during processing. The majority of these polyps lost were very small in size, $78 \%$ less than 0.5 $\mathrm{cm}$ in diameter. Most of the polyps lost were destroyed using the hotbiopsy technique. Only two per cent of all lost polyps were above 1.0 $\mathrm{cm}$ in diameter. The total number of the various histological types of polyps is shown in table 8 .

Table 8: Histological types of all polyps.

\begin{tabular}{|c|c|c|}
\hline Type & Number of polyps & $\%$ \\
\hline \multicolumn{3}{|l|}{ Neoplastic: } \\
\hline tubular adenomas & 981 & 61 \\
\hline tubulo-villous adenomas & 199 & 12 \\
\hline $\begin{array}{l}\text { villous adenomas } \\
\text { polypoid carcinomas - adenocarcinoma }\end{array}$ & 58 & 4 \\
\hline arising in adenomas & 40 & 3 \\
\hline \multicolumn{3}{|l|}{ Non-neoplastic } \\
\hline juvenile polyps & 40 & 3 \\
\hline inflammat ory polyps & 32 & 2 \\
\hline metaplastic polyps & 118 & 7 \\
\hline others*) & 138 & 8 \\
\hline total & $\overline{1606}$ & 100 \\
\hline
\end{tabular}

*) Others include normal colonic epithelium, lipomas, hemangiomas and fibrous polyps.

Since differentiation is made on histological grounds between neoplastic and mon-neoplastic polyps, the findings in this series of these two types of polyps are also described separately. 
The distribution of all the neoplastic polyps is shown in fig. 23 and table 9. while their size is shown in table 10, as well as the malignant types of these polyps. i.e. the adenocarcinomas arising in adenomas and the polypoid carcinomas.

Tabte 9: Dictribution of all neoplastic polyps

\begin{tabular}{lccccccc} 
Site & tubular & tubulo-villous & willous & carcinamo & $\%$ & total & $\%$ \\
rectum & $(40)$ & $(12)$ & $(2)$ & $(0)$ & & $(54)$ & $(4)$ \\
sigmoid & 442 & 118 & 26 & 32 & $(2.4)$ & 618 & 49 \\
descending colon & 288 & 39 & 16 & 8 & $(0.4)$ & 349 & 27 \\
Iransverse colon & 144 & 23 & 10 & 2 & $(0.2)$ & 179 & 14 \\
ascending colon & 67 & 7 & 4 & - & & 78 & 6 \\
\hline total & 981 & 199 & 58 & 40 & & 1278 & 100 \\
$\%$ & 77 & 16 & 4 & 3 & 100 &
\end{tabular}

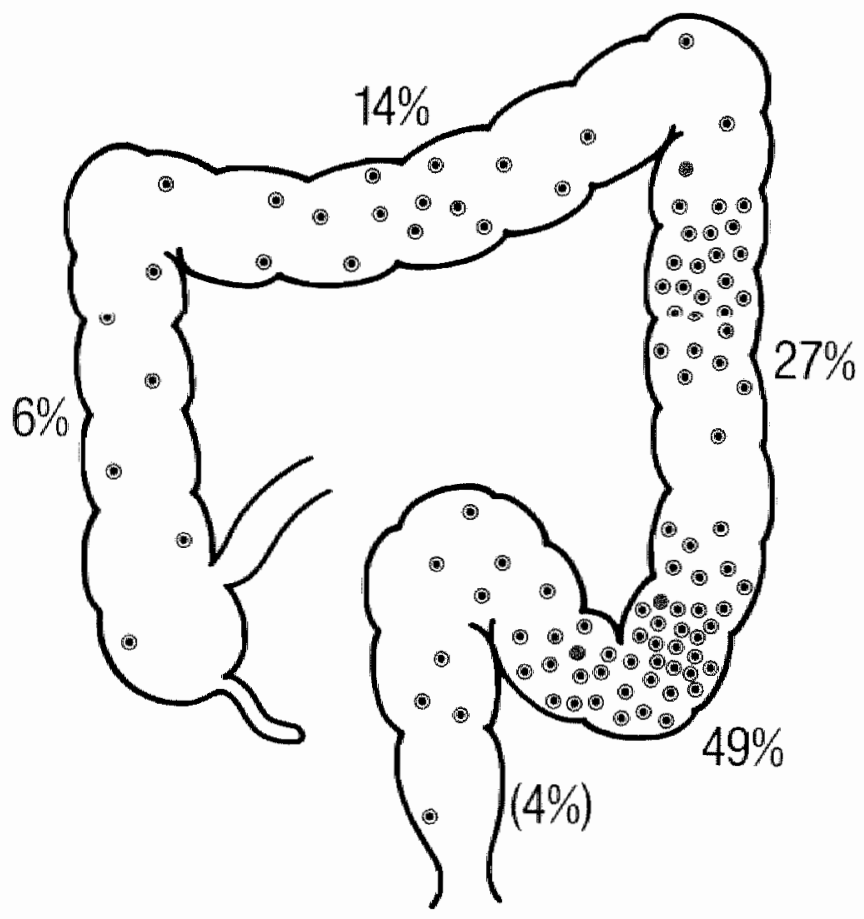

Fig. 23: Distribution of all neoplastic polyps

- malignant adenomas and polypoid carcinomas. 
Table 10: Size of the neoplasilo polyos.

\begin{tabular}{rrrrrrr} 
Size $(\mathrm{cm})$ & rubular & tubulo-villous & villaus & carcinoma & total & $\%$ \\
\hline$<0.5$ & 385 & 7 & 2 & - & 394 & 30 \\
$0.6-1.0$ & 360 & 76 & 17 & 1 & 454 & 35 \\
$1.1-2.0$ & 164 & 76 & 22 & 17 & 279 & 22 \\
$2.1-3.0$ & 33 & 30 & 9 & 14 & 86 & 7 \\
$3.1-4.0$ & 9 & 5 & 5 & 5 & 24 & 2 \\
$>4.1$ & 2 & 1 & - & 3 & 6 & 1 \\
not known & 28 & 4 & 3 & - & 35 & 3 \\
\hline rotal & 981 & 199 & 58 & 40 & 1278 & 100
\end{tabular}

The distribution of all non-neoplastic polyps is shown in table 11 and fig. 24. while their size is shown in table 12. The distribution of the "other" types of non-neoplastic polyps (see table 8) is not mentioned because of insignificant numbers.

A more detailed analysis of the several types of neoplastic and nonneoplastic polyps will be given in this chapter, while an analysis of the malignant types will be given in chapter 4.4 .

Table 11. Distribution of all non-neoplastic polyps.

\begin{tabular}{lcccccc} 
Site & iuverile & inflammatory & metaplastic & total & $\%$ \\
\hline rectum & $(-)$ & $(5)$ & $(30)$ & $(35)$ & $(18)$ \\
sigmoid & 15 & 16 & 57 & 88 & 46 \\
descending colon & 9 & 5 & 18 & 32 & 17 \\
tronsverse collon & 9 & 4 & 9 & 22 & 12 \\
ascending colon & 7 & 2 & 4 & 13 & 7 \\
\hline \multicolumn{1}{r}{ total } & 40 & 32 & 118 & 190 & 100
\end{tabular}




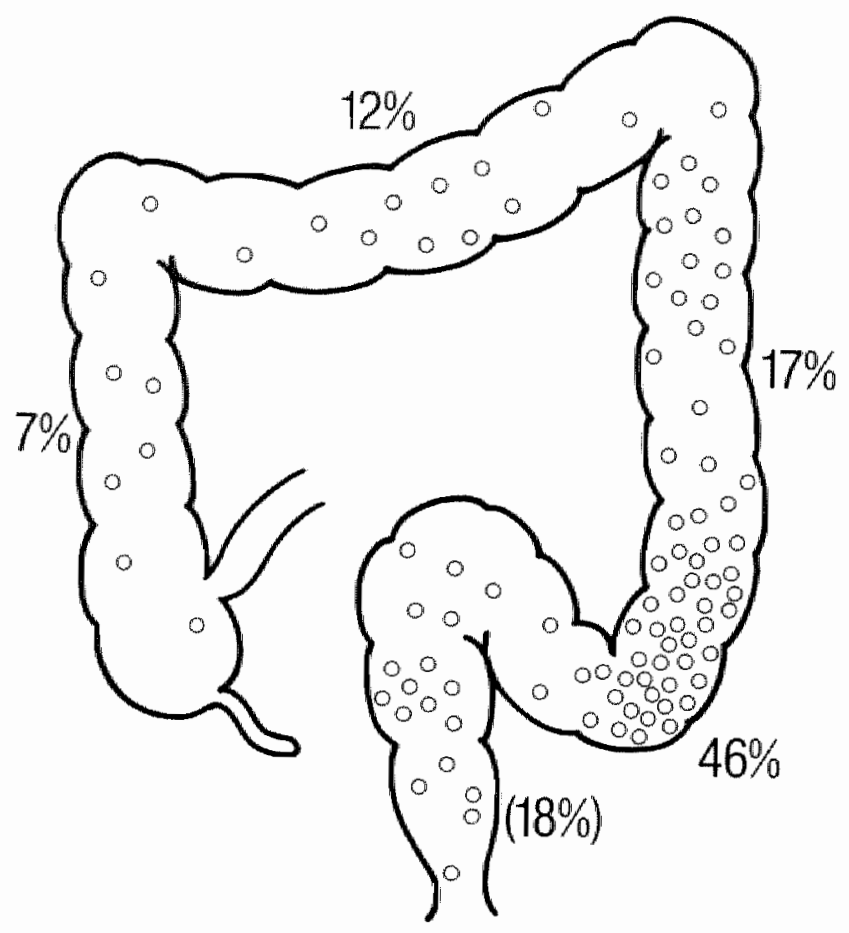

Fig. 24: Distribution of all non-neoplastic polyps

Table 12 . Size of the non-neoplastic polyps.

\begin{tabular}{rrrrrr} 
Size $(\mathrm{cm})$ & juvenile & inflammatory & metaplastic & total & $\%$ \\
\hline$<0.5$ & 1 & 11 & 92 & 104 & 55 \\
$0.6-1.0$ & 21 & 7 & 24 & 52 & 27 \\
$1.1-2.0$ & 12 & 12 & 2 & 26 & 14 \\
$2.1-3.0$ & 4 & 2 & - & 6 & 3 \\
$3.1-4.0$ & - & - & - & - & - \\
$>4.1$ & 2 & - & -118 & 190 & 100
\end{tabular}

A differentiation is made between the benign and malignant forms of these neoplastic polyps; the distribution of the benign types is shown in table 13 and fig. 25 , the rectum localization being not representative. The size range of these polyps is shown in table 14,35 polyps lack any information on size. 


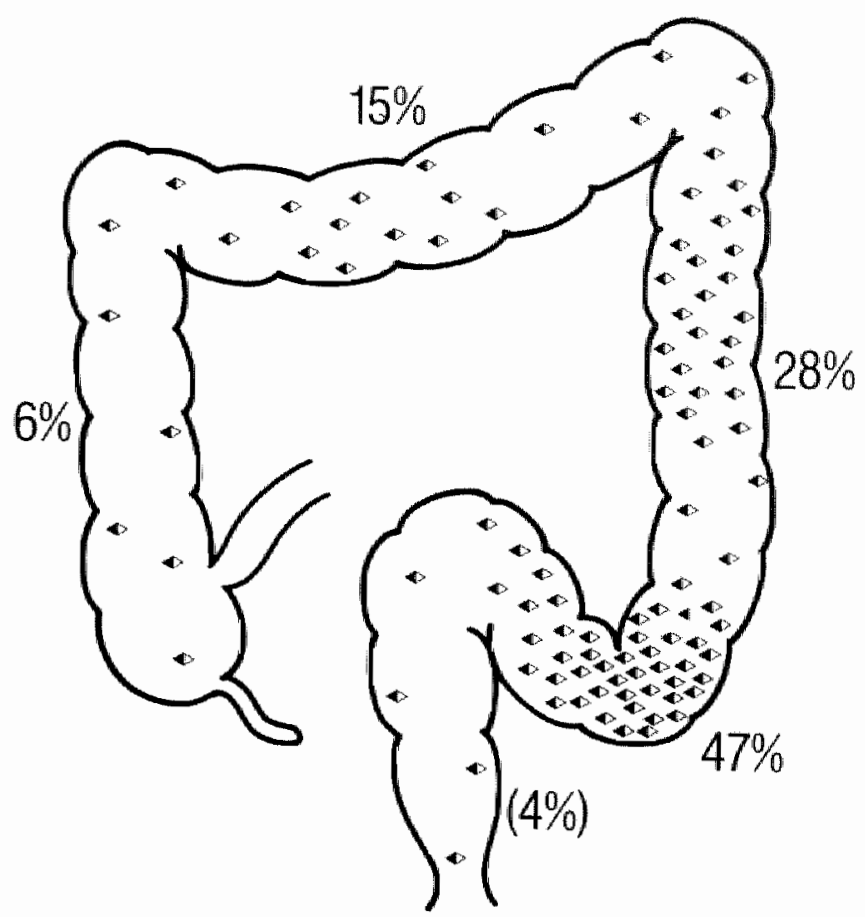

Fig. 25: Distribution of all neoplastic polyps excluding the malignant types

Table 13. Distribution of all neoplastic polyps, excluding the malignant types.

\begin{tabular}{lcccccc} 
& tubular & tubulo-villous & villows & iotal & $\%$ \\
\hline rectum & $(40)$ & $(12)$ & $(2)$ & $(54)$ & $(4)$ \\
sigmoid & 442 & 178 & 26 & 586 & 47 \\
descending colon & 288 & 39 & 16 & 343 & 28 \\
transwerse colon & 144 & 23 & 10 & 177 & 15 \\
ascending colon & 67 & 7 & 4 & 78 & 6 \\
\hline & 981 & 199 & 58 & 1238 & 100 \\
& 79 & 16 & 5 & 100 &
\end{tabular}


Table 14 . Size range of the neoplastic polyps, excluding the malignant types.

\begin{tabular}{rrrrrr} 
Size $(\mathrm{cm})$ & tubular & tubullo-villous & villous & tofal & $\%$ \\
\hline$<0.5$ & 385 & 7 & 2 & 394 & 32 \\
$0.6-1.0$ & 360 & 76 & 17 & 453 & 36 \\
$1.1-2.0$ & 164 & 76 & 22 & 262 & 21 \\
$2.1-3.0$ & 33 & 30 & 9 & 72 & 6 \\
$3.1-4.0$ & 9 & 5 & 5 & 19 & 1.5 \\
$>4.1$ & 2 & 1 & - & 3 & 0.5 \\
not known & 28 & 4 & 3 & 35 & 3 \\
\hline total & 981 & 199 & 58 & 1238 & 100
\end{tabular}

\subsubsection{Neoplastic polyps}

All data on the neoplastic polyps were studied these polyps consist of the tubular, tubulo-villous and villous adenomas and the polypoid carcinomas and adenocarcinomas arising in adenomas. Only the removable neoplastic polyps are discussed here, the non removable ones being described in chapter 4.5

A total number of 1278 neoplastic polyps were found, the distribution of these polyps as judged colonoscopically being shown in figl. 23 and table 9. As mentioned in chapter 4.1 , the number of polyps found in the rectum is not representative. The size of these polyps is shown in table 10 . For a total number of 35 polyps $(3 \%)$ there was no information on size, either endoscopically, radiologically or histologically.

The distribution of the three types of benign reoplastic polyps is shown separately in fig. 26, 27 and 28 , and also in tables 15,17 and 19 . The size range of these polyps is shown separately in tables 16,18 and 20 .

Table 15. Distribution of the lubular adenomas.

\begin{tabular}{lcc} 
Site & Number of polyps & $\%$ \\
\hline rectum & $(40)$ & $(4)$ \\
sigmoid & 442 & 45 \\
descending colon & 288 & 30 \\
transwerse colon & 144 & 14 \\
ascending colon & 67 & 7 \\
\hline & 981 & 100
\end{tabular}




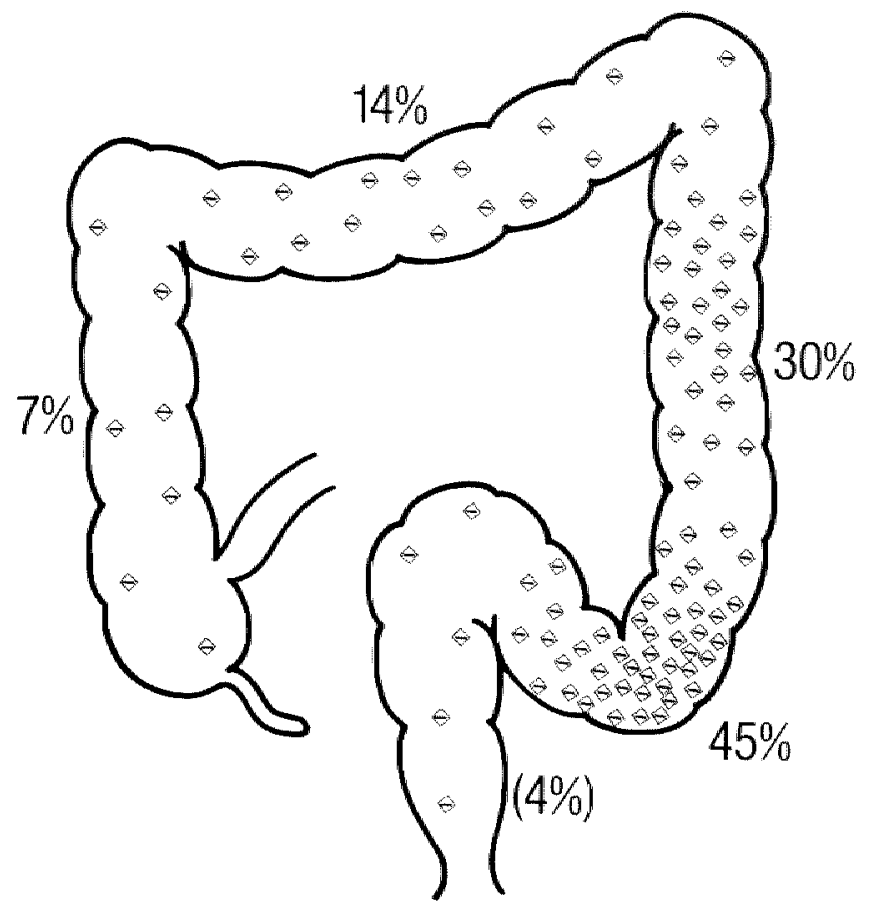

Fig. 26. Distribution of the tubular adienomas.

Table 16: Size of the tubular adenomas.

\begin{tabular}{rcc} 
Size $(\mathrm{cm})$ & Number of polyps & $\%$ \\
\hline$<0.5$ & 385 & 40 \\
$0.6-1.0$ & 360 & 38 \\
$1.1-2.0$ & 164 & 17 \\
$2.1-3.0$ & 33 & 3.9 \\
$3.1-4.0$ & 9 & 0.9 \\
$>4.1$ & 2 & 0.2 \\
nat known & $(28)$ & 100 \\
\hline total & 981 &
\end{tabular}




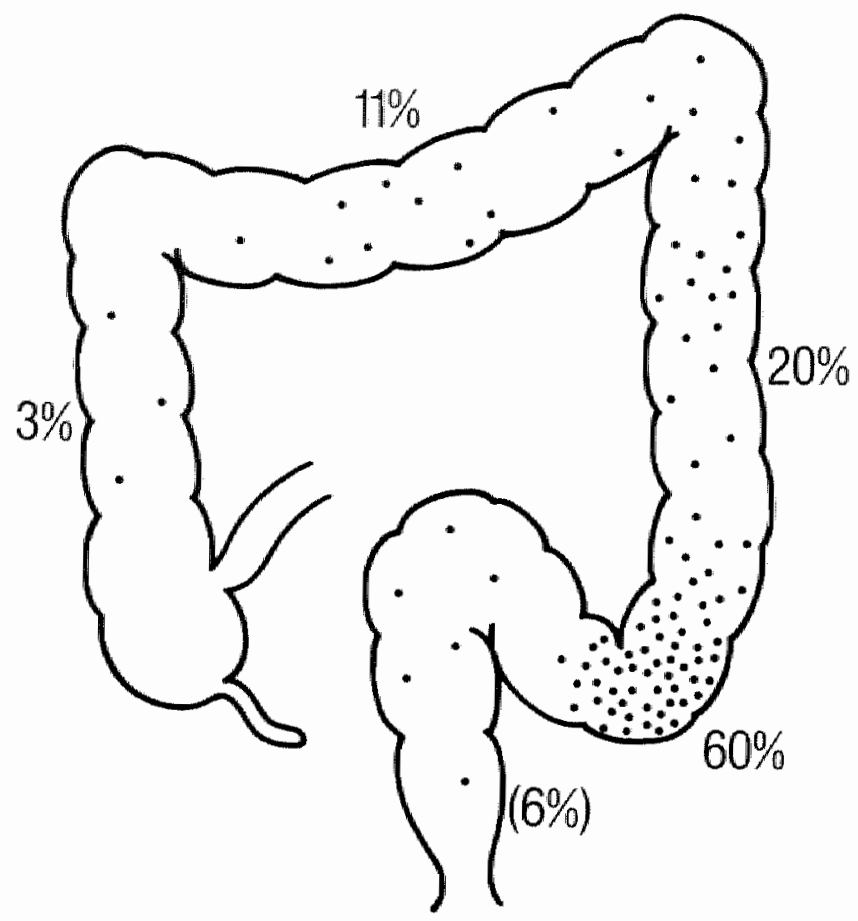

Fig. 27. Distribution of the tubulo-villous adenomas.

Table 17. Distribution of the tubulo-villous adenomas

\begin{tabular}{lcc} 
& Number of pollyps & $\%$ \\
\hline rectum & $(12)$ & $(6)$ \\
sigmold & 118 & 60 \\
descending colon & 39 & 20 \\
Iransverse colon & 23 & 11 \\
oscending colon & 7 & 3 \\
\hline \multicolumn{1}{r}{ total } & 199 & 100
\end{tabular}


Table 18 . Size of the tubulo-vilious adenomas.

\begin{tabular}{rcc} 
Size $(\mathrm{cm})$ & Number of polyps & $\%$ \\
\hline$<0.5$ & 7 & 3.5 \\
$0.6-1.0$ & 76 & 39 \\
$1.1-2.0$ & 76 & 39 \\
$2.1-3.0$ & 30 & 15 \\
$3.1-4.0$ & 5 & 3 \\
$>4.1$ & 1 & 0.5 \\
not known & $(4)$ & \\
\hline total & 199 & 100
\end{tabular}

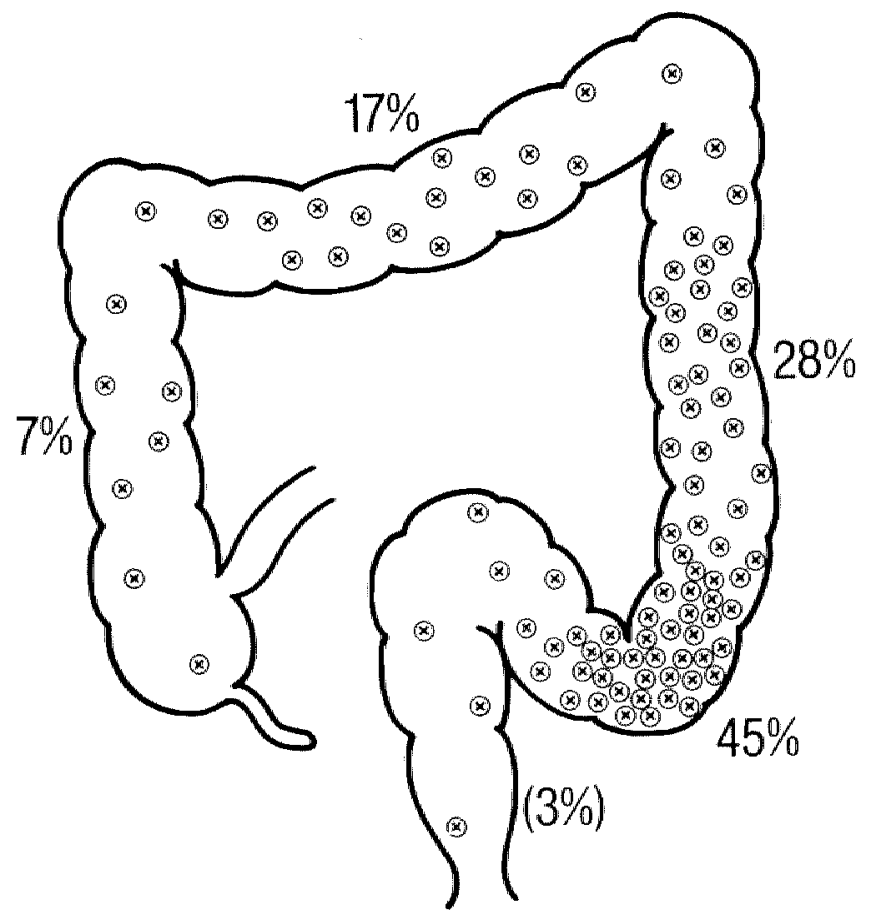

Fig. 28. Distribution of the villous adenomas. 
Table 19. Distribution of the villous adenomas.

\begin{tabular}{lcc} 
Site & Number of polyps & $\%$ \\
\hline rectum & $(2)$ & $(3)$ \\
sigmoid & 26 & 45 \\
descending colon & 16 & 28 \\
rransverse colon & 10 & 17 \\
ascending colon & 4 & 7 \\
\hline total & 58 & 100
\end{tabular}

Table 20: Size of the villous adenomas

\begin{tabular}{rcr} 
Size $(\mathrm{cm})$ & Number of polyps & $\%$ \\
\hline$<0.5$ & 2 & 4 \\
$0.6-1.0$ & 17 & 31 \\
$1.1-2.0$ & 22 & 40 \\
$2.1-3.0$ & 9 & 1.6 \\
$3.1-4.0$ & 5 & 9 \\
$>4.1$ & - & - \\
not known & $(3)$ & \\
\hline total & 58 & 100
\end{tabular}

\section{Discussion}

The adenomas are the most important polyps in the colon, because they may develop malignancy (see chapter 2.4). For this reason, every adenoma should be excised completely, preventing possible growth of malignancy. Adenomas occur in all parts of the colon, the majority being located in the left colon, especially in the sigmoid. This distribution does not depend on the histological type, the majority of all three types of adenomas being located in the sigmoid colon. In the ascending colon, onlly a few adenomas were found. The most common adenoma found is the tubular adenoma, followed by the tubulo-villous adenomas, the villous types being the minority. Even small polyps can be adenomas, as shown in table 14. The majority of the tubular adenomas are less than $0.5 \mathrm{~cm}$ in diameter, 
while no malignant polyp was of this minute size. The total number of 394 adenomas of this size shows that even small polyps can be adenomas and not necessarily non neoplastic. Therefore, all small polyps should be excised too.

Villous adenomas were infrequently found and also included some small lesions less than $1.0 \mathrm{~cm}$ in diameter. It is in these small villous adenomas where the chance occurs to find small malignant carcinomas, since the chance of a villous adenoma to grow malignant is much larger than the other two types of adenomas.

Large polyps do occur, sometimes not completely removable by snare polypectomy. Only 3 polyps larger than $4.1 \mathrm{~cm}$ in diameter could be excised completely by colonoscopic means, the other large polyps were unremovable. Most of the polyps found in this study were adenomas, a total number of 1305 polyps including the malignant types.

Only $190(12 \%)$ polyps have been found to be non neoplastic. Other authors $(58,126,152)$ found aiso adenomas in the vast majority of colonic polyps.

\subsubsection{Non-neoplastic polyps}

\section{Juvenile polyps}

Juvenile polyps were found in 19 patients, their age ranging from $8-44$ years, with a mean of 21 years of age. A total number of 40 juvenile polyps were retrieved and confirmed by histology. Their location and size being shown in table 21 and 22 , while fig. 29 shows the distribution of these polyps.

Table 21: Distribution of juwenile palyps.

\begin{tabular}{|c|c|c|}
\hline Site & Number of polyps & $\%$ \\
\hline rectum & $(-)$ & $(-)$ \\
\hline sigmoid & 15 & 38 \\
\hline descending collon & 9 & 22 \\
\hline transverse collon & 9 & 22 \\
\hline ascending colon & 7 & 18 \\
\hline total & 40 & 100 \\
\hline
\end{tabular}




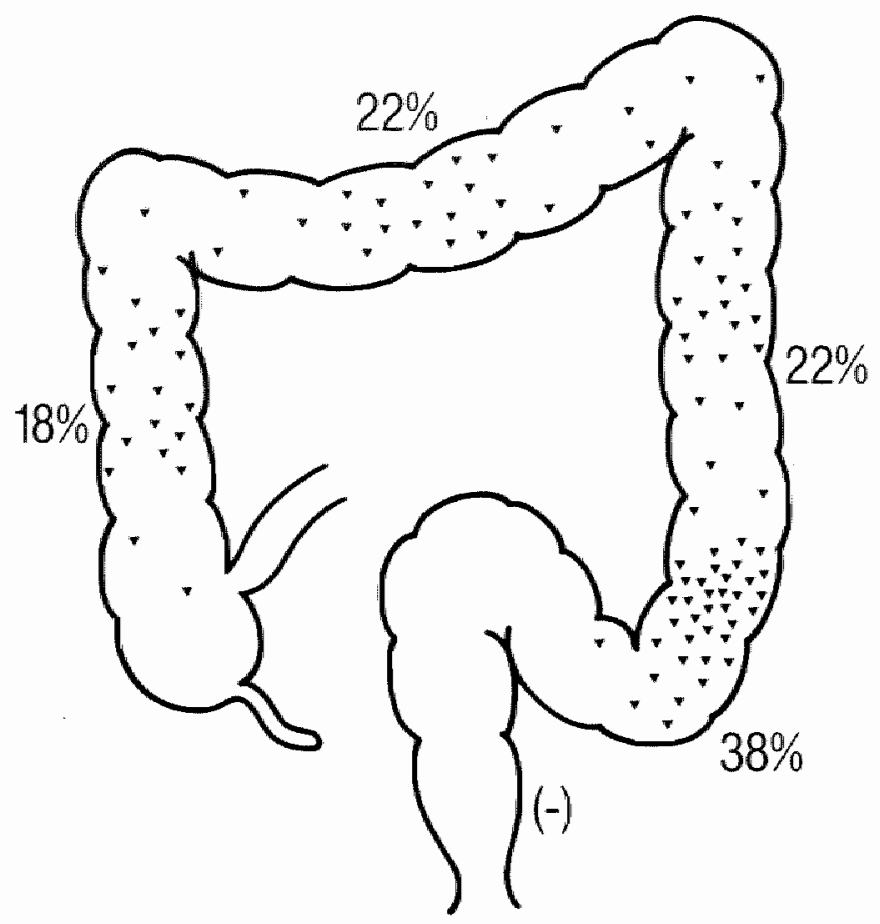

Fig. 29: Distribution of the juvenile polyps.

Table 22: Size of juvenile polyps.

\begin{tabular}{rcr} 
Size $(\mathrm{cm})$ & Number of polyps & $\%$ \\
\hline$<0.5$ & 1 & 2 \\
$0.6-1.0$ & 21 & 53 \\
$1.1-2.0$ & 12 & 30 \\
$2.1-3.0$ & 4 & 10 \\
$3.1-4.0$ & - & - \\
$>4.1$ & 2 & 5 \\
\hline total & 40 & 100
\end{tabular}




\section{Discussion}

The juvenile polyps, together with the Peutz-Jeghers polyps are classified as the hamartomas. In this study however, only the juvenile polyps are described and discussed. The reason for this is that not all Peutz-Jeghers polyps are removed firom the colon.

In patients with known Peutz-Jeghers syndrome submitted for colonoscopy, only large polyps thought to be causing symptoms or blood loss were removed. The remaining polyps, often in large numbers, are left unremoved.

The juwenile polyps were found incidentally and usually not readily recogmized. Even when the endoscopic diagnosis is of a juvenile polyp. this polyp is removed and submitted for histology since definite differentation between a juvenile polyp and an adenoma is frequently difficult.

Most of the patients with juvenile polyps were adolescent in this series. This is due to the fact that the majority of the children with colonic problems were referred to a children's hospital and not to St. Mark's Hospital. Juvenille polyps are usually found in childhood, and the age distribution in this series is not representative.

The total number of 40 juvenile polyps reflects only a small part $(2 \%)$ of all the polyps found in the colon. The importance of removing these polyps is twofold: firstly to be certain that the polyp is not an adenoma and secondly because of its symptoms or blood loss. No malignancy has been found in this study related to juvenile polyps.

Regarding the distribution of the juvenile polyps, excluding the rectum, they are almost equally distributed throughout the collon with a slightly predominant location in the sigmoid (38\%). About half of the polyps $(55 \%)$ are less than $1.0 \mathrm{~cm}$ in diameter. A few exceeded $4.1 \mathrm{~cm}$ in diameter; these were located in the sigmoid and transverse colon.

It is therefore concluded that though juvenile polyps are not frequently found they should be removed for histological assessment. occasionally they are very large in size.

\section{Metaplastic polyps}

A relatively large number of metaplastic polyps were found, the majority being sampled using the hot biopsy technique. The distribution and size of all metaplastic polyps removed by colonoscopic means is shown in table 23 and 24 and fig. 30 . Only in one patient was a carcinoma found in the same area (recto-sigmoid) as a metaplastic polyp, probably a chance occurremce. 
Table 23. Distribution of metaplastic polyps.

\begin{tabular}{|c|c|c|}
\hline Site & Number of polyps & $\%$ \\
\hline rectum & $(30)$ & (26) \\
\hline sigmoid & 57 & 49 \\
\hline descending collon & 18 & 14 \\
\hline transwerse colon & 9 & 8 \\
\hline ascending colon & 4 & 3 \\
\hline total & 118 & 100 \\
\hline
\end{tabular}

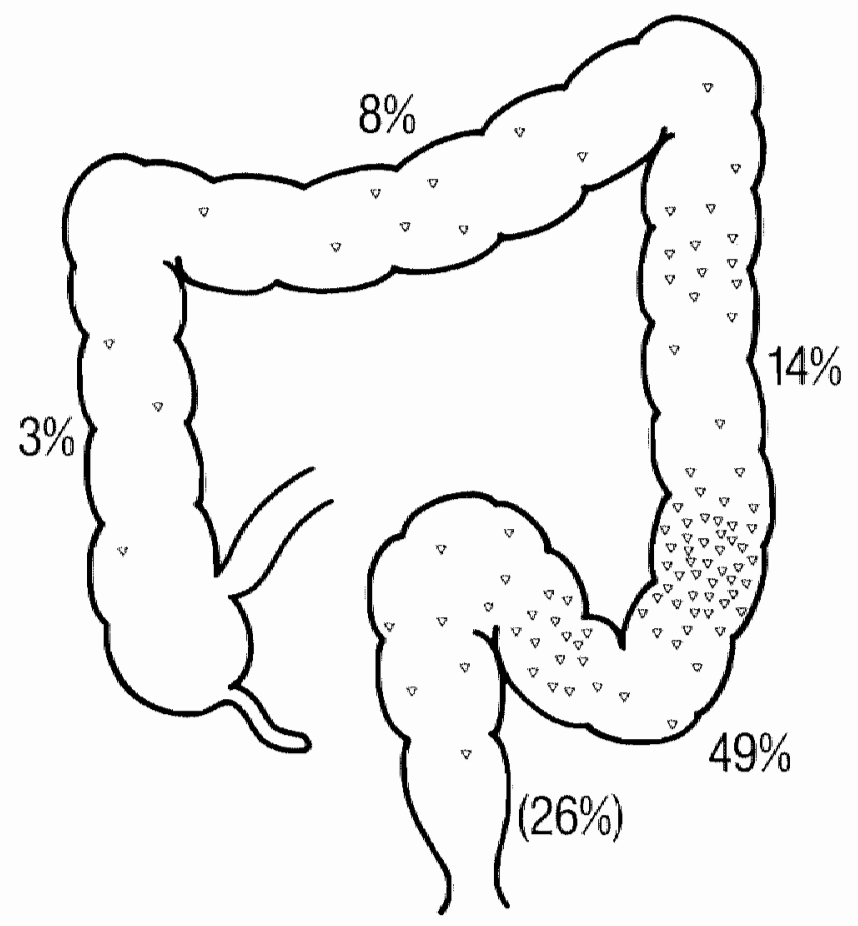

Fig. 30: Distribution of the 118 metaplastic polyps. 
Table 24: Size of metaplastic polyps.

\begin{tabular}{rcr} 
Size $(\mathrm{cm})$ & Number of polyps & $\%$ \\
\hline$<0.5$ & 92 & 79 \\
$0.6-1.0$ & 24 & 20 \\
$1.1-2.0$ & 2 & 1 \\
\hline total & 118 & 100
\end{tabular}

\section{Discussion}

The term metaplastic polyp is in this study preferred to the term "hyperplastic". As introduced by Morson (1962) the term "metaplastic" indicates a change from a normal to an abnormal epithelium, and to avoid the implications of excessive growth inherent in the word "hyperplastic".

These polyps are most commonly found in the rectum (106.113) but occasionally in other parts of the colon (7). In this study the number of metaplastic polyps found in the rectum again dit not reflect the true incidence, since an unknown number of these polyps would have been removed by rigid sigmoidoscopy. This is the reason that the majority of these polyps $(49 \%)$ were found in the sigmoid

Regarding the size of these metaplastic polyps, $79 \%$ were $0.5 \mathrm{~cm}$ in diameter or less. Only one per cent of these polyps were larger than $1.1 \mathrm{~cm}$ in diameter, a fact also stressed by Gibbs (1978).

In this study, a total number of 675 polyps were found lless than 0.5 $\mathrm{cm}$ in diameter, if the rectum is excluded. The number of metaplastic polyps in the colon (without rectum) is 88 . This means an incidence of $13 \%$ of metaplastic polyps in all minute colonic lesions less than $0.5 \mathrm{~cm}$ in diameter.

In the rectum by contrast, Lane and Lev (1963) pointed out that the metaplastic polyp is by far the most common lesion.

The finding of a carcinoma in one patient in the same area as the metaplastic polyps is probably a chance occurrence. As stressed by other authors $(7,91,106)$ no relation has been found in this study between metaplastic polyps and carcinoma. 
Inflammatory polyps

Fig. 31 and table 25 and 26 shows the distribution and size of Iymphoid polyps and inflammatory polyps, the latter usually occurring in patients with longstanding ulcerative colitis. Not all inflammatory polyps seen endoscopically were removed, only in case of large size or doubtful nature is the polyp removed for histological verification. Although other small inflammatory polyps were found in association with other types of inflammatory bowel disease (Crohn's disease. ischaemic disease), none were large enough to merit polypectomy

\section{Discussion}

Regarding distribution, although the rectal incidence is not representative, the sigmoid colon is by far the most common place to find these polyps $(50 \%)$, only a few polyps were found in the right colon. Most of the polyps were less than $2.0 \mathrm{~cm}$ in diameter, the majority however being less than $0.5 \mathrm{~cm}$ large.

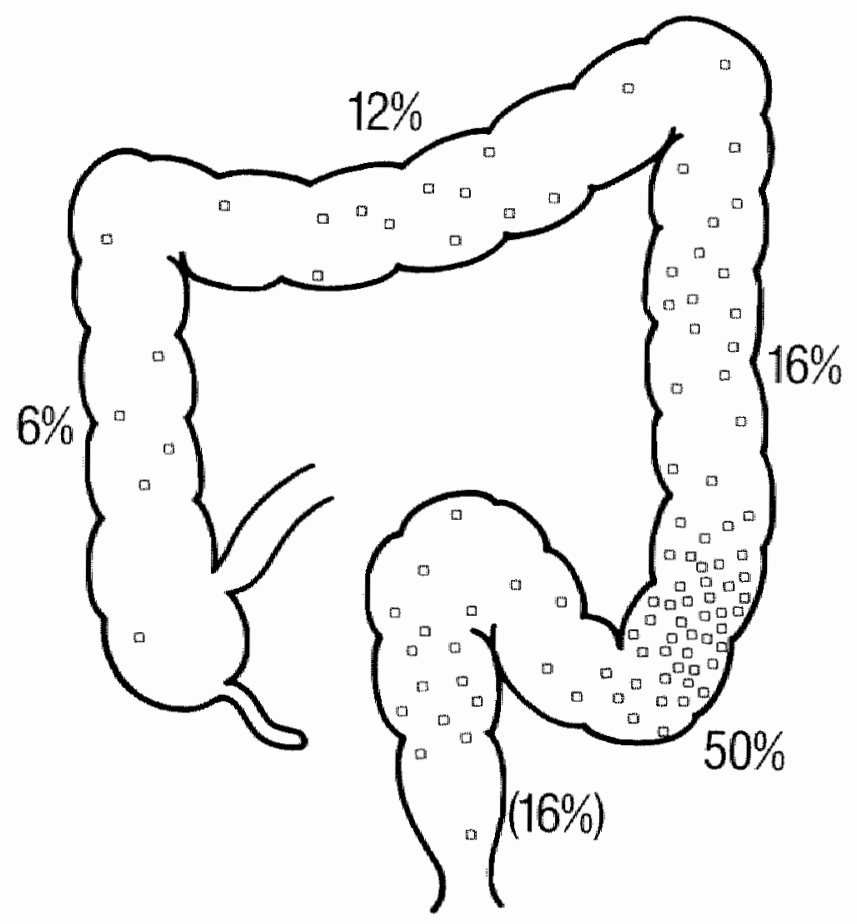

Fig. 31: Distribution of the snared intlammatory polyps. 
Table 25: Distribution of snared inflammatory polyps.

\begin{tabular}{lcc} 
Site & Number of polyps & $\%$ \\
\hline rectum & $(5)$ & $(16)$ \\
sigmoid & 16 & 50 \\
descending colon & 5 & 16 \\
transwerse colon & 4 & 12 \\
ascending colon & 2 & 6 \\
\hline total & 32 & 100
\end{tabular}

Table 26: Size of snared inflammatory polyps.

\begin{tabular}{rrr} 
Size $(\mathrm{cm})$ & Number of polyps & or \\
\hline$<0.5$ & 11 & 34 \\
$0.6-1.0$ & 7 & 22 \\
$1.1-2.0$ & 12 & 38 \\
$2.1-3.0$ & 2 & 6 \\
\hline total & 32 & 100
\end{tabular}

The total number of 32 polyps found in this study does not reflect the true incidence, since most of the inflammatary polyps with their typical endoscopic appearances were left unremoved. However. mucosal biopsies were taken from many of these unremoved polyps as well as from the surrounding mucosa in longstanding ulcerative colitis patients to rule out malignant changes. These biopsies and the relation between ulcerative colitis and carcinoma is not the subject of this study. 


\subsection{Malignant adenomas and polypoid carcinomas: removable polyps}

The figures of all malignant adenomas and polypoid carcinomas which were completely removed colonoscopically will be rewiewed here. Obviously, the histological assessment is the most important criterion of completeness of excision. Therefore, some of the patients needed further surgical treatment because of incomplete removal, while others did not.

The histological criteria to determine malignancy have been described by Fenoglio et al (1973) and Muto et al (1975) including the criteria for completeness of excision (188). If areas of carcinoma invade the muscularis mucosae, not reaching the resection line, excision is regarded as complete (fig. 32). However, the degree of tumour differentiation plays an important role. If the tumour is welldifferentiated, a conservative policy including careful follow-up is justifiable, because the risks of operative mortality and morbidity are problably greater than the patient having lymphatic metastases. A moderately differentiated tumour gives a risk of 5-10 per cent of Iymphatic secondaries, and therefore local excision is justifiable. A poorly differentiated tumour is a definite indication for local excision since there is about a 15 per cent risk of lymphatic secondaries (188)

When invasion reaches the resection line, it should be assumed to have spread into the submucosa or the muscularis propria and therefore the resection is incomplete. In this case, surgery should be advised.
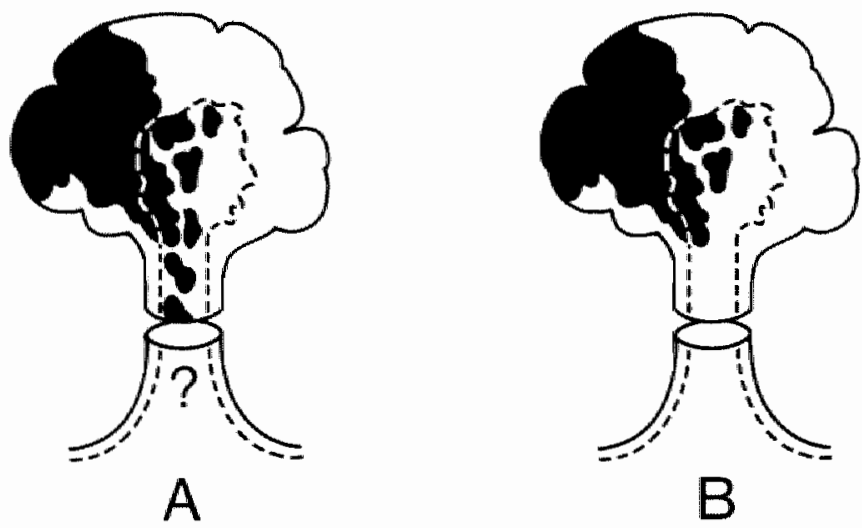

Fig. 32: Araes of carcinoma invading the muscularis mucosae and the resection line.

A. incomplete excision.

B. complete excision. 
Whether surgery should be undertaken depends upon several other conditions such as the age and general condition of the patient. If the risk of possible post-operative complications will exceed the possible risks from carcinomatous spread in terms of time and quality of life, operation should not be performed. This pollicy is of course individually determined in each patient.

The figures presented here represent only the completely removed malignant adenomas as judged colonoscopically and histologically. The unremovable polyps are reviewed in chapter 4.5 .

A total number of 38 patients were found to have 40 malignant adenomas or polypoid carcinomas completely removed by colonoscopic snare polypectomy. Two patients had two malignant adenomas each. The distribution of these polyps is shown in fig. 33 and table 27 which also shows the numbers of the three types of malignant adenomas (tubular, tubulo-villous and villous adenomas) and the polypoid carcinomas separately. Their relation to benign adenomas and localization is shown in table 28 , whereas the malignancy incidence related to size is shown in table 29.

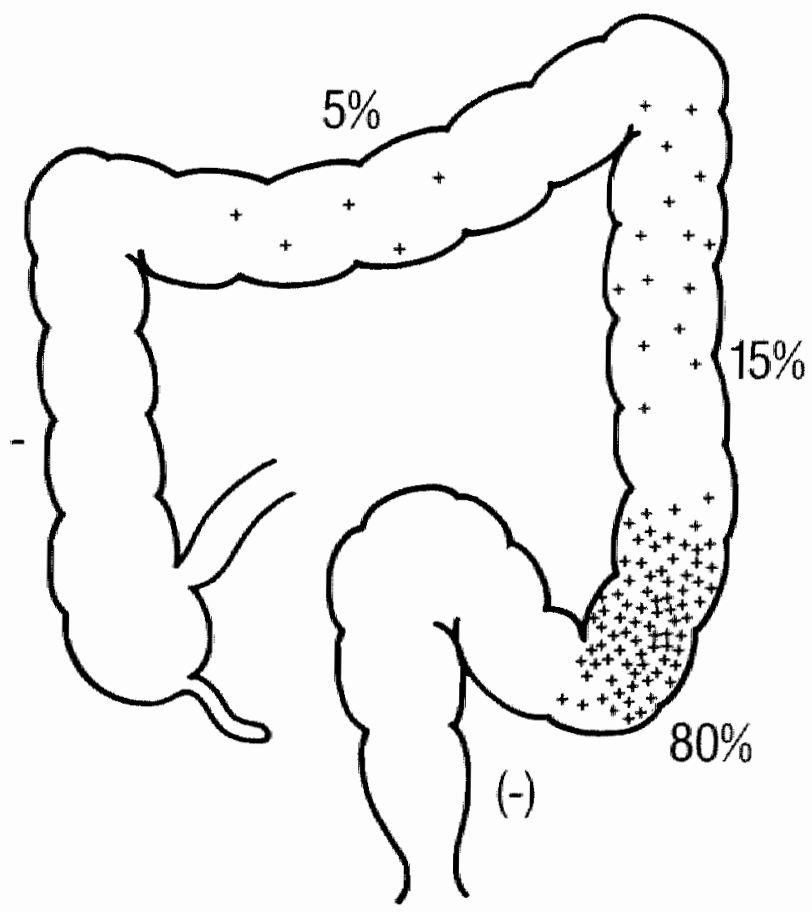

Fig. 33: Distribution of the malignant adenomas and polypoid carcinomas. 
Table 27: Distribution of the malignant adenomas and polypoid cancinomas.

\begin{tabular}{|c|c|c|c|c|c|c|}
\hline & \multicolumn{3}{|c|}{ invasive carcinamo } & \multirow{2}{*}{$\begin{array}{l}\text { polypoid } \\
\text { carcinoma }\end{array}$} & \multirow[t]{2}{*}{ total } & \multirow[t]{2}{*}{$\%$} \\
\hline & fubular & tubulovillous & villous & & & \\
\hline rectum & - & - & - & - & - & - \\
\hline sigmoid & 20 & 8 & 2 & 2 & 32 & 80 \\
\hline descending colon & 3 & 2 & 1 & - & 6 & 15 \\
\hline transwerse colon & - & 1 & 1 & - & 2 & 5 \\
\hline ascending colon & - & - & - & - & - & - \\
\hline rotal & 23 & 11 & 4 & 2 & 40 & 100 \\
\hline$\%$ & 57 & 28 & 10 & 5 & 100 & \\
\hline
\end{tabular}

Table 28: Imcidence of malignant and benign adenomas (colonascopically removed) and their relation to localization.

\begin{tabular}{lcccccc} 
Site & \multicolumn{5}{c}{ MALIGNANT / BENIGN } \\
& \multicolumn{2}{c}{ tubular } & \multicolumn{2}{c}{ tubulo-villous } & \multicolumn{2}{c}{ villous } \\
& & $\%$ & & $\%$ & & $\%$ \\
\hline rectum & $-/(40)$ & - & $-/(12)$ & - & $-/(2)$ & - \\
sigmoid & $20 / 442$ & 5 & $8 / 118$ & 7 & $2 / 26$ & 7 \\
descending colon & $3 / 288$ & 1 & $2 / 39$ & 5 & $1 / 16$ & 6 \\
transverse collon & $-/ 144$ & - & $1 / 23$ & 4 & $1 / 10$ & 10 \\
ascending colon & $-/ 67$ & - & $-/ 7$ & - & $-/ 4$ & - \\
\hline & $23 / 981$ & 2 & $11 / 199$ & 6 & $4 / 58$ & 7
\end{tabular}

Table 29: Incidence of malignant and benign adenomas related to size in colonoscopically removable adenomas

\begin{tabular}{|c|c|c|c|c|c|c|}
\hline \multirow{3}{*}{ Size $(\mathrm{cm})$} & \multicolumn{6}{|c|}{ MALIGNANT / BENIGN } \\
\hline & \multicolumn{2}{|c|}{ tubular } & \multicolumn{2}{|c|}{ tubulo-villows } & \multicolumn{2}{|c|}{ willous } \\
\hline & & $\%$ & & $\%$ & & $\%$ \\
\hline$<0.5$ & $-/ 385$ & - & -17 & - & $-/ 2$ & - \\
\hline $0.6=1.0$ & $-/ 360$ & - & -176 & - & $1 / 17$ & 6 \\
\hline $1.1-2.0$ & $12 / 164$ & 19 & $3 / 76$ & 4 & $1 / 22$ & 5 \\
\hline $2.1-3.0$ & $7 / 33$ & 21 & $6 / 30$ & 20 & -19 & - \\
\hline $3.1-4.0$ & $2 / 9$ & 22 & $2 / 5$ & 40 & $1 / 5$ & 20 \\
\hline$>4.1$ & $2 / 2$ & 100 & -1 & - & $1 /-$ & - \\
\hline not known & 28 & & 4 & & 3 & \\
\hline total & $23 / 981$ & 2 & $11 / 199$ & 6 & $4 / 58$ & 7 \\
\hline
\end{tabular}


The size of each malignant type is shown in table 30, the smallest being $1.0 \mathrm{~cm}$ in diameter (an adenocarcinoma in a villous adenoma) The largest polyps being over $4.1 \mathrm{~cm}$ in diameter. all of them removed piecemeal.

Table 31 shows the distribution of the polypoid lesions and their size. The majority of them being between $1.1-3.0 \mathrm{~cm}$ in diameter and located in the sigmoid colon ( 27 polyps $=67.5 \%$ ).

Table 30: Size of the malignant adenomas and polypoid carcinomas

\begin{tabular}{rrrrr|rr} 
& \multicolumn{3}{c|}{ invasive carcinoma } & polypoid & total & \% \\
Size $(\mathrm{cm})$ & tubular & tubulovillous & villous & carcinoma & & \\
\hline$<0.5$ & - & - & & - & - & - \\
$0.6-1.0$ & - & - & 1 & - & 1 & 2.5 \\
$1.1-2.0$ & 12 & 3 & 1 & 1 & 17 & 42.5 \\
$2.1-3.0$ & 7 & 6 & - & 1 & 14 & 35 \\
$3.1-4.0$ & 2 & 2 & 1 & - & 5 & 12.5 \\
$>4.1$ & 2 & - & 1 & - & 3 & 7.5 \\
\hline total & 23 & 11 & 4 & 2 & 40 & 100 \\
$\%$ & 57 & 28 & 10 & 5 & 100 &
\end{tabular}

Table 31: Relation between size and localization of the malignant adenomas and polypoid carcinomas.

\begin{tabular}{|c|c|c|c|c|c|c|c|}
\hline Size $(\mathrm{cm})$ & reclum & sigmoid & $\begin{array}{l}\text { descending } \\
\text { calon }\end{array}$ & $\begin{array}{c}\text { transverse } \\
\text { calon }\end{array}$ & $\begin{array}{l}\text { ascending } \\
\text { colon }\end{array}$ & total & $\%$ \\
\hline$<0.5$ & - & - & - & - & - & - & - \\
\hline $0.6-1.0$ & - & 1 & - & - & - & 1 & 2.5 \\
\hline $1.1-2.0$ & - & 15 & 2 & - & - & 17 & 42.5 \\
\hline $2.1-3.0$ & - & 12 & 2 & - & - & 14 & 35 \\
\hline $3.1-4.0$ & - & 3 & 1 & 1 & - & 5 & 12.5 \\
\hline$>4.1$ & - & 1 & 1 & 1 & - & 3 & 7.5 \\
\hline total & - & 32 & 6 & 2 & - & 40 & 100 \\
\hline$\%$ & & 80 & 15 & 5 & - & 100 & \\
\hline
\end{tabular}


The results of the barium enemas were reviewed in regard to the clinical symptoms (table 32 ). In $21 \%$ of the 38 patients, the barium enema showed no signs of polyps, the colonoscopy being performed because of persistent rectal bleeding.

Table 32: Clinical symptoms and bartum results in patients with malignant adenomas and polypoid carcinomas.

\begin{tabular}{lcc} 
Rectall bleeding & $\begin{array}{c}\text { barium enema } \\
\text { no polyp }\end{array}$ & $\begin{array}{c}\text { barium enema } \\
\text { polyp }\end{array}$ \\
$\begin{array}{l}\text { Others: follow-up } \\
\text { abdominal pain } \\
\text { constipation }\end{array}$ & 8 & 24 \\
\hline rotal & 8 & 2 \\
$\%$ & 21 & 3 \\
\hline & & 30 \\
\hline
\end{tabular}

After histological assessment, 28 polyps (70\%) were found to be completely removed, while the other 12 polyps $(30 \%)$ were incompletely excised (table 33 ). The patients with completely removed polyps were not subjected to surgery, but regularly checked by colonoscopy. The others were advised to have surgery. Two patients, however, did not have surgery because of age and medical problems contraindicating surgery; no information could be obtained on the subsequent management of three patients. Of the seven patients who were advised to have surgery, three patients had residual carcinoma found in the resected specimen, while in the other four patients $(57 \%)$ no carcinoma was found (table 34 ).

Table 33: Completeness of excision in malignant adenomas and polypoid carcinomas.

$\begin{array}{cc}\text { complete removal } & 28(70 \%) \\ \text { incomplete removal } & 12(30 \%) \\ \text { surgery }: 7 & \\ \text { no surgery : } 2 & \\ \text { not known : } 3 & \end{array}$


Table 34: Results of surgery after incomplete removal of a matignant adenoma or a polypoid carcinoma.

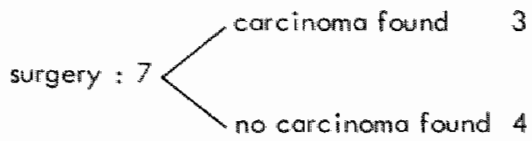

The relation between the size of the polypoid lesion and the completeness of excision is shown in table 35 . In the size range between $1.1,-3.0 \mathrm{~cm}$ in diameter, 24 polyps $(74 \%)$ were completely excised, while only seven polyps $(26 \%)$ could not be excised completely. In the larger size range, over $3.1 \mathrm{~cm}$ in diameter, the majority could not be completely removed ( $5 / 8$ polyps $=62.5 \%)$.

The completeness of excision related to the type of malignancy is shown in table 36. Only two polypoid carcinomas were completely excised, whereas 26 out of 38 adenocarcinomas arising in adenomas could be excised completely.

Table 35: Completeness of excision according to size.

\begin{tabular}{rcl} 
Size $(\mathrm{cm})$ & complete & incomplete \\
\hline$<0.5$ & - & - \\
$0.6-1.0$ & 1 & - \\
$1.1-2.0$ & 14 & 3 \\
$2.1-3.0$ & 10 & 4 \\
$3.1-4.0$ & 2 & 3 \\
$>4.1$ & 1 & 2 \\
\hline tatal & $28(70 \%)$ & $12(30 \%)$
\end{tabular}

Table 36: Relation between type of malignancy and completemess of excision.

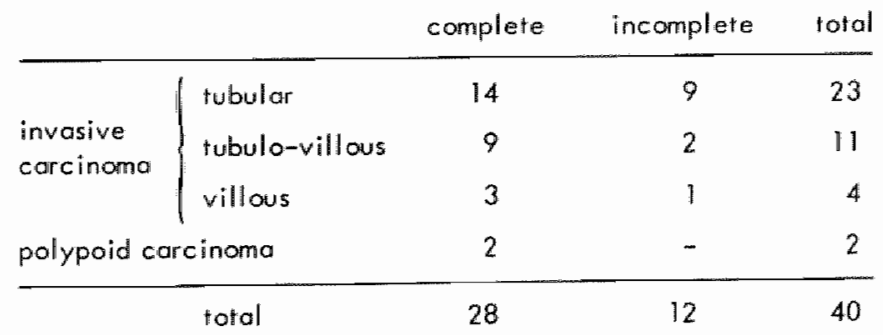


The length of follow-up and the number of patients with complete removal with or without evidence of residual cancer is shown in table 37. Twenty-two patients did not show any sign of malignancy in the follow-up period, ranging from six months to more than four years: two patients with three malignant adenomas were lost for follow-up. while another two patients showed signs of metastasis.

The first patient was an 80 year old man complaining of blood loss per rectum. A barium enema showed wo polypoid lesions in the signoid and descending colon. Afler colonoscopic polypectomy. the lesion in the desceriding collon was shown to be a tubular adenoma. while in the sigmoild colon, a $1.8 \mathrm{~cm}$ pedunculated adenocarcinoma arising in a lubular adenoma was found. The excision was histologically complete. The patient refused follow-up colonoscopy. Nineteen months later the patient died and postmortem examination showed diffuse abdominal metastasis of a colonic carcinoma.

The second patient was a 75 year ald woman who came in complaining of blood loss per rectum. A batium enema performed at her local hospital showed no abnormality. Because of persistent blood loss, a colonoscopy was performed. A $2.2 \mathrm{~cm}$ polypoid lesion in the sigmoid was tound and excised. Histology showed a completely excised adenocarcinoma in a tubulo-willous adenoma. Three months later, howewer, just before the first follow-up colonoscopy was to be performed. she was admitted to her local hospital because of small bowel obstruction. A diffuse carcinomatosis was found, histologically probably originating from the owary or the collon. No definite origin of the carcinomalosis could be determined.

The patients with incomplete colonoscopic removal who had surgery were follawed-up for a period of six months to more than four years and none of them showed signs of carcinoma (table 38). This table shows also the follow-up of the two patients who were judged to be too great a risk for operation. They were without signs of carcimoma two and three years after polypectomy.

Table 37: Follow-up of patients with complete removal.

\begin{tabular}{rcc} 
Years & No residual cancer & Residual cancer \\
\hline $1 / 2-1$ & 5 & 1 \\
$1-2$ & 5 & 1 \\
$2-4$ & 10 & - \\
$>4$ & 2 (3 palyps) & - \\
\hline total & 22 & 2
\end{tabular}

lost for follow-up: 2 patients ( 3 polyps) 
Table 38: Follow up of patients with incomplete removal.

\begin{tabular}{cccccc} 
Years & $\begin{array}{c}\text { No residual } \\
\text { cancer }\end{array}$ & $\begin{array}{c}\text { Residual } \\
\text { cancer }\end{array}$ & & $\begin{array}{c}\text { No residual } \\
\text { cancer }\end{array}$ & $\begin{array}{c}\text { Residual } \\
\text { cancer }\end{array}$ \\
\hline $1 / 2-1$ & 1 & - & - & - \\
$1-2$ & 1 & - & 1 & - \\
$2-4$ & 1 & - & 1 & - \\
$>4$ & 4 & - & - & - \\
\hline total & 7 & 0 & 2 & 0
\end{tabular}

\section{Discussion}

A large number of these patients with malignant adenomas or polypoid carcinomas presented with rectal bleeding as the main clinical symptom $(32 / 38=84 \%)$. Only a few had other complaints. All these patients underwent a barium enema, but still no polyp was seen in eight patients (21\%), all of them with rectal bleeding. These radiologically missed polyps were all located in the sigmoid colon. stressing the fact again that this part of the large bowel is the most difficult to visualize optimally on X-ray (188). In patients with persistent bleeding and a negative barium enema, a colonoscopy should be performed.

It is obvious from table 27 that most of the endoscopically completely removed malignant adenomas and polypoid carcinomas were located in the left colon. The most obvious explanation is the early presence of symptoms in left sided lesions, while the right sided polyps are discovered by chance or when they reach a large size. The incidence of malignancy in adenomas is shown in table 28. However, these are only the colonoscopically removable malignant adenomas and does not represent the total incidence of malignant adenomas. This total incidence is impossible to determine, as described in chapter 4.5. Even in case of removable malignant adenomas the incidence of malignancy in villous adenomas is $7 \%$ compared to $2 \%$ in tubular adenomas.

As presented in table 35 completeness of excision decreases as the size increases. More of the large malignant adenomas were judged incompletely removed, large size possibly being an indication that the lesion was of long standing. The smallest malignant adenoma was found in a villous adenoma, its diameter between $0.6-1.0 \mathrm{~cm}$. No smaller carcinomas were found in this study. 
From the histological point of view, the grade of malignancy determines also the completeness of removal. Poorly differentiated malignancy indicates surgery regardless of "complete removal". Although poorly differentiated adenocarcinoma occurring in ademomatcus polyps is unusual, but if diagnosed, surgery should be attempted, as there is a significant risk of lymph node metastases having already occurred in such cases (112 A, 188). Williams (1976) suggested that even after complete removal of a moderately differentiated tumour, local excision is justified. This policy has however changed in recent years and at present an expectant policy including frequent follow-up colonoscopy is advised.

Even when histological assessment showed the carcinoma as not completely removed, at surgery four patients $(57 \%)$ showed no signs of residual carcinoma. This justifies consideration of the indications of surgery in patients with an uncompletely removed malignant adenoma. If major contra indications against colonic surgery are present, such as cardiac, pulmonary or other internal problems. careful colonoscopic follow-up could be attempted, until local recurrence necessitates surgical intervention.

Table 36 shows the relation between type of malignancy and completeness of excision. Based on these figures, no correlation could be established regarding type of the adenocarcinoma and whether the excision is complete or incomplete.

On follow-up, $22(85 \%)$ out of 26 patients with complete colonoscopic excision showed no signs of residual tumour or recurrence, while two patients were lost from follow-up. One patient showed signs of carcinomatosis of the colon, but this might have been discovered in an early phase if the patient had not refused follow-up colonoscopy. The other patient showed carcinomatosis causing small bowel obstruction several months after complete colonoscopic removal of a malignant adenoma. Since no definite origine of the carcinomatosis. could be established it is still questionable whether the malignant adenoma caused the spread.

Overall, the prognosis of patients with malignant adenomas must be considered good. The operated patients showed no signs of residual tumour, while only one patient showed carcinomatosis of the colon after complete removal. The temporary overall result is a $97 \%$ cure rate, but the follow-up period is still short. 


\subsection{Unremovable polyps}

Including those unremovable by snare polypectomy or shown to be malignant and requiring surgery).

Apart from the polyps just described in chapters 4.1 to 4.4 . a number of polyps could not be removed by snare polypectomy despite several attempts. These polyps were usually large in size and most of them sessile. If polyps were judged endoscopically unremovable only a forceps or snare biopsy was taken for histological assessment. Other polyps were removed piece-meal, but the removal was incomplete with adenomatous or the possibility of carcinomatous tissue left, as judged by the endoscopist or histology report. In some cases difficult location of the polyp could make removal impossible despite various changes in position of the patient or using various colonoscopes These unremovable polyps were seperately studied. They form an important group, particularly because of their size. As stressed before, the chance of maligancy is strongly increased in large polyps (see chapter 2.4).

\section{Material}

In a total of 61 patients 65 polyps were found unremovable colonoscopically. They form $4 \%$ of all the polyps managed by snare polypectomy. In location, 36 polyps were found in the left colon, while 29 polyps were located in the right part of the large bowel. A detailed distribution is shown in table 39 and fig. 34 .

Table 39 . Distribution of the unremovable poiys.

\begin{tabular}{lcc} 
Site & Number of polyps & $\%$ \\
\hline rectum & $(2)$ & $(3)$ \\
sigmoid & 25 & 38 \\
descending colom & 9 & 14 \\
transverse colon & 9 & 14 \\
ascending colon & 20 & 31 \\
\hline \multicolumn{1}{c}{ total } & 65 & 100
\end{tabular}




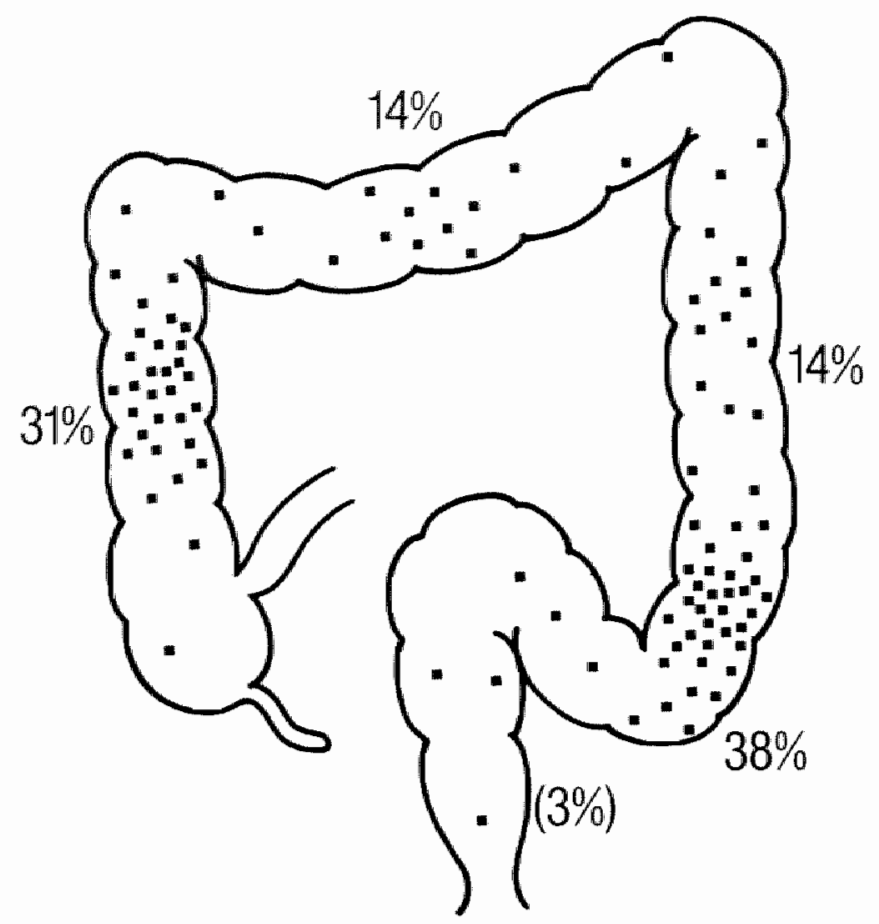

Fig. 34: Distribution of the 65 unremowable polyps

Table 40: Size of the unremovable polyps.

\begin{tabular}{rrr} 
Size $(\mathrm{cm})$ & Number of polyps & $\%$ \\
\hline$<0.5$ & - & - \\
$0.6-1.0$ & - & - \\
$1.1-2.0$ & 9 & 14 \\
$2.1-3.0$ & 27 & 42 \\
$3.1-4.0$ & 25 & 38 \\
$4.1-5.0$ & 3 & 5 \\
$>5.1$ & 1 & 1 \\
\hline total & 65 & 100
\end{tabular}


Table 40 shows the size of these polyps as estimated by the endoscopist. The configuration (judged by the endoscopist) shows 64 polyps as being sessile, whille only one polyp was pedunculated (polypoid carcinoma), located in the ascending colon. The relation between size and location is shown in table 41 .

Histological assessment could be achieved from the biopsy material taken by forceps or snare. The histological results are shown in table 42 . while the location of these various types of polyps being showm in table 43 .

All the patients with these unremovable or incompletely removed polyps were sent back to their referring consulltants with surgical advise. The results of these advises on surgical management could not be analysed. Several efforts were made, including letter writing and questioning by telephone to the widespread located referring hospitals. However, poor response and insufficient data were obtained on the surgical procedures and the definite histological assessment. Therefore, no representative analysis on these unremovable polyps could be performed.

Table 41: Relation between size and location of the unremovable polyps

\begin{tabular}{rrrrrr|r} 
Size $(\mathrm{cm})$ & rectum & sigmoid & descending & transverse & ascending & total \\
\hline$<0.5$ & - & - & - & - & - & - \\
$0.6-1.0$ & - & - & - & - & - & - \\
$1.1-2.0$ & - & 3 & 3 & - & 3 & 9 \\
$2.1-3.0$ & - & 10 & 2 & 8 & 7 & 27 \\
$3.1-4.0$ & 2 & 9 & 3 & 1 & $\left.10^{*}\right)$ & 25 \\
$4.1-5.0$ & - & 3 & - & - & - & 3 \\
$>5.1$ & - & - & 1 & - & - & 1 \\
total & 2 & 25 & 9 & 9 & 20 & 65 \\
\hline
\end{tabular}

*) one polyp pedunculated, all others sessile 
Table 42: Histology of the urremovable potyps.

\begin{tabular}{lrr} 
Histology & Number of polyps & $\%$ \\
\hline tubular & 14 & 22 \\
tubulo-villous & 9 & 14 \\
villous & 15 & 23 \\
adlenocarc. in TA & - & - \\
& 1 & 1 \\
TV & 5 & 8 \\
polypoid carc. & 21 & 32 \\
\hline
\end{tabular}

*) $\mathrm{TA}=$ tubular adenoma

$T V=$ tubulo-villous adenoma

$V A=$ villows adenoma

Talole 43: Relation between histological types and location of the unremovable poryps

\begin{tabular}{|c|c|c|c|c|c|c|}
\hline Histology & rectum & sigmaid & descending & transwerse & ascending & lotal \\
\hline trubular & - & 12 & 1 & 1 & - & 14 \\
\hline tubulo-villous & 2 & 2 & 1 & 3 & 1 & 9 \\
\hline villows & - & 2 & 1 & 1 & 11 & 15 \\
\hline adenaca. in TA & - & - & - & - & - & - \\
\hline TV & - & 1 & - & - & - & 1 \\
\hline VA & - & - & 1 & 1 & 3 & 5 \\
\hline polypoid carc. & - & 8 & 5 & 3 & 5 & $2 \pi$ \\
\hline tethal & 2 & 25 & 9 & 9 & 20 & 65 \\
\hline
\end{tabular}

\section{Discussion}

The location of these unremovable polyps shows a large part being in the ascending colon (31\%), in contrast to the distribution of the neoplastic polyps found in this study (see fig. 25). This could mean that polyps in the right part of the colon are difficult to remove colonoscopically because of the technical difficulties in reaching the right colon and to have the polyp in proper position in front of the colonoscope. Another more important feature is that an undue proportion of sessile villous polyps occur in the ascending colon and 
caecum (tables 41,42 and 43 ) and are larger because they grow silent. In the ascending colon, eight polyps out of the 20 were malignant. Five of them were polypoid carcinomas, while the other three were adenocarcinomas arising in villous adenomas. As would be expected. most of these polyps were unremovable because of their size (the majority of them $(80 \%)$ being between 2.1 and $4.0 \mathrm{~cm}$ in diameter) but in addition the sessile configuration of these polyps was technically a major problem; all but one being sessile in this group. A pedunculated polyp, even if it is large, can be removed piece-meal and complete removal is possible. But in sessile polyps, especially large ones, although piece-meal removal is sometimes theoretically possible there is a risk either of a perforation because of too much tenting of the bowel wall or on the other hand of incomplete removal. Because of the narrow margin between these two risks the last situation will generally occur resulting in these polyps being regarded as incomplete removed. The experience of the endoscopist will also determine whether a polyp is uncompletely removed or judged as unremovablle before making any attempt.

Even if a biopsy has proven an unremovable polyp to be benign. surgery must generally spoken be the next step. As mentioned previously (see chapter 2.4.3), a biopsy of a polyp does not necessarily reflects its true nature and complete removal is the only way to ensure that no malignant focus has been left. If there are stringent contraindications to surgery, collonoscopic follow-up and multiple biopsies or partial removal of the polyp is the proper way of management, untill an absolute indication for surgery arises, if and when proven malignancy occurs, hopefully before metastases. 


\section{5 complications}

As colonoscopy is the initial procedure of the colonoscopic

polypectomy, the complications of 3500 colonoscopies (including the 972 examinations with polypectomy) will be described in this chapter. The complications are divided in four categories:

5.1. General complications.

5.2. Haemorrhage.

5.3. Perforation.

5.4. Death.

\subsection{General complications}

General complications occurred due to either the medication or the procedure itself.

Thrombo-phlebitis due to intravenous diazepam injection is known to have occurred in five patients, but as no routine survey was made in the post-examination period, the incidence may have been significantly higher. Injections were routinely made into the largest available vein, usually in the antecubital fossa, in order to reduce the risk of this complication.

Abdominal distension occurred in two elderly patients causing the procedure to be abandoned; it was shown radiographically to be due to small-intestimal reflux of air. Minor degrees of distension have occurred after colonoscopy in other patients but this discomfort is avoided by not over-insufflating and by aspirating excess air during withdrawal.

Vaso-vagal complications occurred in five patients; in three of these cases respiratory arrest or prolonged apnoea occurred after sedation, reversed by assisted ventilation. In another two cases the combination of hypotension and vomiting caused abandonment of the procedure, the 
episode reversing spontaneously with head-down posture. Other minor episodes occurred, with or without sedation (and sometimes during bowel preparation) but did not interfere with the procedure.

\subsection{Haemorrhage}

The haemorrhages are divided into three categories, "minor", "major" and "secondary (or delayed) haemorrhages". Patients with minor haemorrhage did not require bloodtransfusion, while major bleeding was managed with blood replacement and when necessary surgery. Secondary haemorrhage was defined as obvious bleeding occurring several days after polypectomy. There were 62 minor, major and secondary haemorrhages, all of them post polypectomy. Only one other episode of bleeding did not occur after a polypectomy, a minor episode complicating mucosal forceps biopsy in a patient with an angiodysplasia.

Minor haemorrhage is defined as every bleeding, even the slightest amount, occurring after polypectomy not requiring blood transfusion. This occurred in 45 patients; the bleeding stopped spontaneously in 19 patients judged to have lost less than $20 \mathrm{mls}$, and in five other patients estimated endoscopically and in the suction bottle to have lost $40-400 \mathrm{mls}$. In the remaining 21 patients, all bleeding after snare polypectomy, the bleeding stopped after local treatment with either stalk strangulation by the snare-loop; local stalk coagulation; adrenalin and ice-water application or a combination of these measures.

Major haemorrhage occurred in 13 patients after snare polypectomy, in all of whom local measures failed to control the bleeding and transfusion with 1-5 units of blood was required. The bleeding stopped spontaneously at 1-6 hours after polypectomy in ten patients but three required operative treatment since emergency angiography was unavailable. Laparotomy with colotomy and suture ligation of the stalk was performed on these patients.

Secondary (delayed) haemorrhage occurred at 5-14 days after polypectomy in five patients. In three of them bleeding stopped spontaneously without transfusion and one patient required a further colonoscopy with local coagulation, while the fifth patient, a haemophiliac, was submitted to surgery which was performed in his own hospital without being referred back for attempted endoscopic control. 
The overall bleeding rate of 63 patients in 3500 colonoscopies is $1.8 \%$. Sixly-two of these haemorrhages following 1326 snare polypectomies, thus representing a post polypectomy haemorrhage rate of $4.7 \%$ with major haemorrhage in 13 patients $(0.9 \%)$. The size range of bleeding polyps is shown in table 44 .

Table 44: Relation between polyp (head) size and haemorthage.

\begin{tabular}{rccc} 
Size $(\mathrm{cm})$ & $\begin{array}{l}\text { Minor } \\
\text { No. }(\%)\end{array}$ & $\begin{array}{l}\text { Major } \\
\text { No. }(\%)\end{array}$ & $\begin{array}{c}\text { Secondary } \\
\text { No. }\end{array}$ \\
\hline $0.5-1.0$ & 5 & - & - \\
$1.1-2.0$ & $18(30)$ & - & - \\
$2.1-3.0$ & $17(27)$ & $7(11)$ & 2 \\
$3.1-4.0$ & - & $4(6)$ & 2 \\
$>4.1$ & 2 & 2 & - \\
Unknown & 3 & - & 1 \\
\hline total & 45 & 13 & 5
\end{tabular}

\subsection{Perforation}

Four frank perforations occurred in this series, three during diagnostic colonoscopy and the fourth after attempted polypectomy. Two other patients developed transient localised abdominal tenderness and short-lived pyrexia 12 hours after polypectomy without free abdominal air radiologically; both were managed conservatively with antibiotic cover and spontaneous recovery. In one of these patients subsequent laparotomy for other reasons confirmed the clinical suspicion of a "sealed perforation". while in another two patients who were symptomless after polypectomy later operation also showed evidence of full-thickness damage at the polypectomy site sealed by adherent omentum or small intestine. The four patients with frank perforations will be described here.

\footnotetext{
- A 69 year ald woman with an unexplained sigmoid colon stricture on $X$-ray had a fixed loop in the distal sigmoid colon, perforated withoul obviously undue force. Laparotomy revealed extensive carcinomatosis involwing the perforated bowel. The patient recovered uneventfully but died 18 months later.
} 
- A s9 vear old man prowed difficulf to examine, the fwo-channel instrument looping the sigmold colon. The single-channel instrument was reinserted and passed through the bowel wall at the apex of the sigmoid loop. without any obviously excessive force being used. Damage to the bowet wall may have occurred with the first instrument facillating perforation with the tip of the second. The laceration was oversewn at operation and the patient made an uneventful recovery.

- A 55 year old woman was examined with the two-channel colonoscope. an alpha-loop being noted in the sigmoid colon during insertion. On withdrawal there was fresh blood in the mid-sigmoid colon and extracolonic fat was seen. Al operation there was $1500 \mathrm{mls}$ blood in the abdominal cavily, the bleeding point was ligated. the laceration oversewn and the patient made an unewentful recovery.

- A 58 year old man with previous ureteric implants into the colon developed unexplained rectal bleeding. Full clinical details were not avalable at the time of endoscopy and he was thought to have ureterosigmoidostomies. A $3.5 \mathrm{~cm}$ irregular polypoid lesion was seen in the mid-descending colon and after snare removal the patient experienced severe pain. The polypectomy specimen showed cystic clilation in an ureteric stoma without evidence of a malignancy. Since renal function on the affected size was prewiously known to be insignificant. nephrectomy was performed and atter a protracted post-operatiwe course. the patient recovered (59).

\title{
5.4. Death
}

\begin{abstract}
Alter the 3500 colonoscopies performed two patients $(0.05 \%)$ died. One death appeared to be directly related tot the sedation used for colonoscopy and the other resulted from mismanagement of an ischaemic episode, apparentlly consequent on colonoscopy.
\end{abstract}

\footnotetext{
- A 75 year old woman with possible carcinoma of the ascending colon was. judged to be a poor operative risk and referred for colonoscopic biopsy. 15 mgs imtravenous diazepam and 25 mgs intravenous pethidine were given by slow intravenous infusion at the start af the procedure. During technical difficulties in passing the sigmoid colon. the patient became distressed and further sedation was necessary in order to continue the procedure. Thirty minutes after the initiall dose, an additionall 10 mgs intravenous diazepam and 25 mgs intravenous pethidine was given ower two minutes and the procedure then continued uneventfully. The radiological diagnosis of cancer was contirmed.

The patient was still sedated but apparently in good state at the end of the examination fifteen minutes later. Fiwe minules after terminating the colonoscopy however, she was noted to be pulseless and apnoeic Although cardiac resuscitation and intubation were immediately instituted and spontaneous pulse and respiration established within 30 seconds the patient remanned hypotensive, her condition deteriorated and she died wo days later. Post mortem examination gave the cause of death as circulatory fallure due to myocardial degeneration.
} 


\begin{abstract}
- A 74 year old woman with unexplained anaemia proved extremely diflicull to collonoscope. Three different instruments were used before the proximall sigmoid colon could be passed and total colonoscopy periormed with normal findings. The patient was transferred back to the referring hospital and at the time of discharge the following day she complained of some left iliac fossa pain. Her symptoms continued at home during the next three days with conservative management by her own doctor. without reference to any hospital. When subsequently admitted 10 a small local hospital as an emergency four days after colonoscopy, her condition deteriorated rapidy and she died before full resuscitation or operation was possible. The cause of death at post montem examination was given as ischaemic colitis of the sigmoid colon, possibly related to colonoscopic trauma.
\end{abstract}

\title{
5.5. Discussion
}

The colon is a long and tortuous organ which requires vigorous cleansing before examination. Even a barium enema is regarded by most patients as an extremely disagreeable experience and intubation with an endoscope is potentially more traumatic. The patients submitted for these examinations are often elderly and infirm and some patients are specifically selected for colonoscopy because they are judged unfit for surgery. It is, if anything, surprising that such a group of patients traumatised with bowel preparation and instrumentation do not have a higher complication rate. In the first 850 colonoscopic examinations no complication occurred. With greater numbers the reported complications ensued and the haemorrhages followed the institution of colonoscopic polypectomy. The development of more flexible and more acutely-angling colonoscopes should reduce the number of perforations expected in diagnostic colonoscopy since they make the more forceful manoeuvres, such as the alpha-loop manoeuvre, unnecessary. Geenen et al (1975) has shown that the greatest danger of complication occurs during the learning phase of colonoscopy; with more experienced colonoscopists available for teaching purposes it may be hoped that even this learning phase will become safer. The most difficult region of the colon to examine is the sigmoid colon, in which all the three diagnostic perforations occurred. The advent of flexible sigmoidoscopy and the use of large numbers of "fibre-sigmoidoscopes" by relatively unqualified endoscopists seems likely to increase the complication rate as well as the diagnostic yield.

Some patients can become significantly dehydrated after the diarrhoea induced for bowel preparation, particularly if hypertonic solutions such as mannitol or magnesium sulphate are used without adequate fluid intake. The use of oral mannitol seems particularly inadvisable in view of the report (13) of a fatal colonoscopic explosion 
alter bowel preparation; this was presumably due to hydrogen formation by colomic bacteria acting on the sugar solution and ignition of the gas during polypectomy (105).

Instrumentation or distension of the colon is a profound vagal stimulus, sufficient to cause nausea, bradycardia, cardiac irregularity or hypotension. The additional use of sedation such as diazepam or pethidine can potentiate these effects or cause primary respiratory depression. particularly if the medication is given in a rapid bolus injection. The availability of intravenous naloxone (Narcan $0.4 \mathrm{mgs}$ iv) as an instant oplate antagonist is a valuable addition to the endoscopist's emergency kit; its use enables a small dose of an opiate such as pethidine to be safely used even in elderly patients, thus reducing the dose of diazepam employed, for which no antagonist is available. Other essential emergency measures include the use of a tipping-table, the availability of a resuscitation bag (Ambu) and nursing staff trained to observe the patient carefully, particularly at the start of the procedure. No routinely blood pressure or cardiographic monitoring were employed, which might be desirable in high-risk patients.

Of the two patients in these series with a fatal outcome, one was probably over-sedated; as a result of this experience less sedation is to be used, especially in older patients. It is advisable to be prepared to abandon an examination unless clinically essential and if a similar situation arose, to defer examination until supervision by an anaesthesist was possible. The second death appeared to relate to instrument trauma at the sigmoid-descending junction and would be made most unlikely by the more flexible and manoeuvreable inslruments now available. The three frank perforations in the sigmoid colon would also be less likely with modern single-channel instruments but difficult examimations still occur unexpectedly. Any colonoscopist should be aware of the possibility of perforation, particularly in a fixed loop, and should be prepared to abandon the procedure. Even in the most skilled hands, colonoscopy is sometimes technically impossible or clinically unreasonable.

No perforation occurred in these series as a result of air-pressure, possibly because of awareness of this hazard (185). Air insufflation should be gentle at all times, particularly in the presence of infllammatory bowel disease or diverticular disease. It is common practice to aspirate whenever possible, to use a reasonable minimum of insufflation to obtain an adequate view and never to continue insufflation unless the patient is comfortable. Because it is more rapidly re-absorbed it is felt that carbon dioxide insufflation may be 
increasingly used for diagnostic collonoscopy in the future.

The reason for the relatively large number of haemorhages occurring after polypectomy in these series $(3.3 \%)$ is uncertain but may be partly due to the large number of patients referred from other hospittals with large polyps (table 44 ). The relevant measurement is the diameter of the polyp stalk rather than its head diameter; the stalle is often poorly demonstrated on barium enema and may also be difficult to measure endoscopically. Any polyp with a head diameter greater than $2 \mathrm{~cm}$ is likely to have a thick stalk and it is the policy that patients with such lesions should have blood taken for cross-matching and be admitted overnight for polypectomy. Patients with smaller polyps are normally managed as out-patients but are occasionally admitted if difficulties arise. Where a polyp stalk is seen to be $1.5 \mathrm{~cm}$ or greater in diameter, the two-snare bipolar technique (189) may" be considered. The relatively frequent occurrence of even "minor" haemorrhages after polypectomy is unwelcome and therefore it is now recommended to snare the polyp stalk at its narrowest point near the polyp head, the snare being immediately replaced lower down the stalk and strangulation applied for 15-30 minutes if any bleeding occurs. Slow oozing from a polypectomy site may be difficult to locate and coagulate but normally stops spontaneously after $2-5$ hours. Pulsatile bleeding requires active measures and it is found that for this purpose the greater suction capacity of a two-channel endoscope or some fibre-sigmoidoscopes is very desirable. Persistent haemorthage can also be arrested anglographically with embolisation. although this technique was not available at the time of the postpolypectomy haemorrhages requiring operation. All the major haemorrhages in this series occurred in polyps with a head diameter greater than $2 \mathrm{~cm}$, which can normally be seen on barium enema. Such large polyps require extra care with removal in hospital where all facilities are available in case of haemorrhage. Prior review of the barium enema is therefore an important safety factor in planning polypectomy.

A survey of the literature reveals a number of case reports on complications ranging from pneumoperitoneum and bowel perforation $(61,78,104,119,133,139,142.159,169)$ to electrocardiographic and cardiac abnormalities $(3,63,144,157,177)$, volvulus $(174)$. incarceration of an incisional hernia (140) or splenic rupture (171) Larger combined series $(53,144,157)$ have suggested a complication rate related to the experience of the endoscopist, a complication rate around one in every 300-500 examinations and a mortality of one in 10,000 , the complication rate for colonoscopic polypectomy being 
higher at about one haemorrhage for 50 polypectomies and one perforation for 300 polypectomies. This complication rate for a potentially therapeutic procedure is not insignificant but satisfactory in wiew of the much greater morbidity and mortality of the abdominat surgery $(62,88,177)$ that it not infrequently replaces.

Diagnastic colonoscopy is, by surgical standards, a relatively safe procedure with few complications. The low complication rate of therapeutic colonoscopy in particular justifies it as the procedure of choice in the management of colonic polyps. The increased use of electro-surgical procedures or diathermy of small haemangiomas or telangiectases and the taking of larger specimens by polypectomy or snare-loop biopsy inevitably increases the hazard of colonoscopy. If diagnostic colonoscopy and fibre-sigmoidoscopy are to fulft their true potential it is essential that the small but significant complication rate is reduced and on the basis of these experiences certain conclusions seem possible: good judgement of the condition of the patient and the colon, optimal facilities in the endoscopy unit, well trained nursing staff and last but not least the skill of the endoscopist and knowledge about his own limitations are important factors, which might reduce the number of complications 


\section{Follow-up}

Once a patient is subjected to colonoscopic polypectomy, whether follow-up is necessary depends upon the histology of the removed polyp. If the removed polyp is non-neoplastic, no follow-up is necessary because these polyps do not change into adenomas or carcinomas. Obviously, the colonic mucosa has the potential to develop non-neoplastic polyps again, but these polyps should be removed when causing symptoms. The colonic mucosa of these patients has allso the potential to produce neoplastic polyps, but the risk is probably no greater than in the normal population.

\subsection{Benign adenomas}

If the polyp is a neoplastic one, follow-up examination is certainly indicated, because the risk to develop another adenoma or carcinoma in the future. However, at present little objective evidence exists about the choice of procedure and the frequency of follow-up in these patients. The logistics of frequent follow-up by expensive techniques poses potentially serious problems far the health service, but without effective follow-up, a proven chance for cancer prophylaxis would be missed. As regarding the procedure, several methods are available, each of them with its own shortcomings and accuracies. Among these procedures are the barium enema (double contrast), several tests on occult blood in stools (gualac, Haemoccultis) and (total) colonoscopy. The stool blood test is the most simple procedure, but also the most non-specific and inaccurate for colonic adenomas. The double contrast barium enema is usually accurate in locating colonic polyps but is time consuming and laborious. Total colonoscopy is the most accurate procedure, but is even more laborious compared to the double contrast barium enema. Therefore, the most simple and accurate procedure or combination of procedures still has to be determined to follow-up colonic 
adenomas, and may differ from patient to patient. As regarding the frequency of follow-up, no agreement has been found in the literature in terms of months or years, nor even whether the follow-up should be lite-long or not.

Up to the time of this study no regular follow-up af this group of patients with colonoscopically removed adenomas had been performed because of lack of facilities. However, a prospective followup study is now under way. This prospective study will determine whether there is any significant difference in polyp/cancer pickup by follow-up at 1,3 or 5 year intervals respectively: and compare the results of history taking. Haemoccult testing for occult blood loss, rigid proctosigmoidoscopy, fibre sigmoidoscopy, total colonoscopy and double contrast barium enema as different methods of follow-up. With such controlled prospective studies it should be possible to provide evidence to formulate effective follow-up schemes for patients who are at high risk to develop colon cancer.

This prospective study includes the 500 patients previously subjected to colonoscopy and polypectomy. They have been separated into groups examined at 1 year ( \pm 3 months), 3 years ( \pm 6 months) and 5 years or more after polypectomy. After obtaining permission from the referring consultant, each patient is offered the opportunity of a follow-up examination. Those accepting are placed on a waiting list organised so that they will be called up at either 1, 3 or 5 or more years from the time of previous polypectomy (when their colon was known to be "cleared" of polyps). Each patient receives a kit for home testing of stoals for occult blood (Haemoccult and instructions for bowel preparation before colonoscopy. Prior to colonoscopy a history is taken (bleeding, altered habit etc.), a rigid procto-sigmoidoscopy performed, and an initial $70 \mathrm{~cm}$ examination of the distal colon made with the calonoscope befare sedation is given, simulating "fibre sigmoidoscopy". The rest of the colonoscopy is performed using carbon dioxide insufflation so that the gas is rapidly reabsorbed after examination. The patient has an air contrast barium enema without further bowel preparation.

Small polyps up to $6 \mathrm{~mm}$ in diameter are biopsied and fulgurated during the colonoscopy, but larger lesions removed at a separate visit.

The endoscopic $X$-ray and pathological findings are recorded and computer analysis is in progress. After analysis of this initial round of follow-up examimations the patients will form the basis of a longer term follow-up study. 
Yield of this prospective study:

1. The cheapest form of "follow-up" would be by Haemoccult testing: information will result about the rate of "false negative" and "false positive" results as well as correlation of positive Haemoccult reactions with established benign and malignant tumours found by other techniques.

2. The traditional techniques of history taking and rigid sigmoidoscopy will be compared in terms of time, comfort and yield with the new and more expensive fibre sigmoidoscopy.

3. By continuing directly to total colonoscopy after the $70 \mathrm{~cm}$ "fibre sigmoidoscopy" the extra yield and additional time taken will be assessed as well as the acceptability to the patient.

4. The barium enema will follow colonoscopy, neither examiner knowing the others results and will provide direct comparison of the two techniques of examination of the wholle colon. No comparably large and detailed study has been published so far.

At present, this prospective study has not been completed and is still going on. But based on the preliminary results, which can not be presented here in detail because of small numbers, certain tentative conclusions can be given:

- rigid procto-sigmoidoscopy is of minimal value.

- fibre sigmoidoscopy finds many more polyps than rigid proctosigmoidoscopy and the flexible procedure takes only a few minutes more than the rigid one.

- total colonoscopy is the most accurate method, but it takes twice the time of a fibre sigmoidoscopy.

- total colonoscopy is more accurate compared to the double contrast barium enema, but both techniques can miss certain small polyps.

- small polyps up to $0.7 \mathrm{~cm}$ in diameter are frequently missed on the barium enema.

- patients with a fixed sigmoid loop due to diverticular disease or previous pelvic operations and found to be very difficult to colonoscope, should not be subjected to follow-up colonoscopy: radiological follow-up might be preferable.

- total colonoscopy is the procedure of choice to follow-up patients with colonic adenomas, but is a laborious procedure. In case not enough facilities are available. a combination of fibre sigmoidoscopy and double contrast barium enema might achieve good results and is a reasonable follow-up method regarding time and labour.

- the "normal" time interval for follow-up should probably be three years, but should be more frequent in patients with numerous 



\section{Summary and conclusions}

The management of colonic polyps has been revolutionized during the last two decades. New concepts on the nature of colonic adenomas and their relationship to carcinomas are important, but of even more importance is the improvement in technology, which has resulted in relatively simple and safe methods to remove colonic polyps. A new chance to prevent colon carcinoma could result from these development.

The introduction explains the basic aspects of this study and its development, the purpose being to evaluate the impact of fibrecolonoscopic polypectomy in the management of colonic polyps. Wherever possible, conclusions and recommendations have been given concerning both clinicall and technical aspects of colonoscopic polypectomy.

The second chapter covers problems concerning the management of colonic polyps, reviewing the indications for removal of these polyps and how they were removed in the past (before fibre-optic endoscopy). Differentiation is made between polyps localized within the reach of the rigid sigmoidoscope, and those located more proximally in the colon. The dual standards previously held regarding the criteria for polypectomy are pointed out, with an agressive approach using the rigid sigmoidoscope but more conservative management in those polyps located more proximally, which then required abdominal surgery. This approach was of course determined by the risk of postoperative complications, which were greater for abdominal colonic surgery compared to trans-anal polyp excision. The history of endoscopy and fibre-optics is reviewed, starting with the development of the light source, the endoscope and lastly endoscopic procedures. 
The technical aspects of the fibre-optic endoscope are briefly reviewed. The chapter also describes the types of colonic polyps most otten found, both neoplastic and non-neoplastic. The adenomacarcinoma sequence is reviewed and the malignancy rates reported in the literature are given. These figures were based on clinical and postmortem studies performed before the fibre-optic era, the malignancy rate for tubular adenomas being $0.5-5 \%$, tubulo-villous adenomas $3-22.5 \%$ and the villous adenomas having the highest malignancy rates $28-68.7 \%$. Therefore, every colonic adenoma should be removed in order to prevent carcinomatous degeneration and preferably as early as possible.

Surgical management of colonic polyps (colotomy and polypectomy or resection and anastomosis) is now obsolete as a primary procedure. Present day management of all colonic polyps is primarily by colonoscopic polypectomy. Only if the polyp cannot be completely removed, surgery is advised.

In chapter three the material and methods of this study are discussed. starting with the indications for colonoscopic polypectomy. These include the patients with radiologically proven colonic polyps, comprising $72 \%$ of the total. Another group of patients had a normal barium enema, but due to persistent symptoms colonoscopy was performed with the unexpected finding of colonic polyps (11\%); the majority of these patients $(75 \%)$ had rectal bleeding.

The third group of patients had no radiological examination, the colonoscopy being performed as a follow-up procedure resulting in the finding of polyps.

The importance of a barium enema examination in regard to the colonic polyps is discussed. $83 \%$ of the patients were examined radiologically, and in $87 \%$ of these patients a polyp was diagnosed. No radiological abnormality was seen in the other $13 \%$ of the patients. but colonoscopy subsequently revealed a polyp. Both colonoscopy and barium enema roentgenography are complementary diagnostic procedures, but colonoscopy has therapeutic advantages in patients with colonic polyps, and colonoscopy is more accurate in case of finding colonic polyps.

Practical aspects of colonoscopic polypectomy include the bowel preparation; the importance is stressed of good preparation resulting in a clean colon, so as to achieve optimal and safe colonoscopy. Full bowel preparation is preferred, which can be achieved satisfactorily using castor oil or senna aperients. Limited bowel preparation using phosphate enemas or bisacodyl suppositories is used for limited colonoscopy (e.g. to check the sigmoid colon). 
Medication is an important aspect of colonoscopy. The patient should not suffer and "titration" of analgesics and sedatives against the patient's pain reaction is the ideal. Too deep sedation and analgesia or general anaesthesia is dangerous for colonoscopy. In this study good results were obtained using a combination of pethidine and diazepam.

The technique and limitations of colonoscopy and polypectomy are discussed, including the value of $\mathrm{CO}_{2}$ and several special techniques of polypectomy. Every colonoscopy should ideally be a total colonoscopy to the caecum; otherwise it will be of limited value, unless a perfect air contrast enema has previously been performed.

In chapier four, the results of colonoscopic polypectomy are given, a total of 972 colonoscopies being performed with 1930 polypectomies. The snare was used in 1299 procedures. The other 631 polyps were removed using the "hot biopsy forceps"; this technique proved to be a simple and effective procedure in the management of small polyps. but still too frequent the tissue specimen is lost during the procedure or processing.

The distribution of polyps in the colon showed a concentration in the sigmoid colon ( $46 \%$ ), and about three quarter of all polyps were located in the left colon distal to the splenic flexure. $74 \%$ of all polyps were less than $1 \mathrm{~cm}$ in diameter, while 498 polyps (26\%) were larger than 1 $\mathrm{cm}$ in diameter.

Neoplastic polyps comprised $80 \%$ of the total, with $60 \%$ tubular adenomas. Malignant adenomas accounted for four per cent of the total. The distribution and size of all types of neoplastic polyps are discussed, as well as those of the non-neoplastic polyps.

Differentiation has been made between complete and incomplete removal of the 40 malignant adenomas and polypoid carcinomas found in 38 patients. Distribution, size and histological results in these patients are discussed, as well as the follow-up and the eventual surgical procedures in some. In 26 patients the removall of 28 malignant adenomas was judged complete at histological assessment, the follow-up period of these patients being belween six months and four years. Twenty-two patients did not show any sign of recurrence, two patients were lost to follow-up, and in two other patients metastases were found, one of them probably of non-colonic origin. 
In twelve patients the colonoscopic polypectomy was incomplete and surgical management was advised and performed on seven patients: residual carcinomatous tissue was found in three patients, but in the other four no sign of residual carcinoma was found.

The conclusion is that colonoscopic polypectomy can be curative in the case of some malignant adenomas or polypoid carcinomas.

Histological and clinicall criteria play an important role in determining the meed for further surgical therapy in the event of complete exicision of a malignant adenoma or polypoid carcinoma.

A totall of 65 polyps (4\%) was urremovable by colonoscopic means, the localization, size and histological results being discussed. Thirtyone per cent of these polyps were located in the right collon, half of these were large willous adenomas. Of the unremovable polyps, $80 \%$ were $1.1-4.0 \mathrm{~cm}$ in diameter. Histologically $32 \%$ were polypoid carcinomas and $23 \%$ villous adenomas.

Chapter five discusses the complications, divided into general complications, haemorrhage, perforation and death.

Thrombophlebitis, abdominal distension and vasovagal complications are among the general complications. Haemorrhage occurred in 62 patients, the bleeding stopping spontaneously in 45 patients. Blood transfusion was necessary in ten patients, while in three patients surgery had to be performed to control the bleeding. Secondary heamorrhage occurred in five patients. The overall haemorrhage rate was $1.8 \%$.

Perforations were diagnosed in four patients $(0.1 \%)$, three during colonoscopy and one during polypectomy. All these patients were submitted to surgical management. Four other patients showed signs of sealled perforations, all of them managed conservatively.

Two patients had fatal complications $(0.05 \%)$ resulting from colonoscopy and polypectomy. One of them probably due to oversedation, the other because of ischemic colitis after the procedure.

Nonetheless it is concluded that colonoscopy and polypectomy have a low complication rate compared to abdominal surgery for colonic polyps.

Chapter six describes the follow-up of patients with colonic adenomas previously removed by colonoscopy and polypectomy. So far, little objective evidence exists about how and when to follow-up such 
patients. Even in this present study no regular follow-up has been performed. Therefore, a prospective follow-up study has been organized and is described in this chapter, although no definite conclusions can yet be presented. However, certain tentative conclusions are given based an preliminary results and impressions. These include among others that total colonoscopy is the ideal method for follow-up in patients in whom it is technically easy probably once in every three years depending upon the number of adenomas found.

In case of completely removed malignant adenomas or polypoid carcinomas, the follow-up should be performed by colonoscopy at more frequent intervals, such as two monthly in the first year. followed by twice and then once a year in the following years. However, follow-up in these patients should be life-long. 


\section{Samenvatting en conslusies}

De behandeling van de pollepen van het colon heeft gedurende de laatste twee decaden een drastische verandering ondergaam. Niet alleen hebben de inzichten belreffende colon adenomen en hun potentiële ontaarding in maligniteit een rol gespeeld, doch belangrijk zijn ook de ontwikkelingen op technisch gebied die het magelijk hebben gemaakt een poliep op relatief "eenvoudige en veilige" wijze te verwijderen door middel van de colonoscopische polipectomie. Een nieuw aspect in de zin van carcinoom preventie zal zich hieruit kunnen ontwikkelen.

In de inleiding wordt vermeld hoe dit proefschrift tot stand is gekomen. De doelstelling hiervan is de waarde te bepalen van de colonoscopische polipectomie bij de behandeling van de colon poliepen. Voor zover mogelijk zijn conclusies en aanbevelingen vermeld aangaande klinische en technische aspecten van de colonoscopische polipectomie.

Het tweede hoofdstuk begint met de problematiek rond de colon poliepen. De indicatie tot verwijdering ervan en op welke wijze ze verwijderd werden in het velleden wordt besproken, het verleden gezien als de periode voor de toepassing van de fiber-optische endoscopie. Tevens werd een onderscheid gemakt tussen de laag gelegen poliepen die bereikbaar waren voor de starre rectoscoop en die poliepen die hogerop gelocaliseerd waren. Gewezen wordt op de in het verleden toegepaste inconsequente houding ten opzichte van de colon poliep, met name de kleinere. De laaggelegen poliepen werden virij agressief benaderd via de starre rectoscoop, terwijl men terughoudend was voor de hoger gelegen poliepen die een abdominale ingreep noodzakelijk maakten. Deze houding was uiteraard te verklaren door de hoge postoperative complicaties bij de abdominale colon chirurgie in vergelijking met de transanale pollep excisie. Vervolgens wordt ingegaan op de historie van de endoscopie en de fiber-optische instrumenten, te beginnen mel de ontwikkeling van de lichtbron, de endoscoop en uiteindelijk van de endoscopie zelf. 
De technische aspecten wan de fiber-optische endoscoop worden in het kort weergegeven.

Dit hoofdstuk omvat tevens de soorten colon poliepen die men frequent aanwezig vindt, de neoplastische en niet neoplastische poliepen. Gewezen word op de potentiele maligme degeneratie van de colon adenomen. Literatuur cijfers aangaande het maligniteitspotentieel worden vermeld, verkregem uit klinische en postmortem studies. allen uit het tijdperk voor de fiber-optische endoscopie. Deze cijfers zijn 0,5-5\% voor de tubuleuze adenomen en 3-22,5\% voor de tubulovilleuze ademomen. De hoogste percentages gelden voor de villeuze adenomen, 28-68,7\%. Gezien deze cijfers, is thet geindiceerd om elk colon adenoom te verwijderen, ter preventie van maligne degeneratie of de therapie $20 \mathrm{vroeg}$ magelijk te verrichten.

Primaire chirurgische therapie (colotomie en polipectomie of resectie en anastomose van een colon segment) is nu obsoleet. De tegenwoordige behandeling van colon poliepen is uitsluitend colonoscopische polipectomie. Indien blijkt dat de poliep niet totaal verwijderd kan worden, wordt chirurgische therapie geadwiseerd.

In hooldstuk drie worden de colomoscopieën beschreven die zijn opgenomen in dit proefschrift.

Allereerst worden de indikaties tot het verrichten van een colonoscopische polipectomie behandeld. Deze indicaties zijn röntgenologisch aangetoonde poliepen, bestaande uit $72 \%$ van het totaal aantal verrichte colonoscopieën.

Een tweede groep patiënten hadden een als normaal afgegeven coloninloop foto, doch de persisterende klachten vormden een indicatie tot colonoscopie waarbij één of meerdere poliepen werden gevonden (11\%). De grootste klacht van deze groep patienten was persisterend rectaal bloedverlies $(75 \%)$. De derde groep patienten had geen colon-inloop foto en de colonoscopie werd verricht voornamelijk als follow-up procedure, resulterend in het vinden van een poliep met aansluitend een colonoscopische polipectomie.

De waarde van de colon-inloop foto wordt vervolgens behamdeld ten aanzien van de colon poliepen. $83 \%$ van de patiënten hadden een colon-inloop foto ondergaan, waarvan in $87 \%$ van de gevallen een poliep werd gezien. De resterende $13 \%$ hadden röntgenologisch geen aangetoonde poliepen, welke wel bij colonoscopie waren gevonden. Colonoscopie en het röntgenonderzoek van het colon zijn elkaar aanvullende diagnostische onderzoeksmethoden, doch de colonoscopie heeft het voordeel therapeutisch te kunnen zijn en is meer accuraat bij de diagnostiek van collon poliepen. 
De praktische kant van de colonoscopische polipectomie wordt begonnen met de darmvoorbereiding. Het belang van een schoon colon wordt benadrukt, om zowel diagnostisch als ook therapeutisch optimaal te werken. Daarnaast geeft een vuil colon meer kans op complicaties.

Een totale darmvoorbereiding geniet de voorkeur. welke goed bereikt kan worden met castor of senna preparaten. Een beperkte darmvoorbereiding met fosfaat clysmata of bisacodyl suppositoria kan gebruikt worden voor een linkszijdige colonoscopie, bijvoorbeeld bij de controle colonoscopieën.

De medicatie van de patiënt vormt een belangrijk aspect bij de colonoscopie. De patiënt mag niet veel pijn ondervinden, doch algehele anaesthesie kan gevaren opleveren. "Getitreerde" toediening van analgetica en sedativa op geleide van de pijn wordt aanbevolen Goede resultaten worden verkregen met een combinatie van pethidine en diazepam.

De techniek van colonoscopie en polipectomie wordt vervolgens behandeld als wel de waarde wan $\mathrm{CO}_{2}$ toediening. Beperkingen van de colonoscopie worden weergegeven, evenals enkele speciale technieken met betrekking tot de polipectomie.

In het vierde hoofdstuk worden de resultaten van de colonoscopische polipectomieën beschreven. Een totaal aantal van 972 colonoscopieen werd verricht met 1930 polipectomieën. De diathermische lis werd gebruikt in 1299 gevallen, de resterende 631 poliepen werden verwijderd met de "hot biopsy forceps". Deze laatste techniek bleek een simpele en effectieve methode te zijn ter verwijdering van kleine poliepen, maar nog te frequent wordt het biopsie materiaal verloren tijdens de ingreep of de verwerking ervan.

De verdeling van alle poliepen in het colon laat een sterke concentratie zien in het sigmoid $(46 \%)$, terwijl ongeveer $3 / 4$ wan alle poliepen in het linker collon gedeelte werden gevonden, distaal van de flexura lienalis. Qua afmeting waren $74 \%$ van alle poliepen kleiner dan $1 \mathrm{~cm}$ in diameter, terwijl $26 \%$ (498 poliepen) groter waren dan $1 \mathrm{~cm}$ in diameter.

De meoplastische poliepen wormden $80 \%$ van het total met als grootste uitschieter de tubulaire adenomen (60\% van het totaall). De maligne adenomen vormden $4 \%$ van het geheel. Vervolgens worden beschreven de localisatie en grootte van de neoplastische poliepen ieder afzonderlijk. Eveneens wordt de localisatie en grootte wan de non-neoplastische poliepen wermeld, met een totaal aantal van 20\% van alle poliepen. 
Een apart gedeelle van hoofdstuk wier word besteeds aan de maligne vormen van colon adenomata. Onderscheld wordt gemaakt tussen complete en incomplete verwijdering van de 40 maligne adenomen. gevonden bij 38 patienten. De localisatie. grootte en histologie worden eveneens beschreven, zo ook de follow-up en de al dan niet verrichte chirurgische therapie. Bij 26 patienten was de colonoscopische verwijdering van 28 maligne adenomen compleet bevonden bij histologisch onderzoek. Bij follow-up van deze patienten over een periode van 6 maanden tot meer dan 4 jaren bleek dat 22 patièten geen tekenen van maligniteit vertoonden. Twee patiënten konden voor follow-up onderzoek niet achterhaald worden, terwijl bij de andere twee patienten tekenen van metastasen waren gevonden. een vam hen vermoedelijk niet uitgaande van het colon.

12 patiênten ondergingen een incomplete verwijdering van een maligne colon adenoom. Chirurgische therapie werd geadwiseerd. welke bij 7 patienten verricht werd. Rest-carcinoom werd gevonden bij 3 patiënten, dach bij de andere 4 patiënten werd geen teken van rest-maligniteit gevonden. De andere 5 patiënten hadden contra-indikaties voor chirurgisch ingrijpen. Er kan worden geconcludeerd, dat colonoscopische polipectomie curatief kan zijn in bepaalde gevallen van maligne adenomen of polipoide carcinomen. Hierbij spelen histologische en klinische factoren een belangrijke rol ter bepaling wan eventueel verder chirurgisch ingrijpen, met name bij de complete verwijdering van een maligne adenoom of een polipoid carcinoom.

Afgezien van de boven beschreven poliepen zijn er poliepen die colonoscopisch niet compleet te verwijderen zijn. Het aantal hiervan is 65, welke $4 \%$ vormt van het totaal. De localisatie, grootte en histologie worden beschreven. $31 \%$ van deze poliepen waren gelocaliseerd in het rechter colon en $80 \%$ heeft een grootte van $1.1-4.0 \mathrm{~cm}$ in diameter. De polipoide carcinomen vormden $32 \%$ van het geheel, terwijl $23 \%$ villeuze adenomen gewonden werden.

De complicaties worden beschreven in hoofdstuk wiff, onderverdeeld in algemene, bloedingen, perforaties en lethale complicaties.

Thrombophlebitis, abdominale distensie en vasovagale complicaties wormden de algemene complicaties.

Bloedingen traden op in 62 gevallen, bij 45 patiënten stopte de bloeding spontaan zonder bloedtransfusies. Tien patiënten hadden bloedtransfusies nodig. terwijl bij drie patiënten tevens chirurgisch ingrijpen nodig was. Secundaire bloedingen traden op in vijf patiènten. De bloedingen traden op in 1,8\% van alle colonoscopieën.

Perforaties werden gevonden bij vier patiënten $(0,1 \%)$, drie tijdens de 
colonoscopie en eén na polipectomie. Al deze patiënten ondergingen chirurgische therapie. Bij vier andere patiënten werd een gedekte perforatie gediagnostiseerd, welke conservatief behandeld werd.

Twee patienten hadden fatale complicaties $(0,05 \%)$ volgend op colonoscopie en polipectomie. Eén hiervan waarschijnlijk tengevolge van de sedatie, de andere tengevolge van een ischemische colitis. Concluderend is de colonoscopie en polipectomie een ingreep met weinig complicaties, zeker in vergelijking met abdominale chirurgie voor colon poliepen.

Hoofdstuk zes beschrijft de follow-up van patiënten met reeds verwijderde colon-adenomen door middel van colonoscopie en polipectomie. Tot op heden zijn er echter geen abjectieve criteria op welke wijze en thoe frequent de follow-up van deze patiënten moet zijn. Ook in het materiaal van dit proefschrift werd geen routine follow-up verricht. Ter beantwoording van deze problematiek werd een prospectief follow-up onderzoek verricht, welke uitvoerig beschreven wordt in dit hoofdstuk. Dit onderzoek is momenteel nog gaande, waardoor op dit moment geen definitieve conclusies getrokken kunnen worden. Gebaseerd op de voorlopige resultaten en klinische beschouwingen kunnen enkele voorlopige conclusies vermeld worden. Deze zijn onder andere, dat totale collonoscopie de idealle follow-up methode is, met een frequentie van eens in de drie jaar, echter ook athankelijk van het aantal adenomen dat gevonden wordt.

Bij patiënten met maligne adenomen of polipoide carcinomen welke compleet verwijderd zijn door colonoscopische polipectomie is het aanbevolen om frequent follow-up te verrichten d.m.v. colonoscopie. De aanbevolen frequentie zal zijn eens per twee maanden in het eerste jaar, vervolgens eens per half jaar in het tweede jaar en daarna jaarlijks. Levenslange controle is echter wel gewenst. 



\section{Appendices}

1. bowel preparation: senna

2. bowel preparation: castor oil

3. bowel preparation: mannitol

4. bowel preparation: phosphate

5. endoscopy report. 


\section{Bowel preparation instruction (to the patient): Senna}

4 days before examination:

stop any iron tablets you may be taking but continue all other medications and any laxative you usually take until you come to hospital

2 days before examination:

eat only light meals of egg. cheese and thin white bread and butter. Have plenty to drink. Do not eat meat, fish, fruit or vegetables in any form.

1 day before examination

Take the whole bottle of senna syrup between $2-3 \mathrm{pm}$.

On the morning of the examination you may have a light breakfast of tea and toast if you wish. You will be given one or more washout enemas on arrival at the hospital.

2. Bowel preparation instructions (to the patient): Castor oill

Obtain from the chemist $1 \mathrm{oz}(30 \mathrm{ml})$ of Castor oil.

4 days before examination:

stop any iron tablets but continue all other medication and any laxative you usually take until you come to hospital.

2 days before examination:

eat only light meals of egg, cheese and thim white bread and butter. Have plenty to drink. Do not eat meat, fish, fruit or vegetables in any form.

1 day before examination:

take the full dose of Castor oil in one dose at $2.00 \mathrm{pm}$. After that take only clear fluids (no milk, except a little in tea or coffee).

On the morning of the examination have only one drink. You will be given an enema at the hospital before being examined. 


\section{Bowel preparation instructions (to the patient) : Mannitol}

4 days before examination:

stop any iron tablets you may be taking but continue all other medications and any laxative you usually take until you come to hospital.

2 days before examination:

eat only light meals of egg, cheese and thin white bread and butter. Have plenty to drink. Do not eat meat, fish, fruit or vegetables in any form.

On 1st day of diet:

take the 4 enclosed senna tablets before going to bed.

On the day before examination:

dissolve the contents of the enclosed sachet $100 \mathrm{gr}$ mannitol crystals in 1 pint of iced water and drink at $4.00 \mathrm{pm}$. You should have finished drinking this by $5.00 \mathrm{pm}$. After you have drunk this you should have only fluids for the rest of the evening (water, tea with sugar, etc.).

On the day of examination:

do not have anything to eat or drink after $7.00 \mathrm{am}$.

You will find that as a result of this preparation you will have diarrhoea. This may cause anal irritation and soreness and it is possible to use a cream such as zinc or castor oil to prevent this if you wish. This can be obtained from the chemist.

\section{Bowel preparation instructions (to the patient): Phosphate Enemas}

4 days before examination: slop any iron tablets you may be taking but continue all other medications and any laxative you usually take until you come to hospital.

On the morning of the examination:

you may have a light breakfast of tea and toast if you wish.

You will be given a single enema at the hospital just before being examined. 
5

\section{ENDOSCOPY REPORT}

Misute:

Age:

Endoscony

Addor ange

Dant

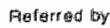

Hosplat Nomber

Copies to:

Indilicalion:

Preparalion:

Medicallor:

瞒制 Ifument:

Endoscopist:

ENDOSCOPY:

HISTOLOGY:

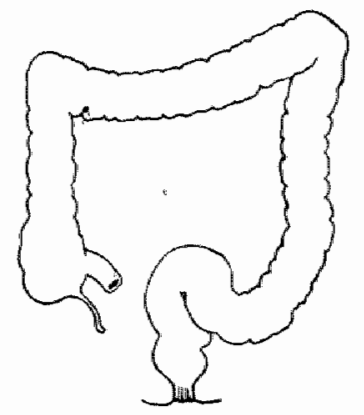




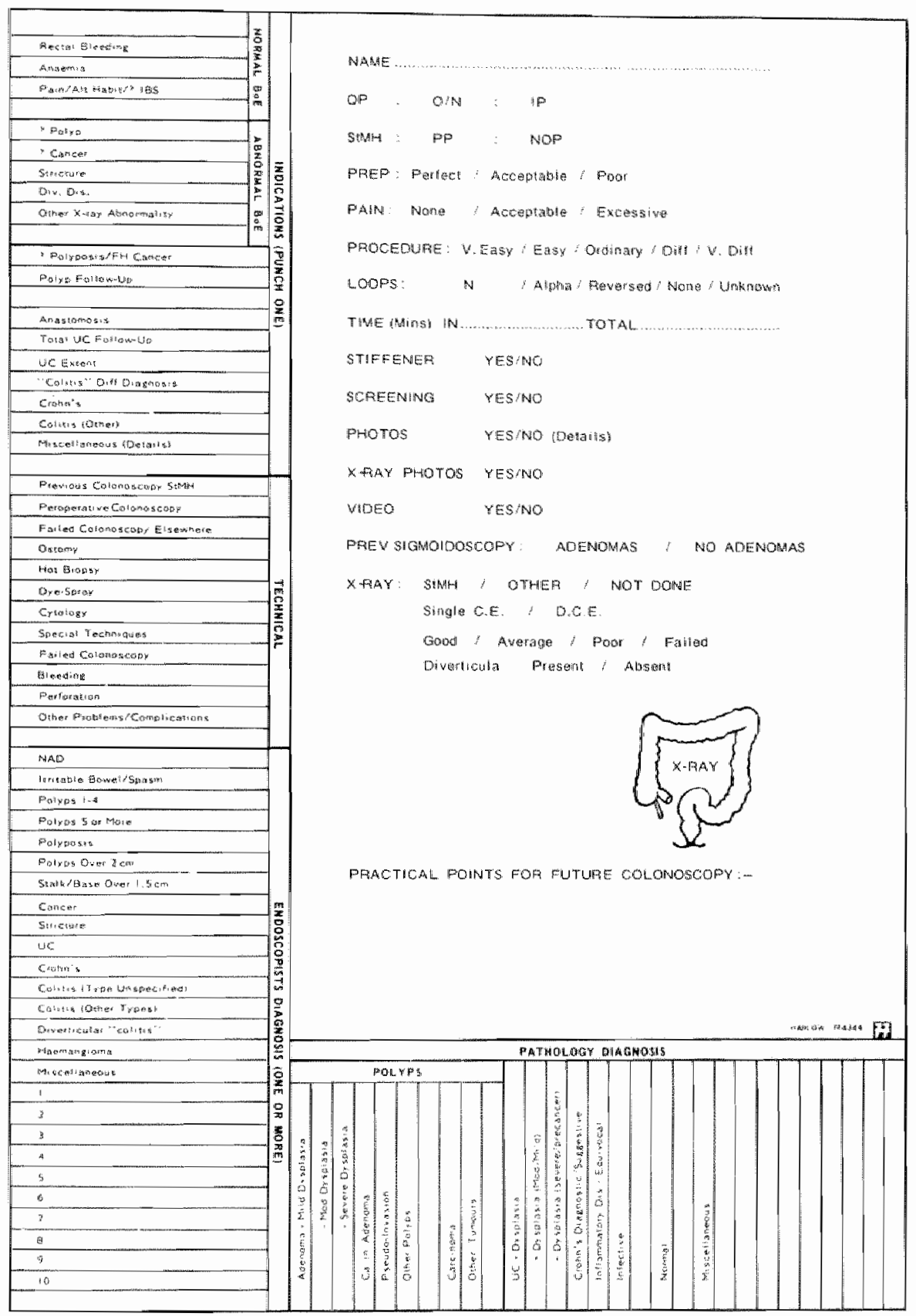





\section{References}

1. ABBOT, F.K. MONAOE. L.S. and SPENCER, F.M.: "The incidence of polyps in 500 procto sigmoidoscopies in asymptomatic young men." Gastroenterology 32: 704. 1957.

2. AINSLIE, B.J. FRANCE, P.W. DAY, C.R.: BEALES, K.J. and NEWNS, G.R.: "Single mode low loss silicon fibre prepared in long lengths." Proc. Opt. Comm. Conterence. pg. 3.6.1. Amsterdam, 1979

3. ALAM, M. SCHUMAN. B.M. DUVERNOY. W.F.C. and MADRAZO, A. C.: "Continuous electrocardiographic monitoring during colonoscopy." Gastrointest. Endosc., 22 : 203. 1976.

4. AMBEFG, J.R, BERK, R.N., BURHENNE, H.J., CLEMETT, A.R., DODDS, W.J., FRIEDLAND. G.W. GOLDBERG. H.J. GOLDSTEIN. H.M. LAUFER, I., LAWSON, T.L. MARGULIS, A.R. MARSHAK, R.H. MILLER, R.E., SHORT, W.F., STEWART, E.T. YOUBER, J.E and ZBORALSKE, F.F.: "Colonic polyp detection: Rolle of Roentgenography and colomoscopy." Radiology, 125 (1): 255, 1977.

5. ANDREN, L. and FRIEDBERG, S.: "Frequency of polyps of rectum and colon, according to age, and relation to cancer." Gastroenterol. $36: 631.1959$.

6. ARMINSKI, T.C., and MCLEAN. D.W.: "Incidence and distribution of adenomatous polyps of the colon and rectum based on 1.000 autopsy examinations." Dis. Col. Rect $7: 249$ 1964.

7. ARTHUR, IF.: "Siructure and significance of metaplastic nodules in the rectal mucosa." J. Clin. Pathol, $21: 735,1968$.

8. BAIAO. J.L.: "An improved method of and means for producing optical images." Brit. Pat spec. no. 285. $738(1928)$

9. BENNETT, J.A., SALMON P.R. BRANCH. R.A., BASKETT, P.J.F. and READ. A.E.A. "The use of inhalational anaesthesia during fibreoptic colonoscopy. Anaesthesia, $26: 294$. 1971

10. BERARDI. R.S.: "Coloscopy and radiology." Internat. Surg. 59:236. 1974.

11. BERGE. T., EKELUND, G. MELLNER, C., PHIL, B., and WENCKERT, A. "Carcinoma of the calon and rectum in a defined population." Acta Chir. Scand. Suppl. 438, 1973

12. BERKOWITZ, D., and BERNSTEIN. L.H.: "Colonic pseudopolyps in association with amoebic colitis." Gastroenterology 68:786, 1975.

13. BIGARD, M:: "Fatal colonilc explosion during colonoscopic polypectomy." in Press. 1980.

14. BLATT, L.J.: "Polyps of the colon and rectum incidence and distribution." Dis. Col. Rect. $4: 277,1961$.

15. BOND. J.H.Jr., and LEVITT. M.D.: "Factors affecting the concentration of combustible gases in the colon during colonoscopy." Gastroenterology $68: 1445.1975$.

16. BOND, J.H., JR., LEVY, M., and LEVITT, M.D.: "Explosion of hydrogen gas in the colon during proctosigmoidoscopy." Gastrointest. Endosc. 23:41, 1976 
11. BUSSEY. H.IA. WALLACE. M.H. and MOPSON. B.C.. Metachronous carcinoma of the large intestine and intestinal polyps." Proc. R. Soc. Med. 60:208, 1967.

18. BUSSEY. H.J.R. "Familial Polyposis Coll." Johru Hopkins Universty Press, Baltimore, 1975 .

19. BUSSEY, H.J.R.: in Morson, B.C.: "The pathogenesis of colorectal cancer." Major Problems in Pathology. W. B. Saunders. Philadelphia, 1978.

20. CASTLEMAN, B. and KPICKSTEIN, H.I." "Do adenomatous polyps of the colon

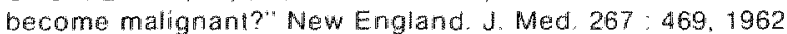

21. CASTLEMAN, B and KFICKSTEIN, H.I.: "Editorial. Polyps of the colon." S.G.O. 116 752, 1963.

22. CASTRO. A.F. AULT, G.W. and SMITH, F.S.: "Adenomatous polyps of the colon and rectum." S.G.O. 92 : 164, 1951 .

23. CHABANON P: "La fibro-colonoscopy."Ann. Gastroent. Hepat. 8: 239. 1972

24. CHAPMAN. 1.: "Adenomatous polypi of large intestine. Incidence and distribution." Anm. Surg. $157: 223,1963$.

25. CHRISTIE, J.P. "Which colonic polyps should be exised endoscopically?" Sowth. Med. J. $69: 1143,1976$

26. CHRISTIE, J.P: "Colonoscopic excision of sessile polyps." Am. J. Gastroenteral. 67 430, 1977

27. CLASSEN, M.: "Fiberendoscopy of the intestines." Gut. 12 : $330,1971$.

28. COLE. J.W. O'MARA, P.S., and HOLDEN, W.D.: "Observations on the relationship of benign adenomalous palyps of the colon to the natural history of colonic cancer." S.G.O. 107:651, 1958 .

29. COLE, H.B.: "Improvements in method of forming optical image transmitting devices." British Paltent 907952 . Oct. 10, 1962.

30. COLLINS, V.P. LOEFFLER, R.K. and TIVEY, H.: "Observations on growth rates of numan tumors." Am. J. Roentgenol. 76 : 988, 1956.

31. CORMAN, M.L., VEIDENHEIMER, M.C., and COLLER, J.A.: "Barium-enema study findings in asymptomalic patients with rectal polyps." Dis. Col. Rect. $17: 325,1974$.

32. CRAPP. A.R. and POWIS. S.A.J.: "Preparation of the bowel by whole gut irrigation." Lancet $11: 1239,1975$.

33. DAWSON, I.M.P., and PRYSE-DAVIES, J.: "The development of carcinoma of the large intestine in Llllogrtive colltis." Br. J. Surg. 47: 113, 1959.

34. DEAN, A.C.B., and SHEARMAN, D.J.C.: "Clinical ewaluation of a new fibreoptic colonoscope." Lancet 1, 550, 1970.

35. DeBEER, AA., GEFFIN, A. OZOKTAY, S., SHINYA, H. and WOLFF, W1.: "Comparison of colonoscopy and contrast $X$-ray study in diagnosis of 500 cases of colorectal disease." JAOA $75: 569$, 1976.

36. DEDDISH, M.R., and HERTZ, R.E.: "Colotomy and coloscopy in the management of neoplasms of the collon." Dis. Col. Rect. 2 : 133, 1959.

37. DEYHLE, P. SEUBERTH, K. JENNY, S. and DEMLING, L.." Endoscopic polypectomy in the proximal colon:" Endascopy $3: 103,1971$.

38. DEXHLE, P. and DEMLING, L. "Coloscopy: techrique, results and indications." Endoscopy $3: 143,1971$

39. DEYHLE. P. "A plastic tube for the maintenance of the straightening of the sigmoid colon during coloscopy." Endoscopy" 4:224, 1972

40. DEYHLE, P.JENNY, S., and FUMAGALLI. 1.: "Endoskopische Polipektomie in proxinalen Kolon." Dtsch. Med. Wochenschr. $98: 219,1973$.

41. DODDS. W.J., SCHULTE. W.J., HENSLEY. G.T., and HOGAN, W.J.: "Peutz-Jeghers syndrome and gastrointestinal malignancy." Am J. Roentgenol, 115 : 374, 1972. 
42. ENQUIST. I.F: "Incidence and significance of polyps of the colon and rectum." Surgery $42: 681,1957$.

43. ENTERLINE, H.T. EVANS, G.W. MERCADO-LUGO. R.. MLLER. L. and FITTS. W.T. "Maignant potential of adenomas of the colon and rectum." J.A.M.A. 179. 322, 1962.

44. ENTERLINE, H.T. and ARVAN, D.A.: "Chromosome constitution of adenoma and adeno-carcinoma of the colon." Cancer 20:1746.1967

45. EPSTEN, M.: "Fiberoptics in medicine." SP\|E $77: 95,1976$

46. FENOGLIO, C.M. KAYE, G.I, and LANE, N.. "Distribution of thuman colanic lymphatics in normat hyperplastic and adenomatous tissue. Its relationship to metastases from small carcinomas in pedunculated ademomas." Gastroenterology 64 51. 1973 .

47. FIGIEL, L.S., FIGIEL, S.J. and WIETERSEN, F.K.: "Roentgenologic observations of growth rates of colonic polyps and carcinoma." Acta Radiol 3:417, 1965.

48. FOX, J.A.: "A fibreoptic colonoscope." Br. Med. J. 3: 50, 1969.

49. FRIEND, W. G.: "Fibreoptic colonoscopy-indications." Dis. Coll. Rect. 19: 386, 1976

50. FRÜHMORGEN, P. and DEMLING, L.: "Koloskopische Polipeklomie." Disch. Med. Wochenscher. $31: 1455,1973$

51. GAISFORD, W.D.: "Gastrointestinal polypectomy via the fiberendoscope." Arch. Surg $106: 458,1973$

52. GANTS, R.T. RAYMOND, B.A., and POPE, J.K.: "Extended colotomy incisions for intraluminal examination of the colon." Ann. Surg. $144: 865,1956$.

53. GEENEN, J.E., SCHMITT, M.G. Jr., WU. W.C., and HOGAN, W.J.: "Major complications of coloscopy; bleeding and perforation." Am. J. Dig. Dis. 20:231, 1975

54. GIANTURCO, C., and MILLER, G.A.: "Routine search for colonic polyps by thigh voltage radiography." Radiology $60: 496,1953$.

55. GIBBS, D.D.: "In: Modern Topics in Gastromintestinal Endoscopy." Ed: Salmon P.R and Schiller. K.F.R., W. Heinemann, 1976.

56. GHBBS, N.M.: "Juwenile and Peutz-Jeghers polyps." In: Morson B.C.: The Pathogenesis of Colorectal cancer. Major Problems in Pathology. W.B. Saunders, Philadelphia, 1978.

57. GILLESPIE, P.E.: "Unpublished reports $1978 . "$

58. GILLESPIE, P.E., CHAMBERS, T.J., CHAN, K.W., DDRONZO. F., MORSON, B.C. and WILLIAMS, C.B.: "Colonic adenomas - a colonoscopy survey." Gut 20:240. 1979.

59. GILLESPIE.P.E. and WILLIAMS, C.B.: In press, 1980

60. GOLIGHER, J.C.: "Surgery of the anus rectum and colon." Bailliere Tindall, London. 3rd ed. 1975 .

61. GORDON, M.J.: "Retroperitoneal emphysema from colonoscopy of the distal limb of a Hartmainn colostomy." Gastrointest. Endosc. 22: 101. 1975.

62. GRINNELL. R.S., and LANE. N.: "Benign and malignant adenomatous polyps and papillary adenomas of the colon and rectum: an analysis of 1856 tumors in 1335 patients." Int. Abs. Surg. 106:519, 1958

63. HALL, S.. and OVASSAPIAN, A.: "Apnea after intravenous diazepam therapy." J.A.M.A. $238: 1052,1977$.

64. HANSEN, L.K.: "Colonoscopy: a study of 50 cases." Scand". J. Gastroent. 6:687. 1971

65. HAUCH, E.W. BUIE L.A., BARGEN, J.A., and SMITH, L.A.: "Adenoma of the rectum and sigmold collon: incidence revealed by proctosigmoidoscopic examination of a group of patients free of complaints referable to the colon and recturn." Gastroenterol $16: 669,1950$.

66. HAYASHI. T., YATANI, R., APOSTOL.J. and STEMMERMAN, G.N.: "Pathogenesis of hyperplastic polyps of the collon a hypothesis based on ultra structure and in-witro kinetics." Gastroenterol. $66: 347,1974$. 
67 HEALD. A.J. and BUSSEY. H. A. "Clinical experiences at Si. Mark's Hosptal with multiple synchronous cancers of the colon and rectum." Dis. Col. Rect. 18: 6. 1975

68. HELWIG. EB: "Eragn tumors of the lange intestine: incidence and distribution." S.G. $76: 419.1943$

69. HELWIG. E.B. "Adenomas of large notesine in children." Am. J. Dis. Child $72: 289$ 1949

70. HELWG. F.C: "The association of benign and malignant polyps of the large intestine." Dis. Col. Rect 3: 343.1960.

7. HEVITT, J. REEVE, J. RIGBY, J. and COX. A.G." Whole gut irrigation in preparation for large bowel surgery." Lancet 11:337, 1973.

7r. HASCHOWITZ. BI., CURTISS, LE. PETEPS. C.W. et al: "Demonstration of a new gastroscope the "fiberscope" "Gasiraenterology $35: 50,1958$

73. HOLGERSEN. L.O. MILLER. P.E. and ZUNTEL. H.A.: "Juvenile polyps of the colon." Surgery $69: 288,1971$

74. WOPKINS, H.H. and KAPANY. N.G.: "A flextble fibrescope using static scanning." Nature (London) $173: 39.1954$

75. HORN. R C. J": "Malignant potertial of polypoid lesions of the colon and reclum." Cancer 28: 146. 1971

76. HOAFILLENO. E.G. ECKEAT, C., and ACKEAMAN. L.V.: "Polyps of the rectum and colon in children." Cancer $10: 1210,1957$

77. JACKMAN. R.J and BEAHRS. O.H.: "Tumors of the large bowel." Major Problems in Clinical Surgery, vol B. W. B. Saunders, Philadelphia, 1968.

78. JACOBSOHN, E,Z.: and LEWY, A, "Colonoscopic perforation; its emergency treatment." Endascopy $B: 15,1976$

79. JALAN, KN., WALKEF, R.J., SIRCUS, W., and MCMANUS, J.P.A.: "Pseudopolyposis in ulceratiwe colitis." Lancel $2: 555,1969$

80. JEGHERS. N.: "Pigmentation of skin." N. Engl. J. Med. $231: 88,122,181,1944$.

81. JOOS. J.: "Theoretical physics." Hafiner. N. York, pg. 352. 1951.

82. KALUS, M.: "Carcinomas and adenomatous polyps of the colon and rectum in biopsy and organ lissue cullure." Cancer 30:972. 1972.

83. KANEKO. M.: "On pectunculated adenomatous polyps of colon and rectum with particular reference to their malignant potential." Mt. Sinai J. Med. $39: 103,1972$

84. KAPANY. N.S: "Fiber optics, part. 1." "Optical properties of certain dielectric cyllinclers." J Opt. Soc. Am. $47: 413.1957$

85. KAYE. GI. FEEOGLIO. CM., PASCAL. A.R., and LANE, N.: "Comparative electron microscopic features of normal. hyperplastic and adenomatous human colonic epithelium. Variations in cellular structure relative to the process of epithelial dillerentiation." Gastro-enterology 64:926, 1973

86. KEELE, K.D.: "The evolution of clinical methods in medicine." Piltman, London, 1963

87. KIEIN. A.A. and SCARBOROUGH. P.A.: "Diagnosis and treatment of adenomatous polyps of the colon." Aret. Surg. 65:65, 1952

89. KLEINFELD.G. and GUMP. F.E.: "Complications of colotomy and polypectomy." S.G.O. $111: 726,1960$.

89. KRATZER, G.L.: "Collonoscopy - current status." Dis. Col. Rect. 7: 45, 1964.

90. KRONBORG, O. and OSTERGAARD, A. "Evaluation of the barium enema examination and colonoscopy in diagnosis of colonic cancer." Dis Col. Rect. 18:674, 1975 .

91. LANE, N. and LEV, R.: "Obserwations on the origin of adenomatous epithelium of the colon. Serial studies of minute polyps in familial polyposis." Cancer 16: 751, 1963.

92. LANE, N. KAPLAN. H. and PASCAL, R.: "Minute adenomatous and hyperplastic polyps of the colon: divergent patterns of epthelial growth with specific associated mesenchymal changes." Gastroenterology 60: 537, 1971. 
93. LAUFEA. 1., SMITH, N.C.W. and MULLENS. J.E.: "The radiological demonstranion of colorectal polyps undetected by encoscopy." Gastronterology 70: $167,1976$.

94. LEWY. A.G. BENSON. JW. HEWLETT. E.L. et al: "Saline Iavage, a rapid afleche and acceptable method for cleansing the gastrointestinal tract." Gastroenterology $70: 157$. 1976.

95. LINNELL, F. SPOUT. H.J., and JOHNSON. R.E." The rates of pattens of growth of 375 tumors of the large intestine and rectum observed serially by double contrast enema srudy (Malmö technique). Am. J. Roentgenol. 90:673, 1963.

96. LIVSTOME, E.M. GREENE, F.L. and TRONCALE, F.J: "Colonoscopic polypectomy: a caveat." New Engl. J. Med. 288: 1304, 1973.

97. LOCKHART MUMMERY. H.E.: "Polyps of the colon and reclum." In R. Maingot: Abdominal Operations. Appleton-Century-Crotts (N. York), 1974.6th ed.

98. LOOSE, HW. and WILLIAMS, C.B.: "Barium enema versus colonoscopy." PlOC. 1 . Soc. Med. 67: 1033,1974

99. MANHEIMER. L.H. "Metastasis to the liver from a colonic polyp." New Eng J. Med $272: 144,1965$

100. MATSUMAGA, F., TSUSHIMA, H and KUBOTO, T. "Photography of the colon." Gastro-ent. Endosc. $1: 58,1959$.

101. MATSUNAGA, F. YAMAGUCHI, T. TANAKA, M. el al: "Sigmoidocamera and cava camera." Gastroenterol. Endosc. (Tokyo) 5 : 105, 1963.

102. MAYO. C.W. and DE CASTRO, C.A.: "Carcinoma of the sigmoid arising from a polyp tirst visualised 15 years previously. Reporl of case." Proc. Mayo Glin. 31 : 597. 1956.

103. MAZIER, W.P., BOWMAN,H.E., SUN, K.M., and MULOOON, „.P.: "Juvenile polyps of the colon and rectum." Dis. Col. Rect. 17:523, 1974.

104. MEYERS. M.A., and GHAHREMANI, G.G.: "Complications of fiberoptic endoscopycolonoscopy." Radiology 115:30\%, 1975

105. MILITO, G., BAT, L. BARTRAM, C.I. and WILLIAMS, C.B.: "Bowel preparation with mannitol is hazardous." In press, 1980.

106. MORSON, B.C.." "Some pecularities in the histology of intestinal polyps." Dis. Col Aect. 5: 337, 1962.

107. MORSON, B.C.: "Factors influencing the prognosis of early cancer of the rectum." Proc. R. Soc. Med. 59:607, 1966

108. MORSON, B.C.: In Goligher, J.C., de Dombal, F.J., Watts, J.Mck., and Watkinson, G. (eds.): "Ulceratiwe Colitis." Bantliere, Tindall and Cassell, London, "968, chap. 2

109. MORSON, B.C. and BUSSEY, H.J.R.. "Predispasing causes of intestinal cancer." Current Problems in Surgery (februaty). Chicago. Year Book Medical Publishers, pg. 3 , 1970.

110. MORSON, B.C., and DAWSON, I.M.P." "Gastrointestinal Pathology." Blackwell Scientific, Oxlord, 1972.

111. MORSON, B.C.: "Evolution of cancer of the colon and rectum." Cancer suppt. 34:845. 1974.

112. MORSON, B.C... ef al.: "Histological Typing of lntestinal Tumours." International Histological Classitication of Tumours. No. 15. World Health Orglanization, Geneva, 1976.

112a. MORSON, B.C.. BUSSEY, H.J.R. and SAMOORIAN. S.: "Policy on local excision for early cancer of the colorectum." Gut $18: 1045,1977$.

113. MORSON, B.C.: "The Pathogenesis of Colorectal Cancer." Major Problems in Pathology, vol 10. W.B. Saunders, 1978.

114. MUTO, T. BUSSEY. H.J.R., and MORSON, B.C.: "The evolution of cancer of the colon and rectum." Cancer $36: 2251,1975$

115. NAGASAKO, K and TAKEMOTO, $T$ : "Fibercolonoscopy without the help of fluoroscopy." Endascopy $4: 208,1972$. 
16. NAGY, G.5: "Fibrecolonotcopy." Med. J. Aust. 1:378, 1973.

"17. NEAL, M.P. Jr. MERLITZKA, A.J. CURAERI. A.R., and PAUL. L. W: "SUrVy procedures for the detection of asymptomatic fumors of the reclum and colon." Cancer $12: 833,1959$.

118. NEBEL. O.T. el al.: "Schishomosal disease of the colon a rewersible form of polyposis." Gastroenterotogy $67: 939,1974$.

119. NIVATVONGS. S.. and GOLDBERG. S.M.: "Results of 100 consecultwe polypectomies with the fiberoptic colonoscope." Am. J. Surg. 128:347, 1974

120. NIWA, w.: "On photography of the colon and pharynx using gastrocamera." Gastroenterol. Endosc. 2:77, 1960

121. NIWA, H.: "Endoscopy of colon" Gastroenterol. Endosc. (Tokyo) 7 : 402, 1965.

122. NIWA, H., UTSUMH, Y. NAKAMURA, T., YOSHIDA, A. YOSHITOSHI, Y, FUJINO. M. KANEKO. E. KASUMI. A, and MATSUMOTO. M. "Clinical experience of colonic Hiberscope." Gastroent. Endosc. (Tokyo) 11:163, 1969.

123. NIWA, H.: "Climical study of colono-fiberscope." Gastrointest. Endosc. 11: 173, 1969

124. OLSON, V.F. and BERCI. G: "Optical illumination for endoscopy."Proc. SPIE ISAn Diego) $40: 2 \pi 1,1973$.

125. ORTMAYER. M: "Small polyps of rectum and lower sigmoid: their relationship to carcinoma of distal colon." J. Am. Med. Wom. Assn. 5:217. 1950.

126. OTTENJAHN, R.: "Colonic polyps and colonoscopic polypectomy" Endoscopy 4.212. 1972.

127. OVERHOLT, B.F.: "Climical experience with the fibersigmoidoscope." Gastrointest. Endosc, $15: 27,1968$

128. OVERHOLT, B.F.: "Flexible fiberoptic sigmoidoscopes." CA Cancer Clin. 19: 80, 1969.

129. OVERHOLT, B.F.: "Technique of flexible fibersigmoidoscopy." South. Med. J. 63: 787. 1970 .

13i0. OVERHOLT, B.F.: "Flexible fiberoptic sigmoidoscopy - technique and preliminary results." Cancer (Philadelphia) 28: 123, 197".

131. OVERHOLT, B.F.: "A/S/G/E guidellines for slandards of training and practice." Gastrointest. Endosc. $22: 46,1975$.

132. OVERHOLT, B.F.: "Colonoscopy "Review" Gastroenterology 68: 1308, 1975.

133. OVEFHOLT, B.F., HARGROVE, R.L. FARFIS, R.K. and WILSON. W.M.: "Colonoscopic polypectomy; silent perforation." Gastroenterology 70:112.1976

134. PAPE, K.S.S.B. OUDSHOORN, H.H. VAN TETERING, J.P.B. en THJTAT. G.N. "Colonoscopische pollpectomie." N. Tijdschr. W. Gen. 118: 1830, 1974.

135. PEUTZ, J.L.A.: "Very remarkable case of familial polyposis of mucous membrane of intestinal tract and masopharynx accompanied by peculiar pigmentation af skin and mucous membrane." Nederl. Maandscht. v. Geneesk. 10:134, 1921.

135. PRICE, A.B.: "Benign lymphoid polyps and inflammatory polyps." In: Marson, B.C.: The Pathogenesis of Colorectal Cancer. Major Problems in Pathology wol. 10, 1975.

136. PROVENZALE. L. and REVIGNAS, A.: "An original method for guided intubation of the colon." Gastrointest. Endasc. 16:11, 1969.

137. RAAD, M.A. "Prevalence of rectal and lower sigmoidal adenomatous polyps in normal adull population." Med. A.nn. D.C. 24:391, 1955

138. RAGINS, H., SHINYA, H. and WOLFF. W.I.: "The explosive potential of colonic gas during collonoscopic electrosurgical polypectomy." S.G.O. 138:554, 1974

139. RAZZAK, I.A. MILLAN, $\Downarrow$ and SCHUSTER, M.M.: "Pneumatic ileal perforation, an unusual complication of colonoscopy." Gastroenterology $70: 268,1976$.

140. REES, B.1., and WILLIAMS, L.A.: "Incarceration of hernia after colonoscopy." Lancet, 1 371,1977 
141. RIDER, J.A. KIRSNER, J.B., MOELLER, H.C., and PALMER, W.L.: "Polyps of the colon and rectum: their incidence and relationship to carcinoma." Am. J. Med. 16:555. 1954.

142. ROBERTS, R., CAMPBELL, C.B. and ISBISTER. W.H.: "Two complications of diagnostic collonoscopy." Med. J. Aust. 2:793, 1976

143. ROGERS, B.H.G.: "The safety of carbon dioxide insufflation during collonoscopic electrosurgical polypectomy." Gastrointest. Endosc. 20: 115, 1974.

144. ROGERS, B.H.G., SILVIS, S.E., NEBEL, O.T. et al.: "Complications of nexible tiberoptic colonoscopy and polypectomy." Gastrointest. Endosc. 22: 73, 1975.

145. ROTH. "S.I. and HELWIG, E.B.: "Juvenile polyps of the colon and rectum." Cancer 16 468,1963

146. RUBIN, C.E. AUTH, D. and BARRETT, B.: "Work group X. Instruments for diagnosis. investigation and treatment of digestive diseases." Gastroenterology 69: 1151, 1975

147. SAKAI. Y.: "The technique of colonofiberoscopy." Dis. Col. Rect. 15: 403, 1972

148. SAKAl, Y.: "Further progress in colonoscopy." Gastrointest. Endosc. $20: 143,1974$.

149. SCARBOUROUGH, R.A.: "The rellationship between polyps and carcinoma of the colon and rectum." Dis. Col. Rect. $3: 336,1960$.

150. SCHNEIDER, R.S., DICKERSON, G.R., and PATTERSON, J.F.: "Localized giant pseudopolyposis. A complication of granulomatous colitis." Am. J. Dig. Dis. $184: 265$, 1973.

151. SHINYA, H., and WOLFF, W.1.: "Colonoscopic polypectomy; technique and safely." Hosp. Pract. 10:71, 1975.

152. SHINYA, H.: "Colonoscopy." Surg. Ann. 8:257, 1976.

153. SILVERBERG, S.G.: "Focally malignant adenomatous polyps of the colon and rectum." S.G.O. 131: 103, 1970 .

154. SIVAK, M. V., SULLIVAN, B.H. WEAKLY, F.L and RANKIN, G.B.: "Colonoscopic polypectomy." Digest. Dis. 19:339, 1974.

155. SKUCAS, J., CUTCLIFF. W. and FISCHER. H.W.: "Whole gut irrigation as a means of cleaning the colon." Radiology $121: 303,1976$.

156. SMITH, T.R., MAEIR, D.M., METCALF, W, and KAPLOWITZ, I.S.: "Transformation of a pedunculated colonic polyp to adenocarcinoma?" Dis. Col. Rect. $13: 382$ "1970.

157. SMITH, L.E.: "Fiberoptic colonoscopy; complications of colonoscopy and polypectomy." Dis. Col. Rect. 19:407, 1976.

158. SNITZER, E.: "Optical wave guide modes in small glass fibers II. Experimental." J. Opt Soc. Am $49: 1128,1959$

159. SPENCER, R.J., COATES, H.L. and ANDERSON, M.J.s Jr.: "Colonoscopic polypectamies." Mayo Clin. Proc. 49:40, 1974.

160. SPRATT, J.S. Jr., ACKERMAN, L.V. and MOYER, C.A.: "Relationship of polyps of the colan to colonic cancer." Ann. Surg. 148:682, 1958.

161. SPRATT, J.S., Jr., and ACKERMAN, L.V.: "Pathologic significance of polyps of the rectum and colon." Dis. Col. Rect. $3: 330,1960$.

162. STARA, G.F.: "Adenomatous polyps and polypoid carcinomas of the large intestine." Am. J. Clin. Path. 29:208, 1958.

163. SUNDERLAND, D.A. and BINKLEY, G.E.: "Papillary adenomas of the large intestine: a clinical and morphological studly of 48 cases." Cancer 1 : 184, 1948.

164. SUGARBAKER, P.H., VINEYARD, G.C., LEWICKI, A.M., PINKUS, G.S., WARHOL, M.J. and MOORE. F.D.: "Colonoscopy in the management of diseases of the colon and rectum." S.G.O. 139: 34 "1, 1974

165. SWINTON. N.W.: "Polyps of rectum and colon." J.A.M.A. 154:658, 1954

166. SWINTON, N.W.: "Colotomy and colonoscopy." Surg. Clin. N. Amer. 40:727, 1960

167. SWINTON, N.W., and WEAKLY, F.L.: "Complications of colotomy and colonoscopy." Dis. Cal. Fect. $6: 50,1963$. 
468. TADA, M. KATOH, S. KOHLI, Y and KAWA, K: "On the dye sprayng method in colono-fiberscopy." Endoscopy 8:70, 9976

169. TAYLOR, F. WEAKLY. F.L. and SULLIVAN, B.H. JP: "Nonoperative management of colonoscopic perforation with pneumopertoneum." Gastrointest. Endosc 24 : 124. 1978

170. TEAGUE, P.H. SALMON. P.R., and AEAD, A.E.: "Fibreoptic examination of the colon: a rewiew of 255 cases." Gut. $14: 139,1973$

171. TELMOS, A, J., and MITTAI, V.K.: "Splenic rupture following colonoscapy." J.A.M.A. $237: 2718,1977$

172. THOENI, RF and MENUCK, L.: "Comparison of barium enema and colonoscopy in the detection of small colonic polyps." Radiology 124:631. 1977.

173. TIEDEKEN. A.: "Uber sechseckzahlen und sechseck packungen um Kreis." Exp. Techn. Phys. 13:369, 1965

174. TAEGONING, D. and BRITTON, D.C.: "Hazards of colonoscopy." Lancet (8010) 544,1977

175. TURELL, R: "Adenomas of the colon and rectum." Conn. Med. 24:82, 1960.

176. TURELL. R.: "Fiberoptic coloscope and sigmoidoscope." Amer. J. Surg. 105: 133. 1963.

177. VAWTER, M, RUTZ, R., ALAAMA, A. et al.: "Elecirocardiographic monitoring during colonoscopy."Am. J."Gastroenterol. 63:155, 1975.

178. WAYE, w.D.: "Colonoscopy." Surg. Clin. N. Amer. 52: 1013, 1972

179. WELCH, C.E and HEDBERG, S.E.: "Pollypoid lesions of the gastro intestinal tract." Major Problems in Clinical Surgery. Vol 11. W.B. Saunders, 1975

190. WELIN, S: "Modern trends in diagnostic radiology of the colon." Br. J. Radiol. 31 : $453,1958$.

181. WELIN, S. YOUBEA, J. and SPRATT, J.S.: "The rates and patterns of growth of 375 tumors of the large intestine and rectum observed serially by double contrast enema study. (Malmö technique)." Am. J. Roentg. Radiother. Nucl. Med. 90: 673, 1963.

182. WILLIAMS, C.B. and MUTO. T.: "Examination of the whole collon with the fibreoptic colonoscope." Br. Med. J. 3: 278, 1972.

183. WILLIAMS, C.B. and TEAGUE, R.H.: "Progress report: Colonoscopy." Gut, 14 ; 990. 1973

184. WILLIAMS, C.B. MUTO. T, and RUTTEP, K.A.P.: "Remowal of polyps with fibreoptic colonoscope: new approach to colonic polypectomy." $\mathbb{B r}$. Med. J. 1.:451, 1973

185. WLLIAMS, C.B., LANE, F, H., and SAKAI, $Y$. "Colonoscopy: an air-pressure hazard." Lancet $2: 729,1973$.

186. WILLIAMS, C. B.: "Diathermy biopsy - a technique for the endoscopic management of small polyps." Endoscopy 5:215, 1973

187. WILHIAMS, C B., HUNT, ..,H., LOOSE, H.W.C., RIDELL,R.A., SAKAI, Y. and SWARBAICK. E.T.: "Colonoscopy in the management of colonic polyps." Br. J. Surg. $61: 673,1974$.

188. WILLIAMS, C.B.: "Modern topics in gastro intestinall endoscopy," Ed. Schiller, K.F.R and Salmon, P.R. Heinemann Med. Books, 1976.

189. WILLIAMS, C.B. and DE PEYER, R.C.: "Bipolar snare polypectomy." Endoscopy " : 47. 1979

190. WLSON.G.S., DALE, E.H., and BRINES, O.A." "An evaluation of polyps detected in 20, 847 routime sigmoidoscopic examinations." Am. J. Surg. 90:834, 1955.

191. WOLFF, W.1. and SHINYA, H.: "Colonoliberoscopy." JAMA 217 : 1509, 1971.

192. WOLFF, W.I. SHINYA, H. GEFFEN, A and OZAKTAY, S.Z: "Colonofiberoscopy: a new and valuable diagnostic modality." Amer. J. Surg. 123: 180.1972. 
193. WOLFF, W. and SHINYA, H.: "A new approach to colonic polyps." Ann. Surg. 178: 367,1973 .

194. WOLFF, W.I and SHINYA. H: "Definitive treatment of "matignant" polyps of the coton." Ann. Surg. 182: $516,1975$.

195. YAEGASHI.K.UTSUMOMIYA, I. WWAA, T. and AOKI, N.: PEUL Jehgers syndrome." Section of Proctalogy meeting. P. S.M. London. 1979.

496. YOUNG, W.T.: Routine examination of the lower bowel: results in 500 asymptomatic cases." Am. J. Surg. 8H:18. 1951.

197. YOUNG, A.C: "Radiology of the colon and rectum." In: Irvine W.T. (ed) Modern Trends in Surgery. London, Butterworths, pg. 32, 1966. 


\section{Curriculum vitae}

The author was born on August 2, 1946 in Malang, Indonesia. He graduated from High School in Surabaya, Indonesia in 1964, and attended the Medical Faculty at the Airlangga University in Surabaya. He continued his medical study in 1966 at the Free University. Amsterdam and graduated in 1972.

His residency in surgery started in the same year at the Westeinde Hospital, The Hague (Chairman J.E.P.M. Regout, afterwards Dr. J.R. Leo). He was registered as a surgeon in the Specialisten Registratie Commissie in 1978.

In 1978 he was granted a Clinical and Research Fellowship in Surgery and Endoscopy at the Massachusetts General Hospital, Harvard Medical School in Boston, U.S.A. (Stephen E. Hedberg M.D.), followed by a Clinical and Research Fellowship in Endoscopy and Surgery at the St. Mark's Hospital, London (Christopher B. Williams B.M., F.R.C.P. and Peter R. Hawley M.S., F.R.C.S.) in 1979

He was appointed as junior staff surgeon in 1979 at the Department of

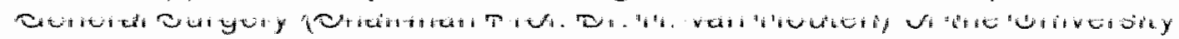
Hospital Rotterdam-Dijkzigt. 


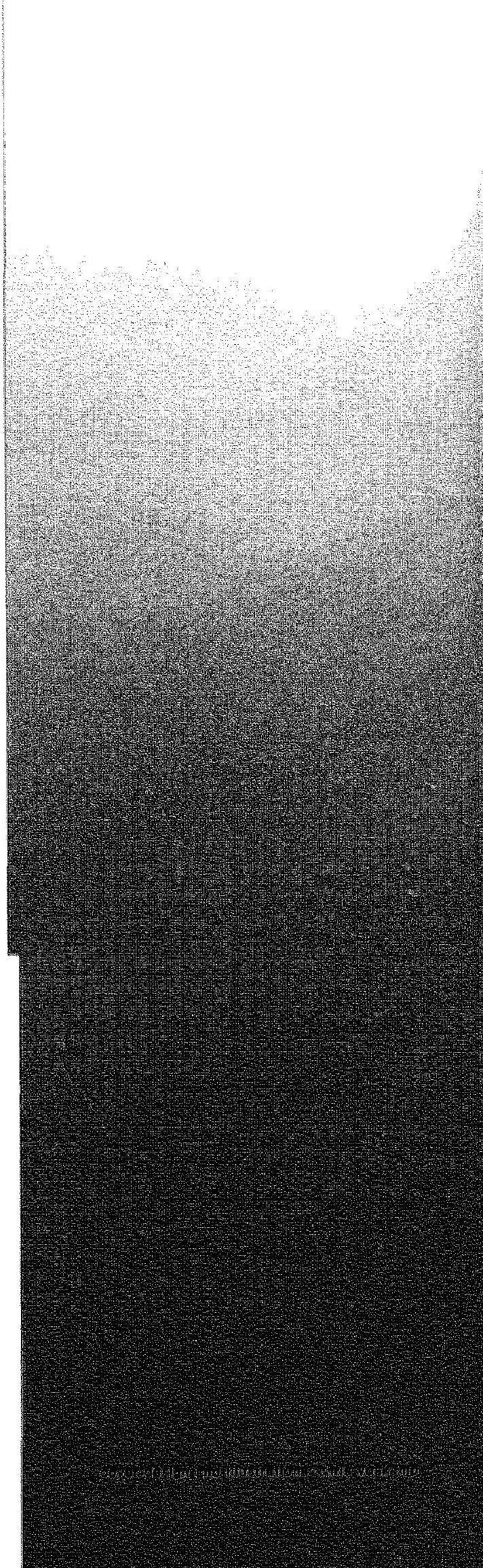

